\title{
A step to reducing tail biting in finisher pigs: \\ Can a management tool help pigs and farmers?
}

\author{
Dissertation \\ zur Erlangung des Doktorgrades \\ der Fakultät für Agrarwissenschaften \\ der Georg-August-Universität Göttingen
}

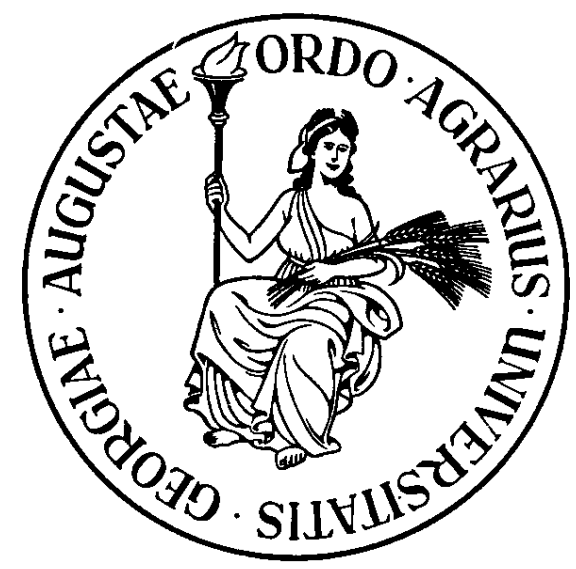

vorgelegt von

Astrid Luise Lydia Elfi vom Brocke

geboren in

Hagen (Westfalen)

Göttingen, November 2014 
D 7

1. Supervisor: Prof. Dr. Dr. Matthias Gauly

2. Co-Supervisor: Dr. Lars Schrader

Tag der mündlichen Prüfung: 20. November 2014 
Für meine Eltern

"Nur wer sein Ziel kennt, findet den Weg."

Laozi 


\section{Table of Contents}

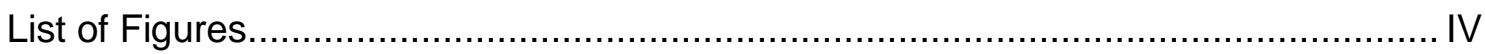

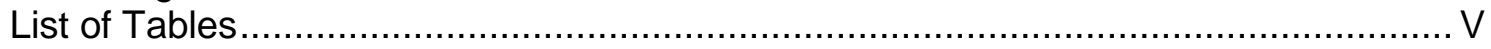

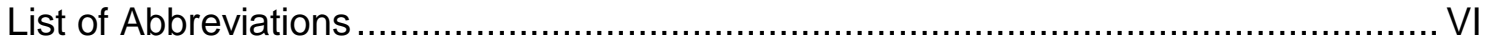

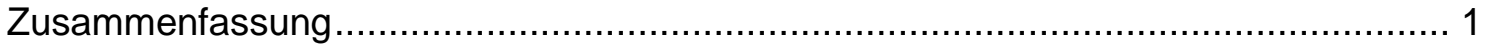

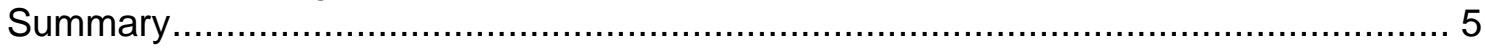

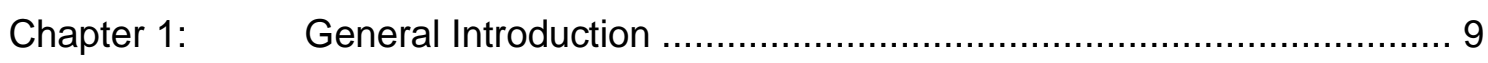

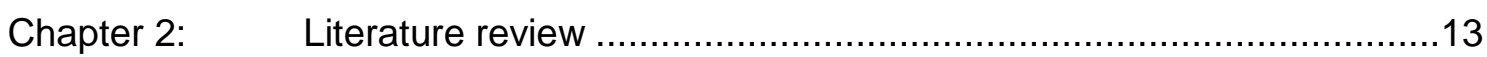

$2.1 \quad$ Introduction to tail biting issues ...............................................13

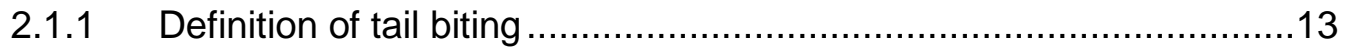

2.1.2 Causation and underlying mechanisms for tail biting ......................14

2.1.3 Consequences of tail biting - Welfare and economic ......................16

2.1.4 Prevention and treatment of a tail biting outbreak .........................17

$2.2 \quad$ Tail biting - the status quo ...................................................... 19

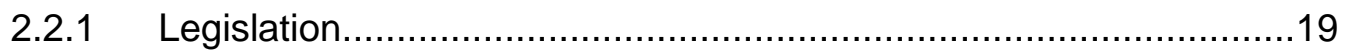

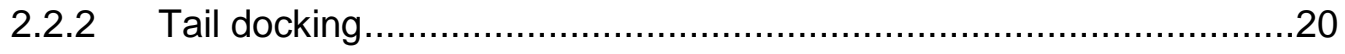

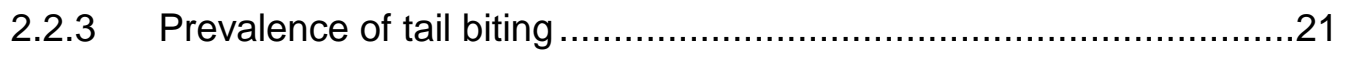

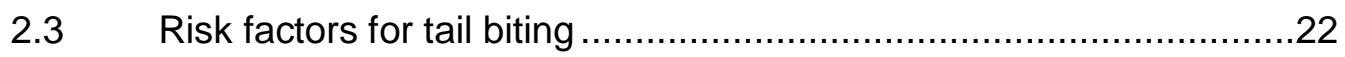

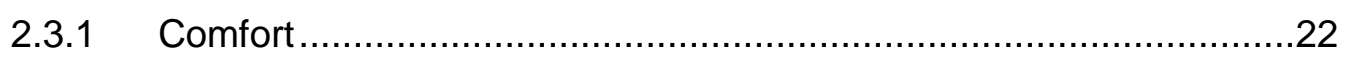

2.3.2 Enrichment.................................................................... 23

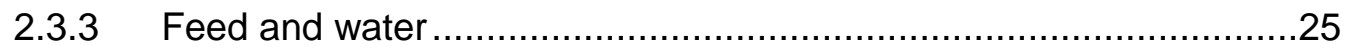

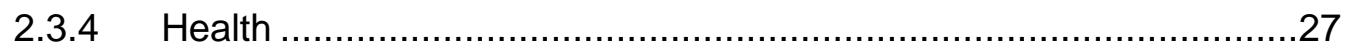

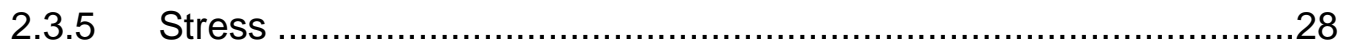

$2.4 \quad$ Animal Health and Welfare Planning ........................................29

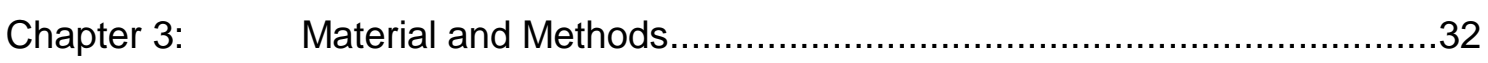

3.1 Tail biting intervention tool .................................................. 32

3.1.1 Development of SchwIP .....................................................

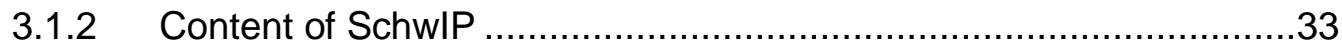

Chapter 4: $\quad$ Training veterinarians and agricultural advisers on a novel tool for tail

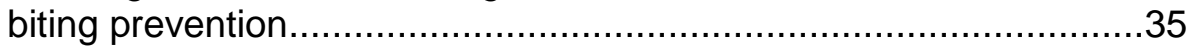

Abstract...................................................................... 35

Introduction .....................................................................

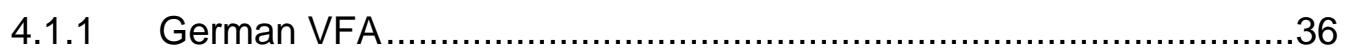

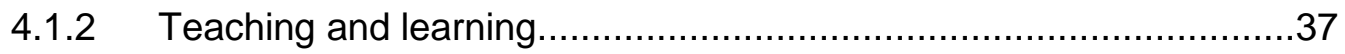

4.1.3 A tail biting prevention tool as an example ...................................37

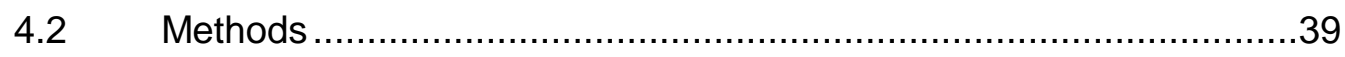

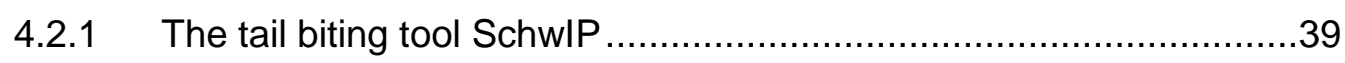

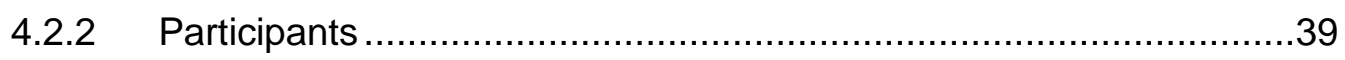




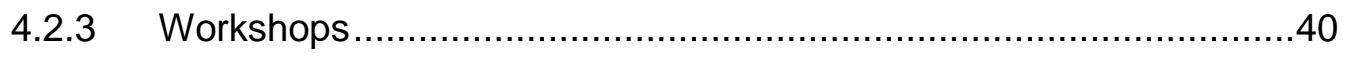

4.2.4 Feedback from participants ..................................................... 41

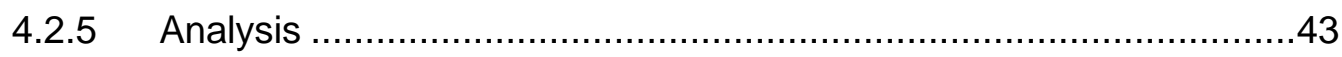

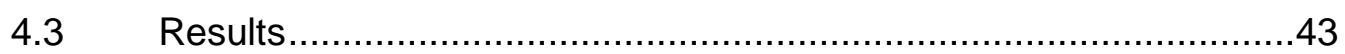

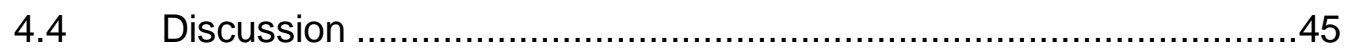

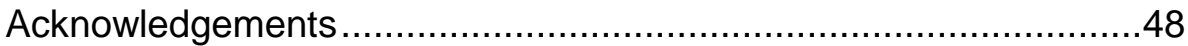

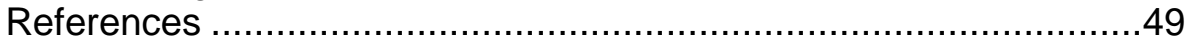

Chapter 5: $\quad$ Reducing tail biting risk on German fattening pig farms with a management tool for risk planning ............................................52

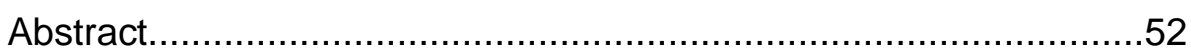

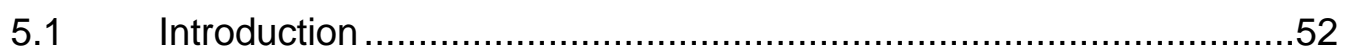

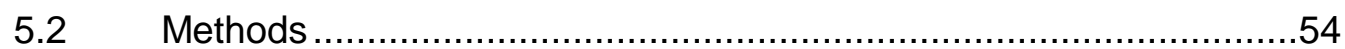

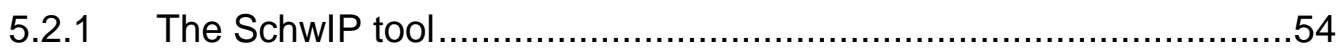

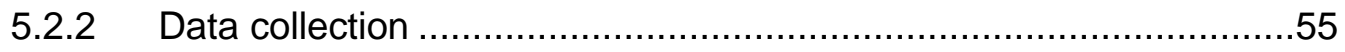

5.2.3 Data management and statistical analysis ...................................56

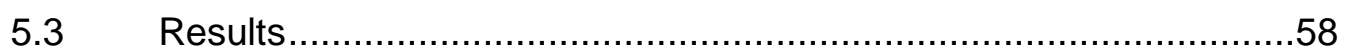

5.3.1 Description of farms and intervention levels .................................58

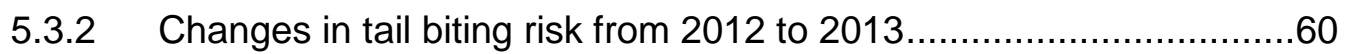

5.3.3 Relationship between implementation and risk score .....................60

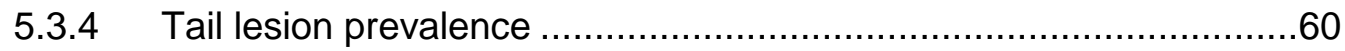

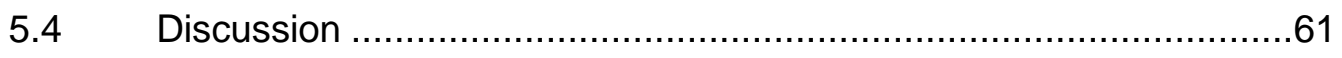

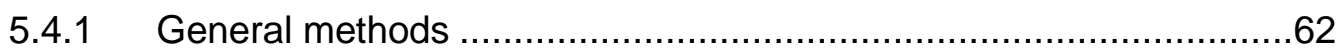

5.4.2 Changes in tail biting risk and implementation level ......................63

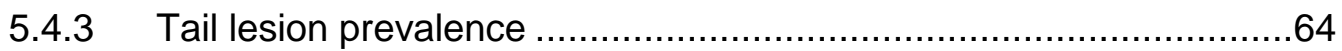

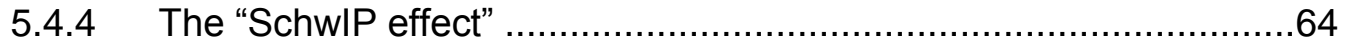

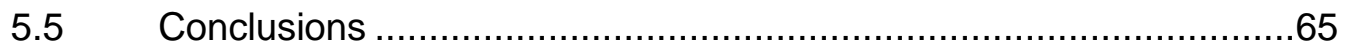

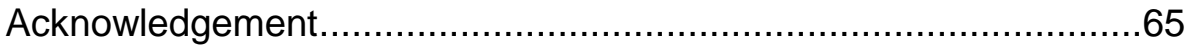

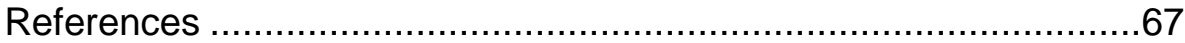

Chapter 6: $\quad$ Tail lesions in German fattening pigs: relationship with post mortem meat inspection and influence of a tail biting management tool........71

Abstract.................................................................................. 71

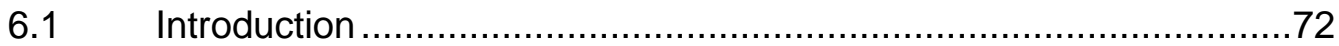

6.2 Animals, material and methods ...............................................73

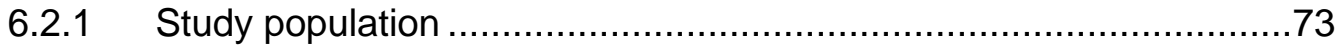

6.2.2 Data collection at the abattoir..................................................

$6.2 .3 \quad$ Tail lesion scoring ........................................................... 74

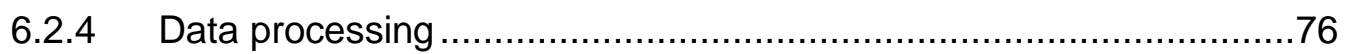

6.2.5 Statistical analysis ............................................................... 77 


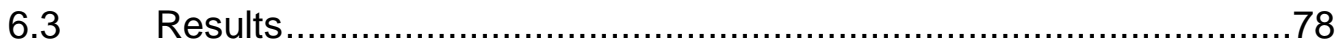

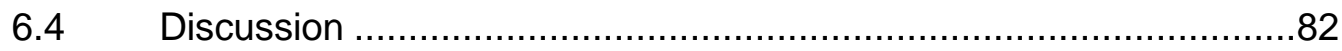

6.4.1 Prevalence of tail lesions ..................................................... 82

6.4.2 Relationships between carcase findings and tail lesions .................84

6.4.3 Comparison with meat inspection data.........................................85

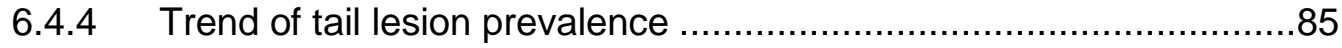

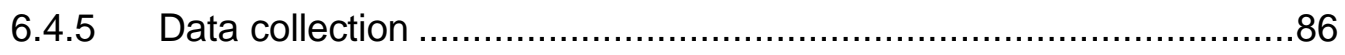

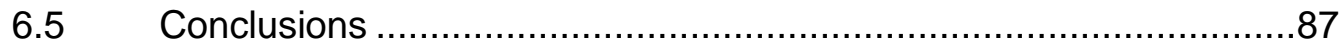

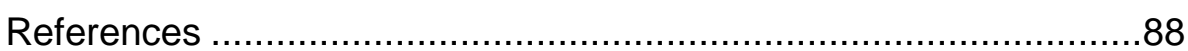

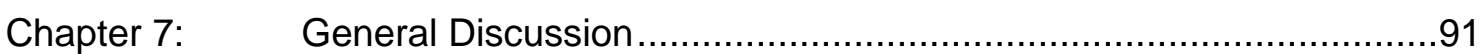

7.1 Training of stakeholders and the provision of knowledge transfer ....91

7.2 Effects of implementation of SchwIP on-farm ..............................93

7.3 The future role of management tools.........................................96

7.4 Tail lesions as welfare indicator ...................................................97

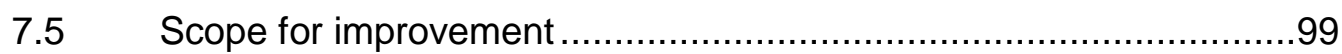

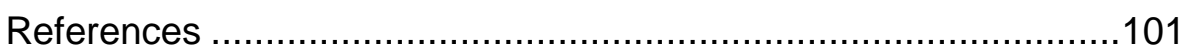

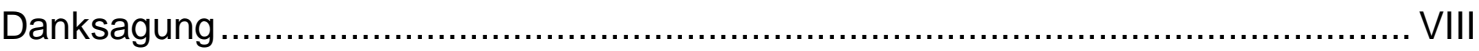

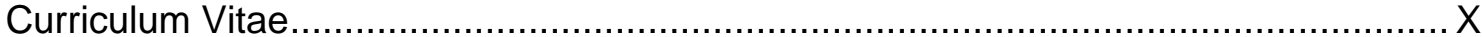

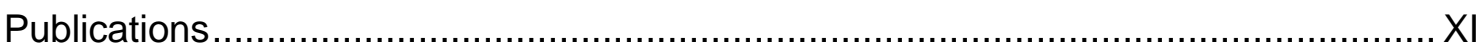

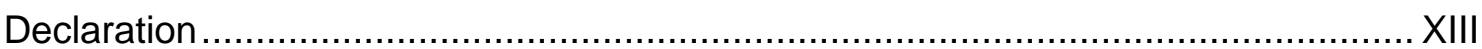




\section{List of Figures}

Figure 4.1: Distribution of evaluation grades for the parameter 'knowledge transfer during workshop' by discussion group type (grade 1 = very good, grade $6=$ very bad; $\bullet=$ mean, medians are equal to upper or lower quartiles; $p>0.05$ ).

Figure 5.1: Geographical location of the farms in the study. (VFA (red, $N=119$ ) = farms visited by farm advisers or veterinarians, one farm is missing due to a lack of the address, and FLI (blue, $\mathrm{N}=68$ ) = farms visited by a member of the research group)

Figure 5.2: Numbers (\%) of farms whose category risk score (CRS) decreased (a), remained constant (b), or increased from 2012 to 213 (c) $(N=188)$. Decreasing CRS was coded as 1 in the logistic model, where neither implementation level, nor category nor their interaction had a significant effect on CRS $\Delta_{\text {bin. }}$. Stress and management were not included in model. Furthermore, numbers (\%) of farms who implemented all (a), some / parts (b) or none (c) of their planned intervention measures in a risk category $\left(N_{\text {comfort }}=121, N_{\text {enrichment }}=130, N_{\text {feed \& water }}=173, N_{\text {health }}=67, N_{\text {management }}=60\right)$.

Figure 6.1: Cameras at the slaughterline of the abattoir after scalding 74

Figure 6.2: Tail lesion scoring key. Complete tail loss was scored independently of lesion score 0 to 3 . CTS $=$ combined tail score. TNP $=$ tail necrosis scored from pictures.

Figure 6.3: Prevalence of tail lesions (\%) on 32 control farms sorted by mean farm prevalence $(\mathrm{N}=2$ to 41 batches per farm; farms $5,14,16,26$ and 31 delivered $\leq 5$ batches)

Figure 6.4: Prevalence of tail lesions (CTS \%) of SchwIP and control farms per seasons. Prevalences differed significantly in winter $(p=0.011)$ but not in any other season. Box $=25$ th -75 th percentile, horizontal line $=$ median, + mean, * outlier $>1.5$ interquartile range. 


\section{List of Tables}

Table 4.1: Evaluation results from workshops where pig veterinarians and farm advisers were trained to use an on-farm tool for tail biting prevention. Workshop groups were classified based on the level of antagonism in their discussions (group type) and evaluation grades as well as numbers of farms visited after workshop were compared between group types.

Table 4.2: Numbers of participants who applied the new tool after their workshop on no farm vs. on one or more farms by group type $\left(x^{2}=0.61\right.$, d. f. $\left.=2, p=0.737\right)$.

.45

Table 5.1: Values for the prevalence of all assessed pigs for each lesion type for the first visit in 2012, the second in 2013 and the difference between the two visits ( $\min =$ smallest value; $\mathrm{Q} 25=1$ st quartile; $\mathrm{Q75}=3$ rd quartile; $\max =$ maximum; $I Q R=$ interquartile range; $N=188$ farms). All $\Delta$ were significant at $p<0.05 .61$

Table 6.1: Prevalence of tail lesions in 36,632 pigs from 32 control farms (730 batches with 6 to 85 pigs recorded from 22.11.2012 to 29.11.2013). Min = minimum, $\max =$ maximum, $\mathrm{SD}=$ standard deviation, $\mathrm{CL}=$ complete tail loss, CTS $=$ combined tail score "lesion". .78

Table 6.2: Frequencies and prevalences of carcase findings with possible relation to tail lesions in the complete and picture dataset (findings with prevalence $\geq 0.22 \%$ only). The picture dataset represents a sample of the complete dataset that includes meat inspection data and tail pictures from SchwIP farms and control farms.

Table 6.3: LSM prevalences (\%) [95\% confidence interval] of selected carcase findings in pigs with or without tail lesions (logistic regression model with random farm effect; $p$-values of individual findings are Bonferroni corrected for 6 tests) and pigs with or without TNMI (logistic regression model without random effects; p-values of individual findings are Bonferroni corrected for 6 tests)

Table 6.4: Number and proportion of recorded necroses by pictures (score 3 ) and TNMI detected at the slaughterline. $\mathrm{TNMI}=$ tail necrosis recorded during meat inspection, TNP = tail necrosis recorded from pictures.

Table 6.5: Prevalence of tail lesions $(\%)$ in four seasons $(\mathrm{S}=\mathrm{SchwIP}$ farms, $\mathrm{C}=$ Control farms; $N_{\text {winter }} S=30, C=27 ; N_{\text {spring }} S=30, C=32 ; N_{\text {summer }} S=31, C=27 ; N_{\text {autumn }}$ $S=30, C=25 ;$ MIN = minimum; $Q 25=1$ st quartile; $Q 75=3$ rd quartile; MAX = maximum; one Wilcoxon test per season). Before $=$ July to November 2012, $N=29$ farms 


\section{List of Abbreviations}

\begin{tabular}{|c|c|}
\hline AHWP & Animal Health and Welfare Planning \\
\hline B.C. & before Christ \\
\hline${ }^{\circ} \mathrm{C}$ & degree Celsius \\
\hline CD & compact disc \\
\hline CF & crude fibre \\
\hline CIWF & Compassion in World Farming \\
\hline $\mathrm{CL}$ & complete loss of the tail \\
\hline $\mathrm{cm}$ & centimetre(s) \\
\hline CRS & total category risk score \\
\hline \multirow[t]{2}{*}{$\mathrm{CRS} \Delta \Delta_{\text {bin }}$} & binary variable of CRS 2012 - CRS 2013, \\
\hline & $\mathrm{CRS} \Delta<0=$ improvement; $\mathrm{CRS} \Delta \geq 0=$ no improvement \\
\hline $\mathrm{CRS} \triangle$ & CRS 2012 - CRS 2013 \\
\hline CTS & combined tail score \\
\hline d.f. & degree of freedom \\
\hline DPM & D.P. Madey \\
\hline DWG & daily weight gain \\
\hline EC & European Commission \\
\hline EFSA & European Food Safety Authority \\
\hline e.g. & for example, abbreviation of Latin 'exempli gratia' \\
\hline et al. & and others, abbreviation of Latin 'et alii' \\
\hline etc. & and the rest, abbreviation of Latin 'et cetera' \\
\hline$€$ & Euro \\
\hline EU & European Union \\
\hline FLI & Friedrich-Loeffler-Institute \\
\hline g & gramme(s) \\
\hline $\mathrm{h}$ & hour(s) \\
\hline HAT & Husbandry Advisory Tool \\
\hline $\mathrm{HIGH}$ & groups with intensely antagonistic discussion \\
\hline i.e. & that is, abbreviation of Latin 'id est' \\
\hline impl & implementation level \\
\hline INT & groups with slightly antagonistic discussion \\
\hline $\mathrm{kg}$ & kilogramme(s) \\
\hline
\end{tabular}




\begin{tabular}{|c|c|}
\hline KTBL & $\begin{array}{l}\text { Kuratorium für Technik und Bauwesen in der Landwirtschaft } \\
\text { e. V. }\end{array}$ \\
\hline LOW & groups with positive, non-antagonistic discussion \\
\hline LSM & Least Squares Means \\
\hline$m^{2}$ & square metre(s) \\
\hline$\mu \mathrm{m}$ & micrometre(s) \\
\hline $\min$ & minute(s) \\
\hline $\mathrm{N}$ & sample size \\
\hline n.a. & not applicable \\
\hline $\mathrm{NaCl}$ & Sodium Chloride \\
\hline $\mathrm{p}$ & probability \\
\hline PABAK & prevalence-adjusted-bias-adjusted Kappa \\
\hline PhD & Doctor of Philosophy \\
\hline$£$ & Pound Sterling \\
\hline PROVIEH & Verein gegen tierquälerische Massentierhaltung e.V. \\
\hline SAS & Statistical Analysis System \\
\hline SchwlP & Schwanzbeiß-Interventions-Programm \\
\hline SQL & Structured Query Language \\
\hline TierSchG & Tierschutzgesetz \\
\hline TierschNutztV & Tierschutz-Nutztierhaltungsverordnung \\
\hline TNMI & tail necrosis recorded during meat inspection \\
\hline TNP & tail necrosis scored from pictures \\
\hline TRS & total tail biting risk score \\
\hline $\operatorname{TRS} \Delta$ & TRS 2012 - TRS 2013 \\
\hline UK & United Kingdom \\
\hline VFA & veterinarians and farm advisers \\
\hline vS. & versus \\
\hline z.B. & zum Beispiel \\
\hline
\end{tabular}




\section{Zusammenfassung}

Schwanzbeißen ist eines der gravierendsten Probleme in der konventionellen Schweinehaltung, da es zu einer erheblichen Einschränkung des Tierwohls führt und zudem wirtschaftliche Einbußen nach sich zieht. Eine Prävention von Schwanzbeißen ist äußerst schwierig, da die Ursachen multifaktoriell sind. Viele Risikofaktoren, die Schwanzbeißen auslösen können, sind durch Untersuchungen hinreichend bekannt, aber das fehlende Bewusstsein für das Vorhandensein dieser Risikofaktoren auf den Betrieben erschwert es den Landwirten, eine Veränderung der Situation herbeizuführen. Ein ganzheitlicher Ansatz ist erforderlich, um die vorhandenen Risikofaktoren auf den Betrieben zu identifizieren und für jeden Betrieb ein entsprechendes individuelles Profil mit seinen Stärken und Schwächen zu erstellen. Vor diesem Hintergrund wurde das Schwanzbeiß-Interventions-Programm (SchwIP) 2011 entwickelt, dem eine betriebsindividuelle Erhebung verbunden mit den Grundsätzen der Planung von Tiergesundheit und Tierwohl (Animal Health and Welfare Planning, AHWP) zu Grunde liegt. SchwIP wurde auf deutschen konventionellen Betrieben mit Mastschweinehaltung angewendet und evaluiert, um Landwirten zu helfen, die Risikofaktoren für Schwanzbeißen zu identifizieren und zu reduzieren, sowie sich der Herausforderung zu stellen, die Gegebenheiten auf den Betrieben zu optimieren.

Das Ziel der vorliegenden Arbeit war es zu ergründen: 1) wie eine ManagementAnwendung in der Praxis verbreitet werden kann und ob ein Wissenstransfer zu den Anwendern erfolgt, 2) ob die Anwendung von SchwlP bezüglich einer Reduzierung von Risikofaktoren für Schwanzbeißen und einer Verringerung der Prävalenz von Schwanzverletzungen auf den Betrieben effektiv ist und 3) ob sich die Effektivität der Anwendung der Management-Hilfe auch in der Erfassung der Prävalenz von Schwanzverletzungen am Schlachthof widerspiegelt.

Es wurden 23 eintägige Schulungen mit 19 Veterinären und 115 landwirtschaftlichen Betriebsberatern durchgeführt, um die ManagementHilfe SchwIP in ganz Deutschland zu verbreiten (Kapitel 4). Die Teilnehmer 
erlernten die Anwendung von SchwIP in interaktiven Schulungen mit einer Kombination aus theoretischen und praktischen Lehrabschnitten. Die Schulungsgruppen wurden subjektiv, basierend auf der Ausprägung ihrer ablehnenden Einstellung gegenüber Bestandteilen oder der Konzeption von SchwIP einer der folgenden drei Kategorien zugeordnet: hochgradig, mittelmäßig oder geringfügig ablehnend. In den nach der Schulung ausgeteilten FeedbackBögen bewerteten hochgradig ablehnende Schulungsgruppen die Anwendbarkeit der Managementhilfe auf den Betrieben signifikant schlechter als die anderen beiden Gruppen. Allerdings wurden keine Unterschiede zwischen den Kategorien der Schulungsgruppen hinsichtlich der Benotung des Wissenstransfers in den Feedbackbögen sowie der sich an die Schulungen anschließenden praktischen Anwendungen auf den Betrieben festgestellt. Insgesamt erachteten $67 \%$ der Teilnehmer Schulungen als geeignetes Medium für das Erlernen zukünftiger Managementhilfen. Als Schlussfolgerung lässt sich ableiten, dass es erforderlich ist, sich Erfahrungen und Grundkenntnisse im Kommunikationstraining sowie in dem Leiten einer Gruppe anzueignen, bevor Schulungen entwickelt und durchgeführt werden, um auf die unterschiedlichen Einstellungen der Teilnehmenden eingehen zu können.

Die Managementhilfe SchwIP wurde auf 188, von Schwanzbeißen betroffenen Betrieben, an jeweils einem Tag zwischen Juni und November im Jahr 2012 und erneut im gleichen Zeitraum im Jahr 2013 angewendet. Die Anwendung erfolgte entweder von einer Wissenschaftlerin der Arbeitsgruppe (68 Betriebe) oder von einem der 68 geschulten Tierärzte bzw. Betriebsberater (120 Betriebe) (Kapitel 5). Die Auswahl der untersuchten Buchten war problemorientiert, das heißt, Buchten wurde Vorrang in der Erhebung gegeben, in denen Schwanzbeißen zum Zeitpunkt des Besuchs vorhanden war oder Buchten, bei denen ein wiederkehrendes Auftreten bekannt war. Insgesamt zeigte sich, dass durch die Anwendung von SchwIP, bezogen auf alle Betriebe, das Gesamtrisiko zwischen den beiden Erhebungen signifikant reduziert werden konnte. Die Landwirte nahmen sich bei jedem Betriebsbesuch Ziele und Maßnahmen vor, unterstützt von dem jeweiligen Anwender und dem generierten SchwlPBetriebsbericht, um das Risiko für Schwanzbeißen auf ihren Betrieben zu reduzieren. Der Grad der Umsetzung der vorgenommenen Maßnahmen (alle, 
einige oder keine Maßnahmen umgesetzt) hatte keinen signifikanten Einfluss auf die Veränderung des Gesamtrisikos von Schwanzbeißen. In den verschiedenen Risikokategorien Komfort, Beschäftigung, Futter \& Wasser, Gesundheit und Stress konnte kein Unterschied im jeweiligen Gesamtrisiko der Kategorien zwischen den Erhebungen festgestellt werden. Allerdings konnte in der Kategorie Beschäftigung ein Wissenstransfer durch die Anwender und das SchwIP verzeichnet werden, da im Jahr 2013 mehr Betriebe eine Beschäftigung anboten, sowie mehr Betriebe Beschäftigungsmaterial (z. B. Stroh, Heu, etc.) anstelle von Beschäftigungsobjekten (z. B. Kette mit Holzstück) bereitstellten. Darüber hinaus zeigte sich, dass sich die Prävalenz von Schwanzläsionen (Blut am Schwanz, entzündliche Schwellungen des Schwanzes, Teil- oder Vollverlust) und von Ohrläsionen (Blut oder Kruste am Ohr) zwischen den beiden Betriebserhebungen signifikant reduzierte.

Begleitend zu den Betriebserhebungen wurde eine Bonitierung der Schwanzläsionen von 32 Betrieben, auf denen das SchwIP angewendet wurde, und von 32 Kontrollbetrieben am Schlachthof durchgeführt (Kapitel 6). Drei Beobachter beurteilten Schwanzläsionen von einer Gesamtstichprobe von 80.034 geschlachteten Schweinen anhand von Fotos, wobei 43.402 Fotos von SchwIP Betrieben im Zeitraum vom 02.07.2012 bis 29.11.2013 bonitiert wurden und 36.632 Fotos von Kontrollbetrieben im Zeitraum vom 22.11.2012 bis 29.11.2013. Die Bonitur erfolgte mit Hilfe einer 4-stufigen Skala (keine/leichte/schwere Verletzung, Nekrose). Zusätzlich wurde beurteilt, ob ein Vollverlust des Schwanzes vorhanden war oder nicht. Für die Auswertung wurden die Verletzungsgrade zusammengefasst zu den Befunden 'Verletzung' und 'keine Verletzung'. Verletzungen wurden unabhängig von dem jeweiligen Schweregrad im Durchschnitt bei $25,4 \%$ der Schlachtkörper von Kontrollbetrieben festgestellt, wobei die Mehrzahl der Verletzungen leichte Verletzungen waren $(23,6 \%$ der Schlachtkörper). Es wurden weniger Schwanzspitzennekrosen in der routinemäßigen Fleischuntersuchung ermittelt als Nekrosen von Fotos bonitiert wurden. Von insgesamt 548 Schwanzspitzennekrosen wurden nur $17 \%$ übereinstimmend sowohl von Fotos als auch in der routinemäßigen Fleischuntersuchung erfasst, wohingegen $53 \%$ der Nekrosen, die in der routinemäßigen Fleischuntersuchung festgestellt 
wurden, auch in der Fotobonitur als solche bewertet wurden. Die Prävalenz von Schwanzverletzungen war in der ersten Saison (Winter), in der sowohl von SchwIP- als auch von Kontrollbetrieben Fotos vorhanden waren, im Beobachtungszeitraum signifikant höher bei den SchwIP-Betrieben als bei den Kontrollbetrieben, aber in keiner der folgenden Saisons. Dies weist auf eine Reduzierung durch die Anwendung der Managementhilfe SchwIP hin.

Zusammenfassend erwies sich die Kombination von einer betriebsindividuellen Erhebung, entsprechend, den in SchwIP integrierten Grundsätzen der Planung von Tiergesundheit und Tierwohl (AHWP) als erfolgreich. Die Risikofaktoren für Schwanzbeißen auf Betrieben mit bestehender Schwanzbeißproblematik konnten reduziert und die Prävalenz von Schwanzverletzungen, sowohl auf den Betrieben als auch im Schlachthof, gesenkt werden. Schulungen mit Betriebsberatern und Veterinären erwiesen sich zudem als ein sehr effektiver Weg, neue Managementhilfen in der landwirtschaftlichen Praxis zu verbreiten und einen Wissenstransfer von der Wissenschaft in die Beratung und daran anschließend an die Landwirte bereitzustellen. 


\section{Summary}

Tail biting is a major welfare and economic problem in pig production which is difficult to prevent on conventional farms due to its multifactorial nature. A wide range of risk factors have already been identified, but a lack of awareness of these risk factors on-farm makes it difficult for the farmers to change the tail biting situation. A holistic approach is required to identify the strengths and weaknesses on each farm to create a specific risk profile. Therefore, the tail biting management tool called SchwlP (abbreviation for "Schwanzbeiß-Interventions-Programm" meaning tail biting intervention programme) was developed, which combines individual farm risk assessment with the principles of animal health and welfare planning (AHWP). SchwIP was evaluated on conventional German finisher farms to help farmers to reduce risk factors for tail biting and to meet the challenge for improving the tail biting situation on-farm.

The main aims of this thesis were to investigate: 1 ) how such a tail biting tool could be distributed in practice and whether knowledge transfer to stakeholders could be provided, 2) the effectiveness of the implementation of SchwIP in reducing the risk score for tail biting and the tail lesion prevalence on-farm, and 3 ) whether the effectiveness of the tool was also apparent in tail lesion prevalence determined at the abattoir.

Twenty-three one-day training courses with 19 veterinarians and 115 farm advisers were conducted to distribute the tail biting management tool SchwIP throughout Germany (Chapter 4). Participants learned how to implement SchwIP in interactive workshops with a mixture of theoretical and practical sessions. Workshop groups were subjectively categorised into one of the three types: low, intermediate, or high antagonistic groups, based on the level of their antagonism towards SchwlP or the concept of SchwIP. Highly antagonistic groups evaluated the on-farm usability of the tool significantly worse in the anonymous feedback forms that were handed-out. However, no differences between the three group types were found in their evaluation of knowledge transfer and implementation of 
SchwlP on customer farms. Sixty-seven percent of training participants recommended training workshops for colleagues for the uptake of similar tools. One important conclusion emerged for future workshop leaders, namely that they should strive for basic communication training and group leadership experience before setting up workshops.

SchwIP was implemented on 188 farms with tail biting problems twice; initially on a one day assessment between June and November in 2012, and again in 2013, either by one researcher ( 68 farms) or by one of the 68 trained farm advisers / veterinarians (120 farms) (Chapter 5). The selection of pens was problem-based, therefore pens with prevalent tail biting problems were given preference. Farmers decided on each visit on aims and measures to minimise the tail biting situation supported by external advice from the operator and the SchwlP farm report. Across all farms the total risk score for tail biting decreased between the two on-farm assessments. The level of implementation rate (all, some or no measures implemented) had no significant influence on the change of the total risk score for tail biting. No differences between the two on-farm assessments were found in the risk factor categories 'comfort, enrichment, feed \& water, health and stress'. However, in the category 'enrichment' knowledge transfer provided by the tool and operators was shown to be effective as in 2013 (second visits) more farms offered enrichment or material instead of objects. Moreover, the prevalence for blood on the tail, swollen tail, tail loss and ear lesions decreased significantly between the two farm visits.

Accompanying the data collection on-farm a tail lesion monitoring in an abattoir was conducted with pigs from 32 farms assessed with SchwIP and from 32 control farms (Chapter 6). Three observers recorded tail lesions from a sample of 80,034 photos. Out of these, 43,402 pigs originated from SchwIP farms, which were recorded from 02.07.2012 to 29.11.2013 and 36,632 pigs from control farms were recorded from 22.11.2012 to 29.11.2013. The photos were assessed using a 4-point scale (no/mild/severe lesions or necrosis). Additionally a complete loss of the tail was assessed as present or absent. For the analysis the lesion scores were summarised to a combined lesion score of either 'lesion' or 'no lesion'. Tail lesions of any severity were observed in an average of $25.4 \%$ of pigs from control farms with the majority of pigs affected by minor lesions (23.6\%). Tail necroses 
recorded at meat inspection were less prevalent than necroses scored from photos. Out of the 548 necroses only $17 \%$ were recorded from both photos and meat inspection, whereas $53 \%$ of the necroses scored at meat inspection were also recorded from photos. Prevalence of tail lesions was during the first season (winter) where photos from SchwlP farms as well as control farms were present, significantly higher in SchwIP farms than in control farms but not in any of the following seasons, suggesting that the implementation of SchwIP led to a reduction of the tail lesion prevalence in SchwIP farms.

In conclusion, the combination of farm-specific risk assessment and animal health and welfare planning which is included in SchwIP successfully reduced risk factors for tail biting and also tail lesion prevalence on-farm and at the abattoir. Training workshops for farm advisers and veterinarians are an effective way to distribute novel tools in practice and to provide knowledge transfer from research to advisory services and subsequently to farmers. 
Chapter 1

General Introduction 


\section{Chapter 1: General Introduction}

An EU wide survey showed that animal welfare is a significant issue for $64 \%$ of consumers who are increasingly concerned about the well-being of farm animals and desire to know how animals are treated and the conditions under which they are raised (European Commission, 2012). Tail docking in pigs is one particular production practice in agriculture which consumers are concerned about due to the pain and stress piglets experience during this procedure. In the EU nowadays, tail docking is the most common preventive method adopted by farmers to prevent tail biting; a behavioural disorder and major welfare problem in pig production (Nannoni et al., 2014).

Tail biting can be described as the oral manipulation of a pig's tail by another pig (Van Putten, 1969), which may result in severe lesions and bleeding of the tail (Arey, 1991). Other individuals become attracted to the blood (Fraser, 1987a), which results in ongoing tail biting activity in the pen (Colyer, 1970), classed as an 'outbreak' when a number of pigs begin biting. A tail biting outbreak has welfare implications for the bitten pigs due to injuries to the tail as well as for the pigs performing the biting because they are unable to cope with their environment (EFSA, 2007). In addition to being a welfare problem, it is also a huge economic problem for the farmers and the pig industry due to reduced weight gain, medication and labour costs as well as condemnations and trimming at slaughter (Wallgren and Lindahl, 1996; Zonderland et al., 2011). In Germany, almost all pigs in conventional husbandry systems are docked to prevent this behavioural disorder (EFSA, 2007). European legislation determines that before tail docking is carried out routinely, changes in husbandry and management have to be addressed (European Commission, 2008). Transfer of scientific knowledge about measures to prevent tail biting and tail docking, as well as to strengthen the awareness of farmers, is critical to bring about a change in the situation (Bracke et al., 2013).

When aiming to avoid tail docking, underlying welfare problems have to be identified and reduced. Many factors are well known to influence a tail biting 
outbreak, but due to the multifactorial nature of apparent predisposing circumstances (Edwards, 2011) it is a difficult task for the farmer to prevent tail biting. The causes are farm-specific and sometimes not obvious or easy to solve. Moreover, it is not enough to care about the appropriate provision of resources; rather, animal-based parameters have to be considered in order to detect tail biting at an early stage (EFSA AHAW Panel, 2014).

The identification of risk factors which might trigger tail biting is mandatory to improve the tail biting situation on-farm, therefore a holistic approach such as Animal Health and Welfare Planning (AHWP) may assist farmers in meeting the challenge of improving the tail biting situation on-farm. AHWP is an on-going process which aims to achieve continuous development and improvement on-farm, based on a strategy including: current status and risks on-farm, an evaluation of the findings, determination of measures to improve the situation and a subsequent review (Nicholas et al., 2008). Farm-specific solutions for farm-specific problems and the farmer's ownership over the planning process are crucial aspects for the success of the plan (Vaarst et al., 2011).

In the UK, animal health and welfare planning is widely-used in organic and conventional husbandry systems to tackle different problems in the livestock sector, whereas in Germany only a few actions have been taken (Nicholas and Jasinska, 2008). Taylor et al. (2012) developed the tail biting husbandry advisory tool (HAT) to help farmers identify and reduce risk factors for tail biting in UK finisher farms. The HAT served as a basis for the German tail biting management tool, called SchwlP (abbreviation for Schwanzbeiß-Interventions-Programm meaning tail biting intervention programme), whose evaluation is the main subject of this thesis. The tail biting risk factors of the HAT were adapted to present conditions before the implementation on-farm, since the husbandry of finisher pigs in the UK and Germany is not the same.

Generally, such management tools are implemented and evaluated by research groups (Green et al., 2007; Main et al., 2012) and the dissemination among farm advisers and veterinarians is often not carried out until the study has been completed. Hence a big drawback is that expert knowledge of practitioners such as farm advisers and veterinarians is not integrated. From the very start, farm advisers and veterinarians were involved in the implementation and evaluation of 
SchwlP to distribute the tool in practice and to gain knowledge about its practical applicability. However, how to distribute novel tools in practice, and whether knowledge transfer could be provided among operators was still a key question (Chapter 4). Novel tools should involve parameters that are valid, reliable, easily applied by trained people, and require only limited time to make decisions for improvements on-farm (Winckler, 2008). SchwIP was a completely new approach to giving advice to German farm advisers / veterinarians, and to farmers in receiving advice and implementing changes on-farm. In order to prove whether the implementation of SchwIP led to improvements, the reduction of risk factors, the implementation of measures and the prevalence of tail lesions on-farm were assessed (Chapter 5). A particularly new approach to collecting follow-up data and to evaluating the effectiveness of tool implementation with regard to an improvement of tail lesion prevalence was the monitoring of tail lesions from slaughtered pigs between the on-farm assessments of thirty-two farms assessed with SchwIP compared with thirty-two control farms (Chapter 6).

Specifically, this thesis aims to:

- distribute SchwIP through one day training courses among agricultural farm advisers and veterinarians and to assess if this way is appropriate for providing knowledge transfer between research and advisory services

- evaluate the implementation of SchwIP and to validate the effectiveness of the tool in reducing risk factors for tail biting on-farm and the ability to reduce the tail lesion prevalence

- gain knowledge about the ability of the tool to reduce tail lesion prevalence from farms where the tool was applied within a period of one year, recorded at an abattoir

This study attempts to improve the tail biting situation on German finisher farms through the implementation of a novel tail biting intervention tool, 'SchwIP', which takes into consideration that every farm has its individual risk factor pattern and that the farmer plays a key role in the reduction of risk factors for tail biting on-farm. 


\section{Chapter 2}

Literature review 


\section{Chapter 2: Literature review}

\subsection{Introduction to tail biting issues}

\subsubsection{Definition of tail biting}

Different definitions and descriptions concerning tail biting are used by different authors (Taylor et al., 2010). Tail biting is 1) described as any form of oral manipulation of the tail (Arey, 1991), 2) equated with cannibalism (McGlone et al., 1990) or 3) is referred to as biting behaviour resulting in lesions of the tail (Schrøder-Petersen and Simonsen, 2001). The diversity in observed tail biting behaviour has been outlined in a work by Taylor et al. (2010) who distinguished between three different behavioural types of tail biting: 'two-stage', 'sudden-forceful' and 'obsessive'. It is suggested that these behaviour patterns have different motivational bases and are due to different underlying problems (Taylor et al., 2010).

The development of a tail biting outbreak usually comprises two stages. In the 'pre-injury' stage pigs often chew on the tail of penmate who is lying or standing still without causing visible wounds or distress (Van Putten, 1980; Fraser, 1987a). The transition to the second stage is not really documented (Taylor et al., 2010) but it is supposed that through a repetition of manipulating behaviour in the 'pre-injury' stage, the tail is bitten and injured more or less accidentally (Van Putten, 1969; Schrøder-Petersen et al., 2003). As a consequence the tail becomes wounded and bleeding and is classed as the 'injury' stage (Fraser, 1987a). This may encourage further biting efforts in the penmates and the wounded animal becomes the object of a hunt (Van Putten, 1969; Sambraus, 1985). In severe cases the wounded pig gives up avoiding others, becomes apathetic, lies much of the time and seldom changes position (Sambraus, 1985). Zonderland et al. (2008) observed a large variation for the time of transition from the 'pre-injury' to the 'injury' stage (on average 7.5 days). The 'sudden-forceful' tail biting (Taylor et al., 2010) is described as a rapid onset where pieces of tissue are wrenched off and severe injuries arise generally without an observed period 
of gentle manipulation (Van Putten, 1969; Fritschen and Hogg, 1983). Obsessive tail biting is performed by one or few pigs who appear to be focussed and fixated on biting tails, showing a large amount of 'sudden-forceful' biting by grabbing and yanking other penmates' tails (Taylor et al., 2010). Tail biting outbreaks are sporadic and unpredictable and therefore it is very difficult to study them in a research setting (Edwards, 2006).

There is no reported evidence that tail biting occurs in other non-domesticated Suids or Peccaries kept in captivity or in the wild (Taylor et al., 2010). So far the origin of tail biting is not fully understood (Fraser, 1987a; EFSA, 2007) but it is considered to be an abnormal and welfare reducing behaviour of pigs with a multifactorial causation (Moinard et al., 2003). Tail biting is a major welfare problem in intensive husbandry systems (EFSA, 2007) but has also been described in outdoor pig production (Walker and Bilkei, 2006).

\subsubsection{Causation and underlying mechanisms for tail biting}

Investigations by Stolba and Wood-Gush (1989) showed that domestic pigs living in a semi-natural enclosure spent $52 \%$ of the daylight period foraging (rooting and grazing) although full rations of food were offered. In another $23 \%$ of the daylight period they examined their environment (locomotion, orienting to stimuli, nosing and manipulating objects). Pigs explore their surroundings to become familiar with it and the various resources in it (Studnitz et al., 2007). Even when there are no novel external stimuli, pigs appear to be motivated to carry out exploratory behaviour (Wood-Gush and Vestergaard, 1993).

Exploratory behaviour is an important consideration in the welfare of pigs (WoodGush et al., 1990) but modern intensive production systems are often very barren due to slatted floors and absence of substrates in which the pigs can root and therefore contrast with the environment in which the pig has evolved (Van de Weerd and Day, 2009). Numerous studies have shown that the provision of enrichment material like straw, peat, or mushroom compost in an otherwise barren housing environment has a beneficial effect on exploratory behaviour and the reduction of tail biting (Fraser et al., 1991b; Beattie et al., 1996; Beattie et al., 
2001; Van de Weerd et al., 2005). Therefore the most common hypothesis for tail biting is that it involves a normal behaviour pattern such as explorative behaviour which becomes redirected to the tails of penmates as a consequence of deficiencies in the environmental conditions of pigs (Van Putten, 1979, 1980; Fraser et al., 1991b; Schrøder-Petersen and Simonsen, 2001).

Exploration and foraging behaviour are closely linked in omnivorous species. In wild boar the basis of the diet is usually plants such as grass, roots and seeds. A pig's snout is well adapted to its feeding habits: with the upper part of the snout pigs can lift objects and dig and turn the soil over to get access to roots and seeds (Jensen, 2002). The lower part of the rooting disc is covered with hair and is kept wet by mucous glands to increase the sensitivity (Van Putten, 1979). A pig's snout is a highly developed sense organ since it consists of as many tactile receptors as a human hand and fingers, and the power of tactile discrimination is only slightly inferior to that of the hand (Adrian, 1943). Together with olfaction, the snout plays a major role in determination of exploratory behaviour (Fraser and Broom, 1990).

Rooting is one of the typical foraging behaviours alongside grazing and browsing, and most pigs will spend a large portion of their time rooting, even if there is only a concrete floor (Jensen, 2002). Restrictive feeding increases the occurrence of rooting behaviour, but is moreover, not entirely eliminated when pigs are fed ad libitum (Day et al., 1995; Beattie and O'Connell, 2002). An increase in exploratory behaviour can be expected at the end of the fattening period if growing pigs are fed restrictedly (Studnitz et al., 2007). In intensive husbandry systems foraging behaviour is limited to times when food is present and as feed intake lasts only 10 min per feeding bout there is a lack of opportunity to forage due to absence of stimuli for the rest of the day (Van Putten, 1980) and the 'need' to root remains unsatisfied (Hughes and Duncan, 1988). Furthermore, feeding pigs with a high energy and nutrient diet leads to increased restlessness due to an absence of satiation. Access to substrates like straw, hay or roughage or a change in the diet (increase fibre content) can reduce oral behaviour like tail biting (Busch, 2006). 


\subsubsection{Consequences of tail biting - Welfare and economic}

Tail biting is a major welfare problem for the bitten pigs due to injuries and pain as well as for the biter since these pigs demonstrating inability to cope with their environment (EFSA, 2007). Deficient husbandry conditions can act as a stressor and reduce the welfare of pigs and may as a consequence lead to the development of tail biting (Schrøder-Petersen and Simonsen, 2001). In addition to being a welfare problem for the pigs tail biting is also an economic problem for the farmers and pig industry. Economic losses to the producer due to tail biting can result from impaired growth and feed conversion ratio, extra treatment and medication costs as well as increased carcase condemnations and mortality level (Sinisalo et al., 2012).

The tail is unprotected against biting while standing at the feeder (Zonderland et al., 2010) hence a normal consequence of protecting the tail might lead to reduced visits at the feeder (Palander et al., 2013). Pigs that received oral manipulation like tail-, ear- and foot or trotter biting irrespective of the severity of wounds grew less well than un-manipulated pigs, which corresponded to a weight difference of approximately $4 \mathrm{~kg}$ at the end of the finishing period (Camerlink et al., 2012). The average daily gain in bitten pigs decreased between $1 \%$ and $11 \%$ after tail biting (Wallgren and Lindahl, 1996; Niemi et al., 2011; Sinisalo et al., 2012). A recent study reported that the average reduction in carcase weight associated with mild tail lesions was $1.19 \mathrm{~kg}$ (Harley et al., 2014).

Tail biting induces an inflammatory response in the tail end leading to activation of acute phase proteins and spread of infection (Heinonen et al., 2010). This inflammatory reaction has even been found in healthy looking tails presumably caused by penmate chewing activities (Simonsen et al., 1991; Munsterhjelm et al., 2013b). Wounds can lead to an increased risk of infection resulting in abscess formation in the hindquarters and the posterior segment of the spinal column (Arey, 1991). Generally, tail bitten pigs have higher rates of carcase damage and condemnation at the slaughterhouses than unbitten pigs (Hunter et al., 1999; Kritas and Morrison, 2007; Marques et al., 2012; Sinisalo et al., 2012). In several slaughterhouse studies relationships have been found between tail lesions and arthritis (Valros et al., 2004; Harley et al., 2012; Marques et al., 2012) tail lesions 
and abscesses (Tuovinen et al., 1994; Wallgren and Lindahl, 1996; Widowski, 2002; Marques et al., 2012) and tail lesions and lung abscesses (Elbers et al., 1992; Huey, 1996; Kritas and Morrison, 2007; Marques et al., 2012). Moinard et al. (2003) stated that (amongst others) respiratory disease and tail lesion prevalence correlate at farm level indicating that tail biting may be more common on disease-prone farms, but tail biting may also contribute to increased disease susceptibility. The damage caused by tail biting among fattening pigs is considerable, though difficult to estimate, as an unknown number of pigs will fail to reach the slaughterhouse and will be culled on farm (Van Putten, 1969). Furthermore, abattoir records are likely to under-record tail lesions if the eventual cause of condemnation is identified rather than the predisposing factor (Taylor et al., 2010).

There is surprisingly limited information available about financial losses due to tail biting for the pig farmers and the whole pig sector. The estimated financial loss due to tail biting in United Kingdom was £3.5 million ${ }^{1}$ in 1999 (Moinard et al., 2003). Zonderland et al. (2011) estimated an annual financial impact of $€ 2,383$ for a finishing farm with 4000 fattening places based on an average tail damage prevalence of $2.12 \%$ among docked weaned piglets and finishers in the Netherlands. Moreover, the costs increase when farms have a higher prevalence or when the farmers have to take more actions in case of a tail biting outbreak. In a recent study Harley et al. (2014) calculated an economic loss value of $€ 1.69$ per study pig if the loss of carcase condemnation/trimming and reduced carcase weights associated with tail lesions were combined. This amount would increase further if indirect costs of carcase lesions were taken into account e.g. feeding, medication and labour (Martinez et al., 2007).

\subsubsection{Prevention and treatment of a tail biting outbreak}

Prevention of a tail biting outbreak requires an early diagnosis, preferably in the pre-injury stage before a pig has been wounded (EFSA, 2007). The effectiveness of stockmen in identifying and dealing with initial bitten tails will determine how

\footnotetext{
$1 £ 3.5$ million = approximately $€ 4.455 .761$ at 20 August 2014 .
} 
fast an outbreak will develop (Taylor et al., 2010). Moreover, pig farmers play an important role because they must be able and willing to take extra measures to prevent tail biting (Bracke et al., 2013). Decision-support tools enable the early identification and mitigation of tail biting risk factors especially for the farm-specific situation and may help farmers to reduce and prevent the occurrence of tail biting (EFSA AHAW Panel, 2014) (see Chapter 2.4 for Detail). If tail biting has been started by one particular pig this animal should be removed immediately to prevent an escalation of biting (Colyer, 1970; Edwards, 2006). Also the early removal of wounded pigs should be carried out (Arey, 1991) because bleeding tails stimulate further biting (Fraser, 1987a). Zonderland et al. (2008) compared two curative treatments in outbreaks of weaned piglets: straw twice daily and removal of the biter. Both treatments seemed to be equally effective in reducing the incidence of fresh blood on the tails, however, neither curative treatment eliminated tail biting entirely. In a British survey $67 \%$ of producers reported that they remove the bitten pigs from the pen while only $43 \%$ said they removed the biter (Hunter et al., 2001). According to Brunberg et al. (2011) it is demanding and time consuming to identify pigs performing low levels of tail biting, but that it is possible to identify pigs performing high levels of tail biting in less than half an hour.

One of the major risk factors for tail biting is the absence of straw or other environmental enrichment in intensive husbandry systems (EFSA, 2007). The positive effects of rooting material on finishing pigs and the reduction of abnormal behaviours such as manipulation of penmates or fittings have been investigated in several studies and can therefore be seen as a promising form of tail biting prevention (Fraser et al., 1991b; Beattie et al., 2000; Beattie et al., 2001; Van de Weerd et al., 2005).

Treatments for bitten pigs include the use of antibiotics and therapeutic solutions (EFSA, 2007) as well as the surgical amputation of a necrotic tail end, which might prevent an ascending infection (Grosse Beilage and Wendt, 2013). 


\subsection{Tail biting - the status quo}

\subsubsection{Legislation}

According to current European legislation Council Directive 2008/120/EC, article 8 of the annex (European Commission, 2008) routine tail docking is not permitted, the procedure can only be carried out, when there is evidence that injury to other pigs' ears or tails has occurred. Other measures such as improving the husbandry conditions should be taken to prevent tail biting before resorting to tail docking. Issues related to inadequate environmental conditions or management systems, including environmental enrichment and stocking density, should therefore be addressed in advance. "Pigs must have permanent access to a sufficient quantity of material to enable proper investigation and manipulation activities, such as straw, hay, wood, sawdust, mushroom compost, peat or a mixture of such" (Annex 1, Chapter 1, 4.).

Tail docking should only be carried out by a veterinarian or trained person experienced in performing the applied techniques with appropriate means and under hygienic conditions. If tail docking is practised after seventh day of life, it should only be performed under anaesthetic and additional prolonged analgesia by a veterinarian (European Commission, 2008). In fact routine tail docking is performed in most member states of the EU except Sweden, Finland, Norway, Lithuania and Switzerland which have either banned it totally or regulated that it has to be done with anaesthesia and for this reason it is no longer carried out (EFSA, 2007).

The implementation of the EC guideline is carried out by the Tierschutzgesetz (TierSchG, 2006, (Animal Welfare Act)) in Germany. In accordance with article 6 (1) No 3 tail docking is only allowed in individual cases for the benefit of the individual animal or for the protection of other animals. Furthermore, all options should be considered to prevent pain and distress of the animals' article 5 (1). A fundamental difference is the fact that tail docking without anaesthesia is forbidden after fourth day of life article 5 (3) No 3 (TierSchG, 2006).

At the end of 2009 the German animal welfare organization PROVIEH submitted a complaint to the European Commission based on the investigative Report of 
Compassion in World Farming (CIWF) which highlighted that in $79 \%(\mathrm{~N}=9)$ of farms visited in Germany the pigs had docked tails and that in $89 \%(\mathrm{~N}=19)$ of farms pigs lived in inadequate environment (CIWF, 2008; Ohm and Johningk, 2011). As a consequence, the European Commission commenced an infringement proceeding against Germany in 2011 because of the fact that German authorities had failed to properly transpose Directive 2008/120/EC into German law. The European Commission (2011) argued that Germany was failing to require changes in environment and stocking density in article 6 (1) No 3 (TierSchG, 2006). In addition there is no clear specification in article 26 (1) No 1 (TierSchNutztV, 2006, (Order on the protection and keeping of production animals)) of types of enrichment. In October 2011 the EC decided to close the EU Pilot $1360 / 10 /$ SNCO but on $6^{\text {th }}$ December 2013 PROVIEH asked the EC to reopen it again due to existing insufficient transposition of the Directive 2008/120/EC (Lorenzen, 2013).

As a consequence of this challenge, several federal states of Germany became proactive; in 2011 Lower Saxony started an animal welfare plan, which at a general level provided the optimisation of husbandry and management specifically banning routine tail docking until 2016 (Baumgarte, 2014). Since 2011 a regulation in North-Rhine-Westphalia declared that a veterinarian has to confirm that other measures have been carried out on a farm if tail docking is still practiced (MKULNV Nordrhein-Westfalen, 2011). Furthermore, a brief statement was recently formulated between the ministry and two agricultural alliances to initiate the avoidance of routine tail docking in the near future e.g. through training sessions with farmers and veterinarians (MKULNV et al., 2014).

\subsubsection{Tail docking}

Tail docking is routinely conducted on pig farms to reduce tail biting problems. The percentage of docked pigs in Germany is nearly $100 \%$ and the small amount of piglets which are un-docked refer mainly to organic husbandry due to their specific requirements (EFSA, 2007). Most farmers do not take any risks, since an outbreak of tail biting causes considerable economic losses and also causes 
problems in managing the herd until slaughter (Spoolder et al., 2011). However, tail docking does not completely remedy the problem of tail biting since it reduces the behavioural disorder but the underlying causes remain unresolved (Nannoni et al., 2014).

Pigs experiencing acute pain in response to tail docking expressed this as increased vocalization during the docking procedure. Pigs also show behavioural changes like increased tail jamming and wagging and scooting compared to sham handled piglets (Noonan et al., 1994; Sutherland et al., 2008). Furthermore, neuromas have been found which indicate an increased sensitivity to pain of the tail stump which underline the hypothesis for why docking prevents tail biting (Simonsen et al., 1991). In a Dutch study $66 \%(\mathrm{~N}=322)$ of conventional farmers stated that they had never tried to stop tail docking and regarded it as a necessary procedure. Therefore reducing routine tail docking requires not only solutions for dealing with tail biting problems on-farm but also a change in farmers' attitudes and awareness of the moral issues involved (Bracke et al., 2013).

\subsubsection{Prevalence of tail biting}

Generally tail biting is recorded as the prevalence or proportion of tail-bitten pigs in a study population on-farm, at the abattoir, or the data refer to a problem-based investigation of pens or farms with tail biting behaviour (Taylor et al., 2010). When large numbers of animals are considered in a representative sample the prevalence of tail biting can also be a reflection of the housing systems and management practices and hence an indicator of the welfare of the pigs (Keeling et al., 2012). The most common method is the monitoring of tail lesions on carcases at the abattoir with the major advantage that a rapid monitoring of pigs from different farms can be carried out (EFSA, 2007).

A recent Irish abattoir study found out that $72.5 \%$ of docked pigs had some tail lesions and $2.5 \%$ of the pigs had severe tail lesions (Harley et al., 2014), whilst a Finnish abattoir study reported $34.6 \%$ tail lesions in un-docked pigs (Valros et al., 2004). Busch et al. (2004) analysed national meat inspection data and found out that $35 \%$ of pigs with tail lesions originated from $10 \%$ of herds highlighting 
the clustered nature of the problem. In contrast to a large number of abattoir studies only a few exist which investigate the prevalence on-farm (Edwards, 2011). Among 90 herds of Danish finisher pigs the mean prevalence of bitten tails was $1.26 \%$ (Petersen et al., 2008). Smulders et al. (2008) visited 60 farms three times a year across Belgium and found $2.1 \%$ tail lesions; in $24.5 \%$ of the pens one animal was affected by tail or ear lesions. Similarly, Goossens et al. (2008) reported that between $0-21 \%$ of pigs showed tail biting behaviour and $3.7 \%$ of growing and $2.4 \%$ of fattening pigs had tail lesions.

It is difficult to compare prevalences between studies and countries due to differences in management, for instance docked vs. un-docked pigs, and partly due to the scoring system of lesions as well as the definition of tail damage (Keeling et al., 2012). Various scoring systems have been suggested for abattoir inspections (Hunter et al., 1999; Valros et al., 2004; Kritas and Morrison, 2007; Keeling et al., 2012) and on-farm recordings (Goossens et al., 2008; Smulders et al., 2008; Zonderland et al., 2008) but none is used universally.

\subsection{Risk factors for tail biting}

\subsubsection{Comfort}

Adequate housing conditions for pigs should include sufficient space for the pig's size (when resting) as well as enough room for movement between the functional areas and for appropriate social behaviour (Spoolder et al., 2012). According to Peet (2003) the pen shape should have a ratio of length to width of between 1.5:1 and 2.5:1 to allow the pigs a differentiation between the dunging and lying area. High stocking density or overcrowding has often been mentioned as associated with an increased risk of tail biting (Arey, 1991; Moinard et al., 2003; Goossens et al., 2008). A recent risk analysis confirmed that the space allowance per pig in the pen is very influential regarding an outbreak of tail biting (EFSA AHAW Panel, 2014). Higher stocking densities restrict pigs in their movements, and frustration, due to inability to reach resources may arise (Taylor et al., 2010). Randolph et al. (1981) found an association between a decrease in space allowance and a decrease in daily weight gain. Moreover, space allowance seems to interact with 
enrichment; it has been shown that in pens with a higher space allowance more pigs manipulated the enrichment material offered (Jensen et al., 2010). However, Beattie et al. (1996) found that adequate enrichment had a greater influence on pig behaviour and reduction of tail biting than higher space allowance.

In a questionnaire survey among Dutch conventional farmers, climate was considered to be the most important risk factor for tail biting (Bracke et al., 2013). Effects of climate on tail biting are complex with many different factors like temperature, deterioration of the air quality, humidity, dust and draughts potentially acting as stressors and leading to increased discomfort and possibly resulting in tail biting (EFSA, 2007; Taylor et al., 2010). Air temperature outside the optimal range of the pig's thermal comfort zone has often been suggested to influence tail biting (Van Putten, 1969; Penny et al., 1981; Sambraus, 1985; Geers et al., 1989). Smulders et al. (2008) showed that high temperatures in the nursery $\left(23-29^{\circ} \mathrm{C}\right)$ influenced subsequent prevalence of tail and ear biting as finishing pigs. One measure to improve pig welfare and reduce tail biting during summer periods is the application of a fogging system as demonstrated by Courboulay et al. (2008). Moreover, it has been reported that tail biting may begin in pens where isolated pockets of stale, humid air are allowed to accumulate (Colyer, 1970). Van Putten (1969) was able to provoke tail biting with poor ventilation, relative humidity of about $80 \%$ and high concentrations of carbon dioxide and ammonia. The regulation of the ventilation system has to consider air movement in all areas of the pens without creating draughts (Schrøder-Petersen and Simonsen, 2001) because these have been suggested to be a potential stimulus for tail biting (Colyer, 1970; Sambraus, 1985).

\subsubsection{Enrichment}

According to EFSA (2007), the lack of straw and absence of adequate enrichment is one of the major risk factors for the occurrence of tail biting in intensive husbandry systems. Several authors have shown that pens with enrichment have lower tail biting and tail manipulation levels than pens without objects or substrates (Fraser et al., 1991b; Beattie et al., 2001; Van de Weerd et al., 2005). 
The provision of straw as a substrate enhances the welfare of pigs as it serves as a stimulus and outlet for exploratory and foraging behaviour (Tuyttens, 2005); as a consequence, pigs in straw-bedded systems have a lower prevalence of tail biting than those in slatted husbandry systems (Scott et al., 2006a; Van de Weerd et al., 2006). Pigs with a prior experience of straw bit other pigs more frequently when they were moved to accommodation without straw than pigs which had no prior experience of straw (Day et al., 2002). It has been shown that small amounts, such as a handful of straw per pig per day, have beneficial effects on the reduction of tail biting (Van Putten, 1980; Zonderland et al., 2008). Furthermore, it has been argued that straw or any other substrate should be replenished daily with clean palatable material because this may increase its novelty (Hunter et al., 2001; Moinard et al., 2003). Day et al. (2002) found that the quantity of straw-directed behaviour was proportional to the amount of straw provided. An increase of the straw amount led to an increase of rooting and a concomitant decrease in tail biting. However, in most intensive husbandry systems straw is not used because it can block the slurry-based manure systems (Zonderland et al., 2008). As one alternative to the loose provision Fraser et al. (1991b) reported that providing $63 \mathrm{~g}$ of straw per pig per day in a straw rack could reduce tail biting in growing pigs, whereas Zonderland et al. (2008) stated that a straw rack was considerably less effective than providing straw loose in the pen twice daily. It has been found that the length of straw affected the quantity and quality of straw-directed behaviours; whilst the provision of straw of any length reduced the occurrence of pig-directed behaviour compared with pens where straw was absent, levels of tail biting were higher in pens with chopped straw than in pens with full-length or half-length chopped straw (Day et al., 2008). Several studies have shown that straw can keep pigs occupied for a longer period than manipulable objects (Scott et al., 2006b; Van de Weerd et al., 2006; Scott et al., 2007) and that the incidence of pens with wounded tails is significantly reduced (Zonderland et al., 2008).

As an alternative to straw and substrates, enrichment objects should be offered to occupy pigs and deter them from performing undesirable behaviours (Van de Weerd et al., 2005). Enrichment objects are often restricted to a single location in the pen, and are usually of limited size that does not allow simultaneous access 
in a group of pigs (Van de Weerd et al., 2006). Bracke et al. (2006) attempted to determine what kind of enrichment is sufficient for weaned and growing pigs via a literature review: they concluded that metal objects are not suitable for pigs, that rubber, rope, wood, roughage and substrates may be sufficient and that straw and compound materials are best. One key characteristic of objects is destructibility since pigs are more attracted to objects when they can perform destructive chewing, whereby they alter, unravel or remove pieces from an object (Feddes and Fraser, 1994). Freely swinging objects at pig-eye level are even more attractive than free objects on the ground of the pen because they cannot become soiled with excreta. Generally it is suggested that the objects should be changed at regular levels to maintain interest (Blackshaw et al., 1997).

\subsubsection{Feed and water}

Deficiencies in protein, energy density, specific amino acids, minerals or fibre content have been associated with tail biting outbreaks due to increased foraging motivation and the strong link with diet selection and gut satiety (Taylor et al., 2010; Edwards, 2011). Pigs fed with low fibre diets may remain hungry after feeding, which can cause restlessness and irritability resulting in tail biting (Colyer, 1970). Fraser et al. (1991a) reported an increase of chewing on a blood-soaked model and a significant reduction in body weight gain when pigs were fed a low protein diet, indicating that tail biting outbreaks may result from low protein diets (Jericho and Church, 1972). Finisher pigs fed with a low protein and low energy diet showed a greater tendency to chew on blood-soaked tail models but it was not proven to be significant (Mclntyre and Edwards, 2002a). Changing the protein and energy ratio according to body weight in a diet due to phase feeding has reduced the prevalence of tail biting (Holmgren and Lundeheim, 2004). However, it has been shown that sudden changes in the diet may trigger tail biting behaviour (Day et al., 2002).

If pigs were fed a diet with a reduced tryptophan content, they showed an attraction to blood soaked models as well as reduced resting behaviour with an increase of exploratory behaviour (McIntyre and Edwards, 2002b). Tryptophan is 
the primary precursor of serotonin and can be used as a therapeutic supplement due to its positive effects expressed in reduced activity and fighting behaviour ( $\mathrm{Li}$ et al., 2006). Martinez-Trejo et al. (2009), compared four levels of dietary tryptophan in piglets weaned at 21 days of age and reported that tail and ear biting were reduced with the two highest levels (0.31 and $0.35 \%)$. Mineral deficiencies were frequently associated with tail biting, and the provision of sodium is a common approach when an outbreak occurs (EFSA, 2007). Although pigs require only up to $0.21 \%$ salt $(\mathrm{NaCl})$ in the diet to meet growth requirements (GfE, 2006), adding $1.5 \%$ salt per $\mathrm{kg}$ feed has been shown to reduce tail biting behaviour (Tsourgiannis et al., 2002). In a study using artificial tail models impregnated with blood vs. controls it was shown that after 4 weeks feeding the pigs a mineral deficient diet (iodized salt, dicalcium phosphate, limestone, iron, zinc, manganese, copper, and selenium) an increase in chewing the blood-covered model occurred (Fraser, 1987b). A heightened response to blood was produced by omitting only iodized salt from the diet, whereas the omission of all other mineral supplements except salt led to a smaller and statistically nonsignificant change. It was therefore suggested that a lack of salt in the diet can increase the attraction to injured penmate tails during an outbreak (Fraser, 1987b).

In a UK survey it was shown that five or more pigs per feed space increased the risk of tail biting by a factor of 2.7 (Moinard et al., 2003). Smulders et al. (2008) suggested that frustration due to restricted access to feeder spaces may have long term effects on pigs' behaviour, i. e. the number of feeding places per animal in the nursery had a significant effect on the subsequent prevalence of tail lesions in fattening pigs. In a Swedish study restricted feeding in troughs where there was less than $30 \mathrm{~cm}$ per pig trough space increased tail biting (Holmgren and Lundeheim, 2004). An increase in the pig:trough ratio and ad libitum feeding reduce the competition around the feeding trough (Nielsen et al., 1996) and has been shown to lower the prevalence of tail biting (Hansen et al., 1982). The optimal number of pigs per feed space is unclear (Gonyou, 2000), thus in practice it ranges from 0.3 up to 40 pigs. It is recommended that feeder spaces should be provided so that at least $20 \%$ of pigs can eat at one time (Moinard et al., 2003). Pigs are known to anticipate the arrival of feed when meals are provided regularly 
(Terlouw et al., 1993) or with acoustic signals (Busch, 2006), therefore an absence or delay in the arrival of feed will contribute to increased foraging behaviour and can cause tail biting (Taylor et al., 2010). In a questionnaire survey, farmers noted problems with the feeding and drinking system as an important factor in tail biting (Paul et al., 2007).

Survey data on the form of feed should be handled with care because they are often confounded with the delivery method, housing system and ingredient compositions of the diet (EFSA, 2007). Nevertheless, findings have shown higher levels of tail biting in pigs given pelleted rather than liquid or meal feed (Hunter et al., 2001; Moinard et al., 2003). Feeding a ration with pellets or meal with reduced particle size has also been associated with a significant increase in gastric ulcer severity compared with feeding ratio with coarse ground particles or an unpelleted ratio (Wondra et al., 1995; Amory et al., 2006).

The number of animals per drinker, the accessibility and the water flow rates are critical parameters stockmen have to consider continuously (Kamphues and Schulz, 2002). In accordance with article 28 (2) No 5 (TierSchNutztV, 2006) one drinker should be offered per 12 pigs and article 26 (1) No 2 regulates that every pig should have permanent access to a drinker with water in sufficient quality and quantity and which is separated from the feeding spaces. Kamphues (2002) reported that a sufficient quantity of water is more often a problem on farms than the quality of the water. In a recent project blood samples of 204 bitten and unbitten pigs were taken; more than half of the bitten pigs had higher values of haematocrit, which is possibly associated with a lower intake of water (SchulzeHorsel and Engeland, 2013). When growing pigs were given ad libitum access to nipple drinkers they spent on average $0.7 \%$ of the day drinking across 26 to 33 drinking events (Li et al., 2005).

\subsubsection{Health}

Tail biting and disease may be related since they act both as a stressor on the affected animals and therefore lower the threshold for the development of each other (Schrøder-Petersen and Simonsen, 2001). Pigs which suffer from disease 
might be more reluctant to avoid biters, and incapable of defending themselves against being bitten (Kritas and Morrison, 2004). Higher prevalence of tail biting have been reported from herds with a poorer health status especially with the presence of respiratory diseases (Moinard et al., 2003; Schroder-Petersen et al., 2004; Kritas and Morrison, 2007). Moreover, anaemia, either including nutritional causes or an infection with Streptococcus haemolyticus has been identified as predisposing to tail biting (Fritschen and Hogg, 1983). The presence of external parasites such as mange mites and lice has been also suggested as a cause for tail biting (Colyer, 1970; Fritschen and Hogg, 1983). Leeb et al. (2010) recommended considering the liver rejection rate generally as part of the Animal Health and Welfare plan for finisher pigs.

Poor health can result in a reduced growth rate and a range of sizes within the group (Taylor et al., 2010). Several authors describe growth retarded pigs as often starting an outbreak of tail biting (Sambraus, 1985; Kritas and Morrison, 2004; Van de Weerd et al., 2005). A greater predisposition to tail biting behaviour might reflect an indirect effect of reduced competitiveness and therefore frustration when motivated to access resources (EFSA, 2007). Thus, smaller pigs are often driven away from the trough or from their resting place by larger penmates (Sambraus, 1985). Growth retarded pigs and runts suffer from chronic stress, which may lead as a consequence to tail biting (Van de Weerd et al., 2005; Smulders et al., 2006)

There have been several reports stating that specific measures for improving the health status have reduced tail biting prevalence on-farm, for instance by vaccination against Lawsonia intracellularis (Almond and Bilkei, 2006), porcine circovirus-2 (Taylor et al., 2012) or by introducing foot baths between different sections of the farm (Smulders et al., 2008).

\subsubsection{Stress}

So far there have only been limited attempts to measure stress in relation to tail biting activity (Munsterhjelm et al., 2013a) and the effects with regards to change in social status (EFSA, 2007). Within a pen of pigs any factor or interaction of 
factors which disturb the normal pattern of behaviour as well as inadequate environmental conditions will act as a stressor and may lead to tail biting (Colyer, 1970). In general, pens of pigs which become restless, active or agitated are more prone to tail biting (Fraser, 1987a; Arey, 1991). There are potentially high levels of stress as animals are moved from their home pens, regrouped or transported (Li et al., 2006). Although there is no clear conclusion emerging from research, a common opinion is that mixing pigs might trigger tail biting in intensive husbandry. Holmgren and Lundeheim (2004) found a lower prevalence of tail biting in farrow to finisher farms indicating that transport and/or change in management and feed may provoke pigs to develop tail biting.

\subsection{Animal Health and Welfare Planning}

Animal health and welfare planning (AHWP) is promoted and widely implemented in the conventional and organic livestock sector in UK whereas in Germany it is mostly associated with research projects (Nicholas and Jasinska, 2008). AHWP on-farm is also well-established across dairy cattle husbandry (Vaarst et al., 2011; Ivemeyer et al., 2012; Main et al., 2012) but to a much lesser extent in the pig sector (Nicholas and Jasinska, 2008) especially in the conventional pig husbandry. AHWP can be a useful tool, and many influencers within the agricultural sector e. g. veterinarians, farm advisers and government have focussed on the development of management change and welfare improvement (Whay et al., 2012). The process of planning requires different steps including (1) an assessment and evaluation of the current status and risks of animal-based and resource-based parameters, (2) a formulation of the farmer's targets and measures as well as (3) a review process (Nicholas et al., 2008). Additionally it should be specific to an individual farm since no two farms are the same due to differences in resources, management and levels of stockmanship etc. (Sibley, 2000). External advice and knowledge of veterinarians or farm advisers can be a great benefit and are essential in supporting and sustaining this process (Vaarst et al., 2011) because they avoid bias which might be introduced through farmers' blindness (Smolders, 2009). Highlighting existing good farm management is essential and should also be systematically evaluated as it is motivating for all 
participants (Nicholas et al., 2008). Finally, AHWP includes a written plan which is dynamic, ongoing and self-perpetuating while it is based on practical and achievable aims and measures to correct the problem and prevent recurrence (Sibley, 2000). It is mandatory that farmers decide and formulate aims and measures for the farm themselves following the SMART principle (specific, measurable, achievable, relevant, and time-based) to guarantee ownership and a full agreement and realisation of the plan (Sibley, 2006; Vaarst et al., 2011). The communication skills and strategies of the well-trained and informed facilitator are of major importance for leading farmers towards implementing change and compliance with action plans (Whay et al., 2012). It has been suggested that farm-specific plans are more likely to be implemented than general advice from stakeholders because the plans are specific to the assessed farms (Vaarst et al., 2011). 
Chapter 3

Material and Methods 


\section{Chapter 3: Material and Methods}

\subsection{Tail biting intervention tool}

A software-based tail biting intervention tool, called SchwlP (abbreviation for Schwanzbeiß-Interventions-Programm meaning tail biting intervention programme) was developed, evaluated and distributed between $1^{\text {th }}$ September 2011 and $31^{\text {th }}$ August 2014. Two doctoral theses originated from this study which complement one another. The application of the tool is described further in Chapter 4 and 5 . The evaluation of the tool is illustrated in Chapter 5 . Therefore at this point only a brief overview of the development and content of SchwIP will be presented.

\subsubsection{Development of SchwIP}

The tail biting husbandry advisory tool 'HAT', which was developed and conducted in UK by Taylor et al. (2012) served as a basis for SchwIP, since the husbandry of finisher pigs in UK and Germany are not the same the tool had to be adapted to present conditions. An expert survey was therefore conducted by means of an online questionnaire (www.Q-Set.de). Experts had an agricultural or veterinarian educational background and were recruited via networking. Eighty-six risk factors originating from the HAT and 10 additional factors were considered. The experts were asked to weight them according to their influence on tail biting in German fattening pig production. Each factor was phrased as a statement (e.g. particle size in feed $<0.5 \mathrm{~mm}$ ) and suggestions for improvement (e.g. ensure a sufficient particle size in feed, it should be $0.5 \mathrm{~mm}$ or greater) were given, which were to appear in the farm report of the completed tool. The impact of a factor were weighted on a scale from +90 until -90 in units of ten $(0=$ no impact, $+90=$ strongly increases risk for tail biting, $-90=$ strongly decreases risk for tail biting). In addition the weighting scale was colour coded ( $\mathrm{red}<0$, green $>0$ ) for a better visualisation. The outcome of the expert survey was the basis in order 
to generate the SchwIP file. The weighted risk factors were categorised to five main risk categories (comfort, enrichment, feed \& water, health and stress). The individual weighting score ranged from 5 to 70 , indicating the relevance to tail biting. A detailed analysis of the expert opinion regarding tail biting risk factors in Germany is illustrated in Madey et al. (2014c) (submitted).

\subsubsection{Content of SchwIP}

SchwIP was coded in Excel (Microsoft Office) and Apache OpenOffice ${ }^{\mathrm{TM}}$ (Apache Software Foundation) spreadsheets. The file contained: 1) an instruction sheet for the user, 2) definitions of terms (e.g. enrichment object), and 3) tables with guidance values for feed and climate, 4) an entry mask for the interview with the farmer, and 5) an entry mask for the direct observations on-farm. If the user entered the necessary data an individual farm report was generated via macros which consisted of five different sections. The first section gave a brief overview of the visited farm. Moreover, it contained a top ten bar chart and for every risk category an additional bar chart, where the bars of the individual risk factors in the respective category were either green (no risk on-farm) or red (risk on-farm). The length of the bars implicated the weighting score behind the risk factors and their impact on tail biting. The acknowledgement of factors which were no risk on-farm were highlighted in the second section of the farm report with explanations of the occasion. The third section illustrates the farm-specific risk factors with explanations and potential proposals for solutions. A detailed compilation of risk factors for each assessed pen of the direct observation on-farm was shown in section four. Finally, the last section is an additional entry mask where the user comprised the aims and measures the farmer decided on to reduce the tail biting risk on-farm. 


\title{
Chapter 4
}

Training veterinarians and agricultural advisers on a novel tool for tail biting prevention

\author{
A. L. vom Brocke, D. P. Madey, M. Gauly, L. Schrader, S. Dippel
}

This chapter has been submitted to Veterinary Record Open 
Chapter 4: Training veterinarians and agricultural advisers on a novel tool for tail biting prevention

Abstract

Many health and welfare problems in modern livestock production are multifactorial problems which require innovative solutions, such as novel risk assessment and management tools. However, the best way to distribute such novel - and usually complex - tools to the key applicants still has to be discussed. This paper shares experiences from distributing a novel tail biting prevention tool ("SchwlP") to 115 farm advisers and 19 veterinarians in 23 one-day workshops. Participants gave written and oral feedback at the end of the workshops, which was later analysed together with the number of farms they had visited after the workshops. Workshop groups were categorised into groups showing a) $\mathrm{HIGH}, \mathrm{b}$ ) INTermediate or c) LOW levels of antagonism against SchwIP or parts of it during workshop discussions. Group types did not significantly differ in their evaluation of knowledge transfer. However, HIGH group members evaluated on-farm usability of the tool significantly lower in the workshop feedback and tended to visit fewer farms. Thus, as antagonistic discussion can influence workshop output, future workshop leaders should strive for basic communication training as well as some group leadership experience before setting up and leading workshops.

\subsection{Introduction}

During the last decades, livestock production developed from family holdings to large specialised production units with complex management requirements. Many health and welfare problems encountered in modern herds are of multifactorial causation, such as lameness in dairy cows or tail biting in pigs. 
Multifactorial causation implicates, that a wide range of risk factors from several areas have to be checked and optimised in order to successfully solve a problem. At the same time, successful solutions cannot be reliably transferred between farms because the key factor combinations differ between individual farms. Therefore, problem specific approaches in close collaboration with science are needed. A useful approach are knowledge-based risk analysis or management tools, which should be applied in the course of animal health and welfare planning (AHWP) for long-term improvement (Green et al., 2007).

Once such tools have been developed, they have to be transferred to farms in an effective way. Veterinarians and agricultural farm advisers (referred to as VFA below) play the key role in this process, because successful solutions require an external person for assessment and discussion of results without imposing intervention measures (Whay et al., 2012). While VFA traditionally were the most important direct source of new scientific findings and other knowledge, referring farmers to suitable specialists as part of AHWP plays an increasing role in extension and veterinary services, because there is too much knowledge available for one VFA to be an expert in every field (Baljer et al., 2004; Jovanić and Delić, 2013).

\subsubsection{German VFA}

Like in many other countries, there is a trend for specialisation of German veterinarians as well as their practices (Radostits, 2001). Most practicing vets are privately organised, yet there are some official organisations funded by the federal states and agricultural insurances which specialise on certain problems, e. g. pig health (national pig health service; Schweinegesundheitsdienst). Advisory services on the other hand reflect Germany's federal structure. They can be state-run, private or both, and advisers work in large teams, loosely associated or single-handedly (Hoffmann, 2004; Boland et al., 2005). Learning new techniques is up to the individual veterinarian or farm adviser. While German veterinarians have to participate in at least 20 hours of vocational training per year, regulations for farm advisers are much more diverse. 
Many veterinary courses and most adviser courses are lecture-based theoretical seminars. As tools for multifactorial problems are usually rather complex, this raises the question of the best way of distributing these tools. Is it sufficient to present them in theoretical seminars and hand out manuals, or do they require other means of training?

\subsubsection{Teaching and learning}

Modern teaching has moved from teacher-centred lecturing towards studentcentred techniques, which accommodate the different ways of how individual people receive and process new knowledge, so-called learning styles (Felder, 1996; Mills et al., 2005). Good teaching caters for as many learning styles as possible, which means presenting knowledge visually and verbally, with theories and facts, and with and without interactive sessions ("teaching around the cycle", (Felder, 1996); see (Bell et al., 2014a) for a practical summary).

People from different professions tend to differ in their learning styles (Kolb, 1981). Veterinary students are mostly active, sensing (seeking sense), visual and sequential learners (Neel and Grindem, 2010), that means, they prefer applying concepts with connection to the real world in practice. The same is true for agricultural education professionals (Cano et al., 1992). Thus, interactive workshops are preferable to lecture-based seminars as means of distributing a novel tool for multifactorial problems to VFA. Nevertheless, knowledge should be presented in as many different forms as possible during a workshop, because individuals will still differ in their individual preferences (Neel and Grindem, 2010; Bell et al., 2014b).

\subsubsection{A tail biting prevention tool as an example}

In Germany, tail biting currently poses a considerable problem in conventional pig production. Tail biting reduces the welfare of the animals and financial gain of the farm (Schrøder-Petersen and Simonsen, 2001), as well as farmer job 
satisfaction. German VFA mainly working with pigs have had very little experience with AHWP. Furthermore, basic pig biology related to welfare (e. g. behaviour) has been taught less intensively at German veterinary or agricultural universities than in the UK, for example.

We therefore adapted the tail biting husbandry advisory tool by Taylor et al. (2012), which had previously been applied by one person in the UK, to German production conditions and for broader use. The German tool is called SchwIP, an abbreviation for "Schwanzbeiß-Interventions-Programm" (tail biting intervention programme). SchwlP was validated by training pig veterinarians and pig farm advisers in interactive workshops, who then applied it on their customer farms and sent us their data. After farm visits, workshop participants were asked, how colleagues should be trained on similar tools in the future. The majority (67\%) of participants recommended participation in an interactive workshop over just using a tool with a manual.

During some of the workshops there was very intense, antagonistic discussion about the SchwIP concept in general or specific details of it. Even though questioning and discussion is part of adult learning (Bell et al., 2014a), it can also decrease the quality of communication in the learning group, which has been associated with its learning success (Webb and Farivar, 1999; King, 2002). Therefore, this raised the question of how antagonistic discussions affect the perception of a workshop by the group and whether it may reduce the motivation to apply the new knowledge after the workshop.

Successful training of VFA for applying novel tools on-farm will enable them to work more effectively with farmers. At the same time, quality of data collected through such tools for tool refinement and research will be improved. In view of the ongoing trend towards more complex veterinary and advisory services as well as suitable novel tools, others will also be facing the question of how to design and conduct interactive workshops for VFA. Therefore, the aim of this paper is to share our experiences from training VFA in the use of a novel tool for reducing tail biting. Besides general descriptions, we focused on differences between groups with different levels of antagonism in discussions. 


\subsection{Methods}

\subsubsection{The tail biting tool SchwIP}

SchwIP is a risk assessment and improvement procedure applied to a farm in regular intervals. During a SchwIP farm visit, the user (adviser, veterinarian) first interviews the pig manager about animal history and general management procedures (weaning, vaccinations, feeding, etc.). Subsequently, the user directly observes a sample of pens, whereby pens where tail biting currently or regularly occurs are given preference over a random sample (problem-based approach). Direct observations include various quantitative and qualitative housing parameters (e.g. pen size, temperature, water flow rate), as well as behavioural and clinical observations (e. g. lesions, runts). The collected data on approximately 180 parameters in total are then entered in the SchwIP file (Microsoft Excel® or Apache OpenOffice ${ }^{\mathrm{TM}} \mathrm{Calc}$ ), which automatically generates a farm specific report with risk profile and calculations for various measures (e. g. stocking density, temperature suitability). After the user has discussed the report with the pig manager, the pig manager decides which risk factors found on the farm he/she wants to minimize and which measures will be used in order to do so. This is documented in the farm plan. After a suitable interval (e. g. one year), the farm assessment is repeated, compliance and success are checked, and a new plan is drawn up (Ivemeyer et al., 2012).

\subsubsection{Participants}

Potential workshop participants were invited through calls in professional magazines, newsletters and at conferences and meetings. Out of 150 applicants, 134 fulfilled the criterion of being a farm adviser or veterinarian who would be able to apply SchwIP on at least one farm with more than 400 fattening pigs and a current tail biting problem. Participants were trained in 23 one day workshops all over Germany from June till September 2012. A PhD student (first author), who had received one day of communications training by a professional trainer conducted the workshops. Participants included a total of 115 farm advisers 
specialising on pig production, of which 26 were official advisers, 79 were private advisers and 10 were advisers from breeding or pig marketing organisations. Furthermore, 14 veterinarians from private practices and 5 from national pig health service took part. Depending on logistics, the workshops consisted of either single or mixed profession groups (14 adviser, one veterinarian, eight mixed groups). Workshop group size was four to six people, except for five groups with seven to 10 participants. In all but three groups at least some participants knew each other. Workshop participation was free of charge and the only condition was a written consent to apply SchwIP on at least one farm.

\subsubsection{Workshops}

Workshops took place during one day from $0900 \mathrm{~h}$ till approximately $1630 \mathrm{~h}$, with 15 min breaks approximately every two hours (or if needed), and a one hour lunch break. They consisted of theoretical and practical sessions which were both a mixture of interactive (Reeves and Hedberg, 2003) and cooperative learning (Dooley and Kossar, 2010). About a week before the appointed date of the workshop an email was sent to the participants with information concerning location and agenda, and asking them to bring a laptop. The workshop started in a meeting room with a projector. A folder was placed at each seat, which contained printouts and a CD with presentations and explanations (Microsoft Power Point $\left.{ }^{\circledR}\right)$, forms for the farm visit (e.g. confidentiality agreement) and a SchwIP file manual. During breaks, the trainer copied the SchwIP file to the laptops of the participants and established the necessary macro settings in Microsoft Excel®/Apache OpenOffice ${ }^{\mathrm{TM}}$ Calc. After an introduction of the trainer and the agenda, participants were encouraged to actively participate in the workshop, and asked to introduce themselves and their main working areas.

The first theoretical session started with a brief overview of SchwIP and the associated research project, and an introduction to pig biology and tail biting causation. Then, the structure of the SchwIP file was explained using screenshots, and potentially ambiguous interview questions were outlined using pictures and drawings. The selection of sample pens for direct observations was 
explained by means of examples followed by an exercise for the participants because of its complex nature. After a 15 min break, the direct observations in the sample pens were explained. Here, the focus was on aspects where participants had no previous experience with (such as observation of behaviour), and on parts where a certain level of agreement was required by the project (classification of clinical parameters and housing characteristics). Finally, the report generated by the SchwIP file was explained and participants briefed about the survey period and data transfer.

During the second half of the day, participants simulated a SchwIP application. Before the workshop, one of the participants had organised a farm for a test assessment. The respective participant answered the interview questions in place of the farmer, and after an $1 \mathrm{~h}$ lunch break the group went to the test farm. In the barn, the trainer demonstrated a pen assessment and gave practical advice. Subsequently, the group moved to a new room and each participant assessed one or two pens within the same room independently on his / her own under supervision of the trainer. After the barn survey the group went back to the meeting room, where each participant entered the data into the SchwIP file and created a farm report. The report as well as possible aims and measures for the workshop farm were then discussed as a group.

\subsubsection{Feedback from participants}

At the end, after all open questions had been discussed, participants were handed out anonymous feedback forms to grade the workshop as well as trainer performance in nine rating questions with grades from 1 to 6 ( 1 = very good, 6 = very bad; parameters see Table 4.1), and one open question to give suggestions for improvement. 
Table 4.1: Evaluation results from workshops where pig veterinarians and farm advisers were trained to use an on-farm tool for tail biting prevention. Workshop groups were classified based on the level of antagonism in their discussions (group type) and evaluation grades as well as numbers of farms visited after workshop were compared between group types.

\begin{tabular}{|c|c|c|c|}
\hline \multirow[b]{2}{*}{ Parameters $^{2}$} & \multicolumn{3}{|l|}{ Group type $^{1}$} \\
\hline & $\mathrm{HIGH}(\mathrm{N}=5)$ & INT $(N=11)$ & $\operatorname{LOW}(\mathrm{N}=7)$ \\
\hline Workshop fulfils expectations & $2(2 ; 3)$ & $2(1 ; 2)$ & $2(1 ; 2)$ \\
\hline Tool usability on-farm & $2.5(2 ; 3)^{a}$ & $1.5(1 ; 2.5)^{\mathrm{b}}$ & $2(1 ; 3)^{a b}$ \\
\hline Scope of workshop & $2(2 ; 3)$ & $2(1 ; 2.5)$ & $2(1 ; 2.5)$ \\
\hline Work pace & $2(2 ; 3.5)^{a}$ & $2(1 ; 2)^{a b}$ & $1(1 ; 2)^{b}$ \\
\hline $\begin{array}{l}\text { Knowledge transfer during } \\
\text { workshop }\end{array}$ & $2(2 ; 2.5)$ & $2(1 ; 2)$ & $1(1 ; 2.5)$ \\
\hline Theoretical introduction & $2(2 ; 2)$ & $2(1 ; 2)$ & $1.5(1 ; 2)$ \\
\hline Practical application & $2(2 ; 2.5)$ & $2(1 ; 2.5)$ & $1(1 ; 2)$ \\
\hline Discussion & $2(1 ; 3)$ & $2(1 ; 2)$ & $1(1 ; 2)$ \\
\hline Handout & $2(1 ; 2)$ & $2(1 ; 2)$ & $1(1 ; 2)$ \\
\hline $\mathrm{N}$ farm visits ${ }^{3}$ & $0.5(0 ; 1)$ & $1(0 ; 2)$ & $1(0 ; 2)$ \\
\hline \multicolumn{4}{|c|}{$\begin{array}{l}\text { 1. HIGH=groups with intensely antagonistic discussions; INT = groups with slightly, antagonistic discussions; } \mathrm{LOW}=\text { groups } \\
\text { with positive, non-antagonistic discussion. Numbers given are median per group type across workshop group medians } \\
\text { (minimum; maximum workshop group median value). }\end{array}$} \\
\hline \multicolumn{4}{|c|}{${ }^{2}$ All parameters were graded from $1=$ very good, grade $6=$ very bad. } \\
\hline \multicolumn{4}{|c|}{${ }^{3}$ Number of farms where participants applied the new tool after their workshop } \\
\hline \multicolumn{4}{|c|}{$a, b$ Superscripts indicate significant differences between group types (adjusted $P$} \\
\hline
\end{tabular}

When everybody had completed the form, participants were asked for informal oral group feedback on the trainer, workshop and SchwIP, which was written down by the trainer. Parts of the technical design of the SchwIP file were changed based on feedback by the first two workshops to make it more user friendly. A few other, minor changes were implemented until workshop 15.

One year after the workshops, 72 from initially 84 participants repeated the farm visits in order to update the risk assessment and farm improvement plans. They were asked for their opinion on SchwlP via anonymous written feedback forms. Forty-six workshop participants answered the question, how interested colleagues should be instructed before using SchwIP: a) intuitively, b) with written instructions, or c) after training in a workshop (multiple answers possible). 


\subsubsection{Analysis}

Workshop groups were subjectively categorised into one of three group types based on the level of antagonism against the SchwIP concept or specific SchwIP parts (e. g. definitions of terms) in discussions during the workshop. Categorisation was done directly after the workshop based on memory and notes of the trainer. Discussion groups which worked very productively had a low antagonistic level (LOW; $N=7$ ). In intermediate groups (INT; $N=11$ ) one or two participants were slightly antagonistic but without influencing the flow of discussions. In groups with an intensely antagonism the discussion were disrupted through persistent questioning by one or two participants (HIGH; $N=5$ ).

The median number of farm visits per workshop group was used as a measure for motivation to implement the new knowledge. Workshop evaluation results as well as number of farm visits were tested for differences between group types using nonparametric Kruskal Wallis tests with subsequent Wilcoxon Rank Sum tests for pairwise comparisons (SAS Institute Inc., 2008). Tests were Bonferroni adjusted, and results were regarded as significant when adjusted $p<0.05$.

\subsection{Results}

Across all groups irrespective of group type, all parameters on the feedback form received a median grade of 2 (good). Five parameters were given grades from 1 (very good) to 4 (unsatisfactory) and four parameters from 1 to 5 (bad). No participant used grade 6 (very bad). Numbers of participant answers per parameter ranged from 121 to 123 . One group gave no oral feedback and one did not fill out the feedback forms. Overall, only $41(30 \%)$ of participants wrote in the comments field on the form.

The majority of workshop groups included at least one person which was strongly (HIGH groups, $\mathrm{N}=5$ ) or intermediately (INT, $\mathrm{N}=11$ ) antagonistic towards the SchwIP or parts of it. HIGH groups assigned significantly higher grades for onfarm usability than INT groups (i. e., rated it less usable; Table 4.1), but not than LOW groups. This was also reflected in the comments on the evaluation forms 
(e.g. HIGH: "difficult to apply on-farm" vs. INT: "good tool, you can do a lot with it on a farm"). HIGH furthermore, assigned significantly higher grades for work pace ("too slow") than LOW groups but not than INT groups. The grades for all other parameters including the transfer of knowledge (Figure 4.1) did not differ significantly between group types.

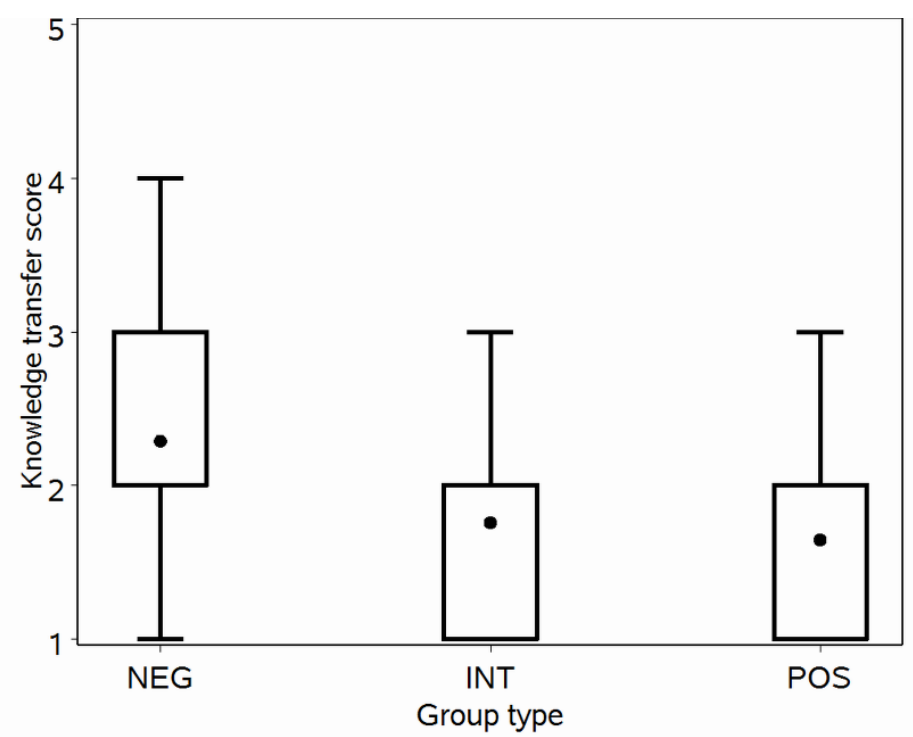

Figure 4.1: Distribution of evaluation grades for the parameter 'knowledge transfer during workshop' by discussion group type (grade 1 = very good, grade 6 = very bad; $\bullet=$ mean, medians are equal to upper or lower quartiles; $p>0.05$ ).

Out of the 134 participants, 84 (62\%) applied SchwIP on at least one farm until within 2 months after the last workshop. A total of 142 farms were visited in that period. The overall median number of farms visited per workshop group was 1 (range of medians 0-2). HIGH group participants tended to visit fewer farms than INT or LOW participants, but there were no significant differences between group types (Table 4.2). 
Table 4.2: Numbers of participants who applied the new tool after their workshop on no farm vs. on one or more farms by group type $\left(x^{2}=0.61\right.$, d. f. $\left.=2, p=0.737\right)$.

\begin{tabular}{lllll} 
& \multicolumn{3}{l}{ Group type $^{1}$} & \\
\cline { 2 - 4 } & HIGH & INT & LOW & Total \\
\hline Tool applied on no farm & 16 & 26 & 18 & 60 \\
Tool applied on $\geq 1$ farm & 15 & 33 & 26 & 74 \\
\hline Total & 31 & 59 & 44 & 134 \\
$\begin{array}{l}\text { 1 HIGH= groups with intensely antagonistic discussions; } \\
\text { with positive, non-antagonistic discussion. }\end{array}$ & & &
\end{tabular}

Regarding the question, how future applicants should be instructed before using a tool similar to SchwIP, participants used 5 combinations of answers.

Out of the 46 participants who answered the question, 16 (35\%) chose after training in a workshop and with written instructions, $13(28 \%)$ chose after training in a workshop only, 9 (20\%) chose with written instructions only, $4(9 \%)$ chose intuitively and with written instructions, $3(7 \%)$ chose intuitively and after workshop training, and 1 participant chose all three options.

\subsection{Discussion}

Novel tools for improving livestock production can assist VFA to more effectively help farmers improve animal health, welfare and production. Additionally, they can be used for knowledge transfer between research and farms. As such tools are usually complex they require training for correct application. This paper describes experiences from successful workshops for training farm advisers and veterinarians in the use of a novel tail biting prevention tool.

From the German fattening pig industry's point of view, animal health and welfare planning is a rather new advisory concept. Furthermore, regarding tail biting as a plainly multifactorial problem was one of the more progressive concepts discussed among German fattening pig stakeholders at the time of the workshops. Nevertheless, the high proportion of groups with participants who were intermediately or strongly antagonistic to SchwIP (5 HIGH and 11 INT groups vs. 7 LOW) was rather surprising. A possible explanation might be that 
participation did not bear any liability except a promise to apply SchwIP on at least one farm. In addition, some participants had been sent by their superiors, because at the time of the workshops public pressure to leave pig tails intact was increasing fast.

The implementation rate of $62 \%$ of participants applying the tool on at least one farm was lower than expected given the (mostly) voluntary participation. Unfortunately, we do not know any publication to compare this value against. One possible explanation is that workshops took place from June till September, resulting in participants starting their farm visits during harvest season, i. e. a period where farmers have little time for visitors. We therefore recommend adjusting training plans to farming seasons, which had not been possible in our project.

Our initial concerns about the effect of antagonistic workshop participants on general workshop outcome were not confirmed. The crucial parameters knowledge transfer as subjectively judged by participants and tool application on-farm did not differ significantly between discussion group types. This agrees with the concept of questioning and discussing being part of adult learning (Bell et al., 2014a) as well as the tendency towards learning in an actively questioning way in agricultural and veterinary students (Cano et al., 1992; Neel and Grindem, 2010). Correspondingly, on-farm usability was evaluated best by INT groups, where this parameter had been discussed slightly antagonistically yet more balanced that in HIGH groups. This apparently constituted a good way of active learning.

One statistical limitation is the rather small number of observations, which might have influenced significance levels. The significantly lower evaluation of tool usability on-farm and workshop work pace by HIGH groups together with the tendency for more farm visits by LOW groups imply, that balanced discussions are important for good workshop results. Workshop leaders should therefore strive to keep all participants equally involved in discussions, e. g. by forming subgroups and actively managing domineering participants (Bell et al., 2014b).

As often happens in research projects, the workshops in this study were led by a PhD student with limited experience as a workshop leader. She had been trained 
for one day by a professional communications trainer at the start of the project. This proved to be very valuable. Especially the advice on workshop structure and dealing with disruptive behaviour was very useful, though the latter also needs personal experience and a certain level of self-confidence for successful application. This should (if possible) be taken into account when selecting or training a future workshop leader.

A group size of six people was perceived as optimal, as it was still manageable during practical training in the barn and participants could work in pairs. Also, mixing professions (here advisers and veterinarians) was very helpful because it gave additional momentum to discussions due to the differences in professional knowledge, experiences and approaches.

Because of the complexity of tail biting and its causality, we had included a short basic lecture about pig behaviour and tail biting causation in order to bring participants to a common level. This was much appreciated by the participants because it had not been part of their formal education.

Handing out the workshop documentation at the start of the workshop made it easier for participants to follow the presentations because they had to take fewer notes. Documentation should include all the information participants need for later application in order to use it as a reference after the workshop.

The combination of theoretical and practical sessions together with frequent breaks helped to keep participants focused. In addition, practical training is essential for tools which have to be applied in a barn. Applying the new knowledge helps in understanding how and why to do something, and often questions arise during the application of instructions which had been clear "in the classroom". This was also reflected in the answers to the question, how colleagues should be trained on similar tools in the future, where $67 \%$ of participants recommended training in an interactive workshop.

In conclusion, multifactorial health and welfare problems in modern livestock production necessitate novel tools to aid veterinarians, farm advisers and farmers in the complex tasks of health and welfare management. Interactive training workshops are needed for successfully distributing such tools. As the quality of workshop content but also of discussions during the workshop can influence 
workshop results, future workshop leaders should strive for basic communication training as well as some group leadership experience before setting up and leading workshops.

\section{Acknowledgements}

Part of this research project was funded by 'Gemeinnützige Gesellschaft zur Förderung der Forschung über die Zukunft des Tierschutzes in der Nutztierhaltung $\mathrm{mbH}^{\prime}$ and the State of Lower Saxony. The authors are very grateful to the participating farm advisers and veterinarians as well as all participating farmers. We especially wish to thank Martina Boden for training and supporting Astrid Luise vom Brocke in workshop planning and leading. 


\section{References}

Baljer, G., Diener, M., Martens, H., 2004. Veterinary Education in Germany. Journal of Veterinary Medical Education 31, 239-241.

Bell, C., Paterson, J., Murison, P., Warman, S., 2014a. How do we learn? In Practice 36, 153-154.

Bell, C., Paterson, J., Warman, S., 2014b. Tips for small group teaching. In Practice 36, 307-309.

Boland, H., Thomas, A., Ehlers, K., 2005. Expertise zur Beratung landwirtschaftlicher Unternehmen in Deutschland - Eine Analyse unter Berücksichtigung der Anforderungen der Verordnung (EG) Nr.1782/2003 zu Cross Compliance. In: Bundesministeriums für Verbraucherschutz, E.u.L. (Ed.) Justus Liebig Universität Giessen, Institut für Agrarsoziologie und Beratungswesen, Bonn, 98.

Cano, J., Garton, B.L., Raven, M.R., 1992. Learning Styles, Teaching Styles and Personality Styles of Preservice Teachers of Agricultural Education. Journal of Agricultural Education 33, 46-52.

Dooley, E.A., Kossar, K.R., 2010. Cooperative Learning for Children with Special Needs. In: Peterson, P., Baker, E., McGaw, B. (Eds.), International Encyclopedia of Education. Elsevier Academic Amsterdam 555-559.

Felder, R.M., 1996. Matters of Style. American Society for Engineering Education (ASEE) Prism 6, 18-23.

Green, M.J., Leach, K.A., Breen, J.E., Green, L.E., Bradley, A.J., 2007. National intervention study of mastitis control in dairy herds in England and Wales. Veterinary Record 160, 287-293.

Hoffmann, V., 2004. Der Beratungsmarkt der Zukunft. B\&B Agrar. 88-91.

Ivemeyer, S., Smolders, G., Brinkmann, J., Gratzer, E., Hansen, B., Henriksen, B.I.F., Huber, J., Leeb, C., March, S., Mejdell, C., Nicholas, P., Roderick, S., Stöger, E., Vaarst, M., Whistance, L.K., Winckler, C., Walkenhorst, M., 2012. Impact of animal health and welfare planning on medicine use, herd health and production in European organic dairy farms. Livestock Science $145,63-72$.

Jovanić, T., Delić, A.T., 2013. The European regulatory framework for farm advisory services. Economics of Agriculture 60, 801-816.

King, A., 2002. Structuring peer interaction to promote high-level cognitive processing. Theory into Practice 41, 33-39.

Kolb, D.A., 1981. Learning Styles and disciplinary differences. In: Associates, A.W.C.a. (Ed.), The Modern American College: Responding to the New Realities of Diverse Students and a Changing Society. Jossey-Bass Inc., San Francisco, 232-255.

Mills, J., Ayre, M., Hands, D., Carden, P., 2005. Learning About Learning Styles: Can It Improve Engineering Education? Mountainrise 2.

Neel, J.A., Grindem, C.B., 2010. Learning-Style Profiles of 150 Veterinary Medical Students. Journal of Veterinary Medical Education 37, 347-352.

Radostits, O.M., 2001. Principles of Health Management of Food-Producing Animals. In: Radostits, O.M. (Ed.), Herd Health: food animal production medicine. W.B. Saunders, Philadelphia, 1-45.

Reeves, T.C., Hedberg, J.G., 2003. Interactive Learning Systems Evaluation. Educational Technology Publications Inc. Englewood Cliffs, New Jersey. 
SAS Institute Inc., 2008. SAS 9.2. SAS/STAT® 9.2 User's Guide. Cary, NC: SAS Institute Inc.

Schrøder-Petersen, D.L., Simonsen, H.B., 2001. Tail Biting in Pigs. The Veterinary Journal 162, 196-210.

Taylor, N.R., Parker, R.M.A., Mendl, M., Edwards, S.A., Main, D.C.J., 2012. Prevalence of risk factors for tail biting on commercial farms and intervention strategies. The Veterinary Journal 194, 77-83.

Webb, N.M., Farivar, S., 1999. Developing Productive Group Interaction in Middle School Mathematics. In: O'Donnell, A.M., King, A. (Eds.), Cognitive perspectives on peer learning. Lawrence Erlbaum Associates, Mahwah, NJ 117-149.

Whay, H.R., Barker, Z.E., Leach, K.A., Main, D.C.J., 2012. Promoting farmer engagement and activity in the control of dairy cattle lameness. The Veterinary Journal 193, 617-621. 


\section{Chapter 5}

Reducing tail biting risk on German fattening pig farms with a management tool for risk planning

A. L. vom Brocke, D. P. Madey, M. Gauly, L. Schrader, M. Wendt, S. Dippel 


\section{Chapter 5: Reducing tail biting risk on German fattening pig farms with a management tool for risk planning}

\section{Abstract}

Tail biting is a major problem in pig production which is difficult to prevent on farms due to its multifactorial nature. This paper presents results from the application of a tail biting management tool for fattening pigs (SchwIP, abbreviation for German "Schwanzbeiß-Interventions-Programm") that combines farm individual risk assessment with the principles of animal health and welfare planning (AHWP). SchwIP was applied on 188 conventional farms throughout Germany (1,200 fattening places, median). Farms were visited on one day in 2012 and 2013, respectively, by one researcher and 68 trained farm advisers and veterinarians. Total tail biting risk score (TRS, range 0 to 100) significantly decreased between 2012 and 2013 across all farms (median difference -3.5, Q25 $=-8.2, Q 75=1.1 ;$ Wilcoxon signed rank test, $p<0.01)$. There were no significant differences between the risk factor categories comfort, enrichment, feed \& water, health and stress. The level of implementation rate (all, some, or none of the planned measures implemented) had no significant influence on tail biting risk change. However, prevalence of blood on tail, swollen tail, tail loss and ear lesions also decreased significantly between the two farm visits (median differences range 0 to -2.2 , Wilcoxon signed rank test, all corrected $p<0.05$ ). Overall, the combination of farm individual risk assessment with AHWP proved to be a promising approach for reducing tail biting risk on German fattening pig farms.

\subsection{Introduction}

Tail biting is a widespread abnormal behaviour in pigs and one of the most common welfare problems in the pig industry (Schrøder-Petersen and Simonsen, 
2001). While biters are unable to cope with their environment, bitten pigs suffer from short- and often long-term pain (EFSA, 2007). Furthermore, tail biting is a considerable economic problem due to reduced weight gain (Wallgren and Lindahl, 1996), extra handling and medication costs (Zonderland et al., 2011), as well as condemnations at slaughter (Huey, 1996). Therefore, the majority of conventional suckling piglets in most European countries are tail docked to prevent tail biting (EFSA, 2007), even though docking itself is a welfare problem since it causes acute trauma and pain (Sutherland et al., 2008). In fact, it has been shown that docked pigs are less likely to be bitten than un-docked pigs (Hunter et al., 1999) but it does not prevent tail biting completely (EFSA, 2007).

Tail biting has a multifactorial causation (Moinard et al., 2003) and a variety of risk factors from different risk categories are well known (review in SchrøderPetersen and Simonsen, 2001). Key risk factors vary from farm to farm and it is the task of farm advisers and veterinarians to select the most suitable farm specific intervention measures based on professional recommendations and scientific knowledge (Whay et al., 2012). An approach following the principle of animal health and welfare planning (AHWP) is essential for reducing tail biting due to the large number of risk factors involved. AHWP includes the assessment and evaluation of the current status of risk factors and outcomes, the planning and execution of intervention actions and regular reviewing (Ivemeyer et al., 2012). Moreover, the process should be farm specific and ensure farmer ownership while including external persons and knowledge (Ivemeyer et al., 2012).

Taylor et al. (2012) developed a husbandry advisory tool (HAT) following the principles of AHWP which successfully helped UK pig producers to reduce tail biting risk in finishing pigs. As pig production systems differ between Germany and the UK (Hendriks et al., 1998; Hunter et al., 2001), the HAT was adapted to German conditions and made into the German tail biting management tool SchwIP (German abbreviation for tail biting intervention programme), which combines software-supported risk analysis with the concept of AHWP (Madey et al., 2014b, in preparation). So far, there have only been pilot activities in organic research projects regarding AHWP and nothing for the conventional pig sector (Nicholas and Jasinska, 2008). Also, tail biting has commonly been addressed 
by focussing on the main field of the consultant (feeding, health, etc.) or by using simple checklists. Thus, our aim was to investigate if the implementation of SchwlP can help farmers in reducing risk for tail biting on conventional German fattening pig farms.

\subsection{Methods}

\subsubsection{The SchwIP tool}

SchwlP was developed and evaluated in a 3 year study in Germany with two on-farm assessments in 2012 and 2013. After the tail biting HAT risk factors (Taylor et al., 2012) were adapted and reweighted according to German pig production standards through an expert survey (Madey et al., 2014c, submitted), SchwlP contained 56 risk factors with a weighting score from 5 to 70 indicating their strength of influence on tail biting (high value $=$ strong influence). Factors were assigned to five main risk categories: comfort (16 factors), enrichment (13), feed \& water (15), health (8), and stress (4). A distinction was made between enrichment material (rootable, e. g. straw), and enrichment objects (solid, e. g. chains with plastic balls). Weighted factors were supplemented by 93 questions regarding additional information (e. g. genetics, ventilation system). For more information on tool development and risk factors see (Madey et al., 2014b, in preparation).

Data on animal management and animal history were collected in an interview with the person responsible for managing the finishing pigs on the farm (referred to as farmer below). Subsequently, a sample of pens was directly observed regarding quality and quantity of housing parameters (enrichment type, water flow rate, pen size etc.), pig behaviour and clinical indicators. The collected data were then entered in the SchwIP file (Microsoft Excel®) or Apache OpenOffice ${ }^{T M}$ Calc), which automatically generated a farm specific report with a risk profile. The profile listed factors present as a risk on this farm in red and those which might be a risk but were managed in a preventative way in green. Causal relationships of all factors were explained and suggestions for improvement given for present risks. In order to identify influential factors, factor lists were ranked by factor 
weight and graphs showed all weights in colour coding. Present risks were represented by weights above 0 in the database and absent risk by weights below 0 . A farm plan was developed based on the farm report in a discussion between the farmer and the person applying SchwIP on the farm. Farmers were encouraged to decide on up to 3 aims and intervention measures suitable for themselves and their farm and wrote their decision in the farm plan. At the second round of farm visits 12 months later the process was repeated and farmers were asked whether they had implemented the measures from last year's plan and reached their aims. The results were noted in the old farm plan and a new plan drawn up.

\subsubsection{Data collection}

All study participants were recruited via calls in farmer journals, at stakeholder events and on the internet. Conventional fattening pig farms with more than 400 fattening places were called for participation in a tail biting prevention study, and veterinarians and farm advisers (VFA) were called to be trained in SchwIP application.

Farms were visited by an FLI PhD student (DPM), as well as 115 farm advisers and 19 veterinarians trained by the first author in 23 one day workshops all over Germany (Vom Brocke et al., 2014a, submitted). Out of 213 farms visited between June and November in 2012, 188 were visited again in the same period in 2013, thereof 68 by the FLI PhD student and 120 by 68 VFA. Dropout was caused by the VFA or farmer losing interest or VFA employer change. The assessment of a farm including discussion of the plan usually took 3 to 4 hours.

Pens selection on the farm was problem-based, i.e. pens where tail biting was currently present or occurred regularly were given preference over a random sample. If several housing systems (combinations of flooring, feeding and group size) were present on the farm, sampling focussed on either the problem system or the system containing most of the pigs. Observers assessed between 1 and 10 pens per farm (median $=4$, Q25 $=3$, Q75 $=7$ in 2012 and 8 in 2013), which on $90 \%$ of farms belonged to one housing system only. If possible, assessment 
included at least two rooms and two pens per room. Only pens with five or more pigs were considered for analysis.

Blood, swelling, or loss (partial or full) of the tails, as well as blood or scabs on the ears were assessed as present or absent on 30 randomly chosen pigs per pen, or the whole group if it was smaller than 30 animals. A tail could be assigned multiple lesions but as animals were not identified, lesion combinations could not be calculated (i.e. five swollen and five bloody tails in a pen could affect between five and ten pigs). All lesion assessments were made while walking in the pen.

\subsubsection{Data management and statistical analysis}

Data from all observers were collected and examined for errors. Data from some VFA needed refinement in order to have all information in a form suitable for analysis (e. g. by extracting information from comments).

Lesion prevalence was calculated in two ways in order to better reflect the situation: a) as the median of all pen prevalence on the farm, and b) by neglecting grouping of animals in pens and dividing the total number of animals affected by all animals assessed on the farm.

Farm aims and measures were categorised similar to risk factors into comfort, enrichment, feed \& water, health, and management. No aims or measures could be assigned to the category stress, while management had not been used as a risk factor category because it would have encompassed most of the factors. Each measure from the 2012 farm plan had been categorised as fully, partly or not implemented by the farmer during the 2013 visit. This was summed up per farm as all, some, or no measures implemented. The same was done by risk category. Seven farms did not plan any measures because they were satisfied with the current situation on their farms (indeed they were among the best farms). These farms were excluded from any calculations related to implementation, which were thus based on 181 farms.

The theoretical weights of all questions answered on the farm were added up as the maximum possible weight sum per farm and visit. Next, all weights above 0 
(i. e. weights from present risks, red in the report) were summed up and divided by the maximum possible weight sum to result in the total risk score (TRS, in \%). Thus, a TRS of $33 \%$ represented a farm where the weights of all risks present were one third of the maximum possible weight sum (if all possible risks were present). The same calculation was done for each risk factor category on the farm, resulting in the category risk score (CRS).

We then subtracted the TRS from 2012 from that from 2013 for each farm, so that the resulting difference TRS $\Delta$ indicated a reduction of tail biting risks when negative and an increase when positive. The same was done with the CRS, resulting in CRS $\triangle$. The change in TRS was analysed using Wilcoxon's signed rank test.

The influence of implementation level (all, some, none) on TRS $\Delta$ was tested using Kruskal Wallis test and Wilcoxon rank sum tests for subsequent pairwise comparisons. p-values were Bonferroni corrected.

Due to the nesting of categories in farms and the skewed distribution of CRS $\Delta$, we calculated a logistic regression model (PROC GLIMMIX) with farm as random effect. In order to do so, CRS $\Delta$ was collapsed into the binary variable $\mathrm{CRS} \Delta$ bin of improvement $(\mathrm{CRS} \Delta<0)$ vs. no improvement $(\mathrm{CRS} \Delta \geq 0)$. As implementation level (impl) was expected to have an additional influence on CRS $\Delta$, category, implementation level and their interaction were tested in stepwise backward elimination. The full model was:

$\ln \frac{p}{\left(1-p_{i j}\right)}=\mu+\mathrm{b}_{i}+\beta_{1}$ category $+\beta_{2}$ impl $+\beta_{3}$ category $*$ impl $+\varepsilon_{i j}$

$p_{i j}=$ probability of $\mathrm{CRS}_{\text {bin }}$ being 1 ("improvement")

$\mu=$ intercept,

bi $=$ random farm effect

$\beta_{1}=$ estimate for category (comfort, enrichment, feed \& water, health, and management)

$\beta_{2}=$ estimate for implementation level (no, some, all measures implemented)

$\beta_{3}=$ estimate for interaction of category and implementation level

$\varepsilon_{i j}=$ error term

Finally, we tested whether the median lesion prevalence or the overall lesion prevalence on a farm differed between 2012 and 2013 using Wilcoxon signed rank tests. Results were Bonferroni corrected for four tests since the different lesion types are related. 
All statistical analyses were carried out using SAS 9.3 (SAS Institute Inc., 2011). Differences were considered significant, if (corrected) $p<0.05$.

\subsection{Results}

\subsubsection{Description of farms and intervention levels}

Farms were distributed all over Germany (Figure 5.1). Out of the 188 farms, 63 were farrow-to-finisher farms and 125 were only fattening farms. Most farms were family run businesses. Median fattening places per farm were 1,200 (Q25 = 850, $\mathrm{Q} 75=1,710)$. Seventy-four percent of farms kept pigs on fully slatted, $12 \%$ on partly slatted, and $5 \%$ on solid floors, the remainder had mixed flooring. All but 14 farms had fully ventilated housing for more details see (Madey et al., 2014b, in preparation).

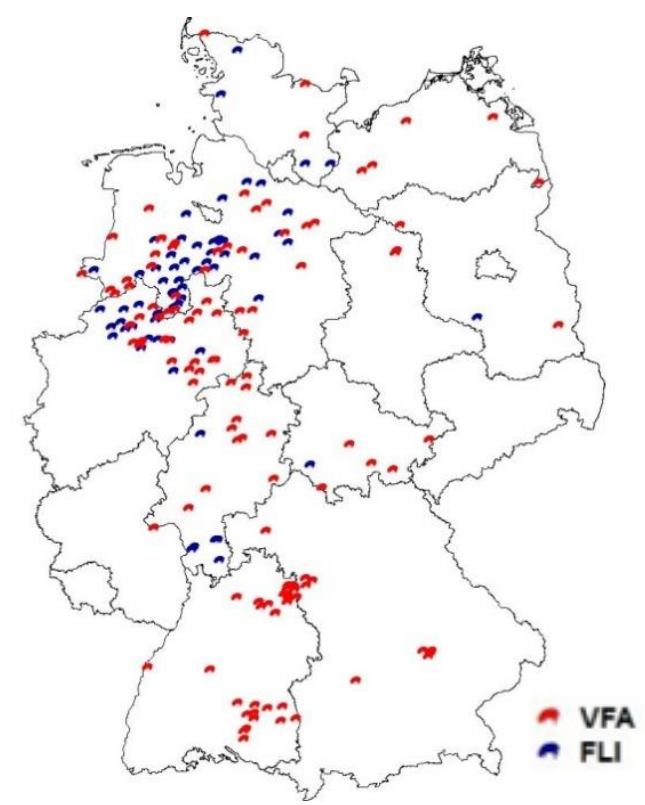

Figure 5.1: Geographical location of the farms in the study. (VFA (red, $N=119)=$ farms visited by farm advisers or veterinarians, one farm is missing due to a lack of the address, and $\mathrm{FLI}$ (blue, $\mathrm{N}=68$ ) = farms visited by a member of the research group).

A notable change took place regarding enrichment. While 164 of the 188 farms did not provide any enrichment material in 2012 (though they might have provided objects), this decreased to 156 farms in 2013. Moreover, the number of farms 
providing neither enrichment material nor objects in at least one of the observed pens decreased from 34 in 2012 to 11 in 2013.

Farmers from 181 farms decided on a total of 551 measures, of which 310 were fully, 121 partly and 120 not implemented. Median number of measures planned per farm was 2.3 (range 1 to 5). Twenty-one point five percent (39) of farmers implemented all of their planned measures, $73.5 \%$ (133) implemented some or parts of measures, and $5.0 \%$ (9) implemented none of the planned measures. Most measures were planned in the category feed \& water, while health was the category where most planned measures were implemented (Figure 5.2).

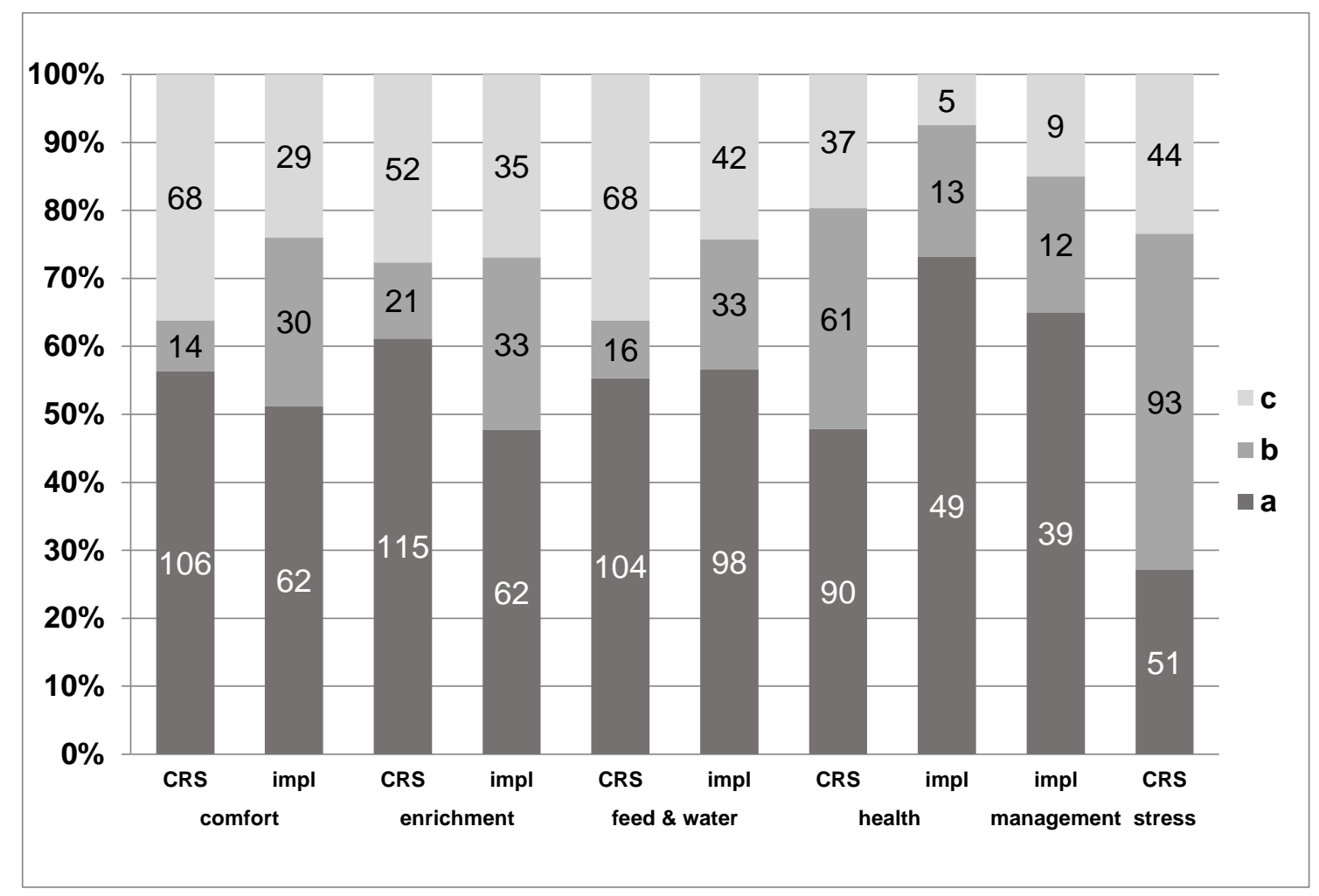

Figure 5.2: Numbers (\%) of farms whose category risk score (CRS) decreased (a), remained constant (b), or increased from 2012 to 2013 (c) $(N=188)$. Decreasing CRS was coded as 1 in the logistic model, where neither implementation level nor category nor their interaction had a significant effect on CRS $\Delta_{\text {bin. }}$. Stress and management were not included in model. Furthermore, numbers (\%) of farms who implemented all (a), some/parts (b) or none (c) of their planned intervention measures in a risk category $(N$ comfort $=121, N$ enrichment $=130$, $N_{\text {feed \& water }}=173, N_{\text {health }}=67, N_{\text {management }}=60$ ). 


\subsubsection{Changes in tail biting risk from 2012 to 2013}

Out of 188 farms, TRS decreased on 131 farms (69.7\%), remained the same on 1 farm (0.5\%) and increased on 56 farms (29.8\%) from 2012 to 2013. Median TRS was 30.4 \% in 2012 (Q25 = 22.8\%, Q75 = 36.7 \%) and 25.8 \% in 2013 (Q25 $=18.9 \%, Q 75=32.8 \%)$. The overall decrease in tail biting risk was significant (median TRS $\Delta=-3.5 \%$ points, Q25 $=-8.2 \%$, Q75 = 1.1 \%; Wilcoxon signed rank test, $p<0.01$ ).

CRS for the categories comfort, enrichment, and feed \& water decreased on the majority of farms from 2012 to 2013, while it remained constant or decreased for health and stress (Figure 5.2). However, CRS $\Delta$ did not differ significantly between categories in the mixed logistic model (mixed logistic model, Type III test, $p>0.05)$.

\subsubsection{Relationship between implementation and risk score}

Implementation level did not influence change in tail biting risk at farm level, as TRS $\Delta$ did not differ between farms who implemented all $(N=39)$, some $(N=133)$ or no $(\mathrm{N}=9)$ measures (Wilcoxon rank sum test, $\mathrm{p}=0.439)$. CRS $\Delta$ was also not influenced by implementation level. Neither category, nor implementation level or their interaction had a significant effect on CRS $\Delta$ (all $p>0.05$, stepwise backward elimination).

\subsubsection{Tail lesion prevalence}

Out of the two prevalence calculated, median pen prevalence showed little variation in either year (all medians $=0$, Q75 ranged from 2.5 to $8 \%$ in 2012 and was 0 for all parameters in 2013), which is why overall lesion prevalence are presented. 
The overall prevalence of tail and ear biting lesions decreased significantly from 2012 to 2013 for all parameters (Wilcoxon signed rank test, all corrected $p<0.05$; (Table 5.1). Test results for median pen prevalence were identical except for tail loss, where the difference between 2012 and 2013 was not significant (corrected $p=0.208)$.

Table 5.1: Values for the prevalence of all assessed pigs for each lesion type for the first visit in 2012, the second in 2013 and the difference between the two visits ( $\mathrm{min}=$ smallest value; $Q 25=1$ st quartile; $Q 75=3$ rd quartile; $\max =$ maximum; IQR = interquartile range; $\mathrm{N}=188$ farms). All $\Delta$ were significant at $\mathrm{p}<0.05$.

\begin{tabular}{llllllll} 
lesion type & year & $\min$ & Q25 & median & Q75 & $\max$ & IQR \\
\hline \hline blood on tail & 2012 & 0 & 0.9 & 4.1 & 10.9 & 42.9 & 10.0 \\
& 2013 & 0 & 0 & 0 & 4.9 & 36.7 & 4.9 \\
& $\Delta$ & -37.5 & -7.8 & -2.2 & 0 & 31.9 & 7.8 \\
\hline swollen tail & 2012 & 0 & 0 & 2.0 & 8.3 & 32 & 8.3 \\
& 2013 & 0 & 0 & 0 & 3.9 & 33.3 & 3.9 \\
& $\Delta$ & -30.4 & -4.6 & 0 & 0.1 & 20.7 & 4.7 \\
\hline tail loss & 2012 & 0 & 0 & 2.1 & 6.3 & 48.7 & 6.3 \\
& 2013 & 0 & 0 & 0 & 3.4 & 60.3 & 3.4 \\
& $\Delta$ & -48.7 & -3.7 & 0 & 0.4 & 47.7 & 4.1 \\
\hline ear lesions & 2012 & 0 & 0 & 2.4 & 7.8 & 100 & 7.8 \\
& 2013 & 0 & 0 & 0 & 3.9 & 49.3 & 3.9 \\
& $\Delta$ & -56.1 & -5.0 & -0.9 & 0 & 41.9 & 5.0 \\
\hline
\end{tabular}

\subsection{Discussion}

This study evaluated the effect of a tail biting management tool on risk for tail biting on conventional German fattening pig farms. Tail biting risk decreased significantly in the course of one year, as did the prevalence of tail and ear lesions based on a small sample of pens.

There was no significant relation between risk decrease and whether farmers had implemented all measures they had written in the farm plan or not. However this might be influenced by the high implementation rate of $95 \%$ of farmers implementing at least one of their planned measures. 


\subsubsection{General methods}

At the time of the study, over $90 \%$ of conventional German fattening pigs were tail docked (EFSA, 2007) and a formal complaint in Brussels generated high pressure to leave tails un-docked. Consequently, stakeholders were very interested in SchwIP. This had the positive effect of being able to recruit many observers and thus many farms, while it had the negative effect of rather small numbers of pens being sampled per farm. This was due to time constraints of the VFA, who applied it as part of their normal customer visits. The resulting time frame of 3 to 4 hours was satisfactory for $79 \%$ of VFA (Madey et al., 2014a), which agrees with recommendations of (Courboulay et al., 2009). Having assured stakeholder acceptance, pen sample size recommendations need to be investigated which satisfy the advisory as well as the scientific aspects of the tool. Another negative effect is the lack of control groups, as it was simply not possible at the time to assess farms regarding tail biting without interacting with the farmer. Unfortunately, the number of farms not implementing anything was too small (9 farms) in order to stand in as control group. However, we have some additional data to support the results (see below).

Lesion scoring was trained during the workshops, yet observer agreement was not tested due to lack of time, as VFA would not have been willing to spend more than one day in the workshop. This is, however, comparable to other large scale studies (e.g. Hultgren et al., 2004), where the high number of observers balances observer influence.

The study population is comprised of farmers who conceived a tail biting problem on their farm and were willing to work on it. However, taking into account the high profile discussion about leaving tails un-docked at the time of recruitment and looking at the key characteristics, farms can be regarded to represent average conventional German fatting pig farms. 


\subsubsection{Changes in tail biting risk and implementation level}

TRS decreased significantly from 2012 to 2013 across all farms. Risk changes did not differ between categories, yet CRS tended to decrease in all categories but health and stress, especially for enrichment (Figure 5.2). The latter was also reflected in the number of farms offering more enrichment or material instead of objects. Changes in this category might have been additionally influenced by public discussion about an infringement proceeding by the European Commission against Germany, whose enrichment material specification in national law was disapproved (European Commission, 2011). However, as the explanation of pig behaviour and their behavioural needs like rooting had been a part of the SchwIP workshop where many participants stated to have learned something new, it is equally likely that SchwIP helped to transfer knowledge about pig behaviour to the farms.

Even though most other intervention studies have shown a correlation between implementation level and improvement of the outcome (Green et al., 2007; Leeb et al., 2010) but see (Main et al., 2012), the relationship between implementation level and risk score change was not significant at farm or category level. We did not relate implementation level to tail lesions because of the often limited sample size. One reason for the lack of association might be the high proportion (95\%) of farms that implemented at least one planned measure. Even though this is comparable to other intervention studies (Green et al., 2007; Leeb et al., 2010; Taylor et al., 2012), it results in unbalanced implementation categories which can hamper test results. In addition, "all" and "partly" implementation may differ depending on the number of measures planned (two out of two vs. two out of three). Farms who did not implement any of their planned measures might also have made other changes triggered by interactions during the visit (Whay et al., 2010). In fact, some farms visited by the FLI researcher (all from category all or partly implemented) reported to have made changes in addition to those in the plan. Furthermore, as tail biting is a multifactorial problem, any improvement contributes to preventing tail biting outbreaks (EFSA, 2007). 


\subsubsection{Tail lesion prevalence}

Parallel to tail biting risk, prevalence of tail or ear biting lesions also decreased significantly across farms. It should be noted, that the validity of these results is somewhat limited due to the small numbers of pens sampled per farm, and the problem-based sampling strategy. Nevertheless, our result agrees with that of Taylor et al. (2010), who also found decreases in tail biting risk along with decreasing lesion prevalence. Furthermore, we additionally monitored tail lesions of 32 SchwlP farms and 32 control farms at an abattoir and found significantly greater reductions of tail lesions in SchwIP farms compared to control farms (Vom Brocke et al., 2014b, in preparation).

\subsubsection{The "SchwIP effect"}

Reducing risk for tail biting through farm-individual risk assessment and an AHWP concept is a new approach for conventional German fattening pig farms. Regarding risk assessment, tail biting problems were usually addressed by checklists or by improving specific areas on the farm, usually the areas of expertise of the consultant. When asked about new knowledge acquired through SchwIP, $69 \%$ of VFA and $79 \%$ of farmers stated they had gained a new overview over their (customer) farm (Madey et al., 2014a). Being a multifactorial problem, it is important to have an overview and know where to start improving on a specific farm in order to successfully prevent tail biting (EFSA AHAW Panel, 2014).

Furthermore, new was the way farmers were encouraged to implement measures, which is a critical element for effective compliance (Green et al., 2007). Traditionally, many farmers are used to following the recommendations of their farm advisers or veterinarians instead of choosing measures suitable for their farm and them as individuals. This has also been found by Leeb et al. (2010) during their first application of AHWP on organic Austrian pigs farms.

Farmer ownership plays a key role in an intervention process because it increases motivation (Nicholas et al., 2008; Vaarst et al., 2011) and thus makes it more likely that changes are implemented, especially in the long run. Apparently 
this was a strong effect in the current study. In the study of Taylor et al. (2012) implementation was lowest on farms which had been advised using the tail biting HAT but did not receive financial incentive (i. e. treated like SchwIP farms). This lack of effect might be due to AHWP history in UK, where it has been used widely but often more as a control than an advisory tool (Nicholas and Jasinska, 2008). UK farmers might therefore regard it in a different, more negative, way. The additional influence of financial incentives for intervention measures is not quite clear (Main et al., 2012; Taylor et al., 2012).

The combination of farmer ownership and involvement of an external expert as done in this study also proved effective in other intervention studies (Whay et al., 2012). Even if farmers are more likely to choose measures that are easy to implement on their farms (Leeb et al., 2010), these changes can already have positive effects on the outcome (EFSA, 2007; Leeb et al., 2010). Moreover, $96 \%$ of farmers in this study chose measures based on their expected effectiveness, rather than their costs, labour or being recommended by the VFA $(72,68$, and $72 \%$, respectively (Madey et al., 2014a)).

\subsection{Conclusions}

Combining farm-individual risk assessment with the concept of animal health and welfare planning proved to be a successful approach for reducing tail biting risk on German fattening pig farms. Especially the generation of a farm overview and farmer ownership for intervention measures contributed to successful intervention.

\section{Acknowledgement}

This study was financially supported by 'Tönnies Forschung - Gemeinnützige Gesellschaft zur Förderung der Forschung über die Zukunft des Tierschutzes in der Nutztierhaltung $\mathrm{mbH}^{\prime}$ and the federal state of Lower Saxony. We would like to thank Dr. Nina Wainwright (nee Taylor) for providing the HAT as a basis for 
Chapter 5

Reducing tail biting risk on German fattening pig farms

SchwIP and Stine Heindorff for her assistance with data collection and management. Furthermore, we are grateful to all farmers, farm advisers and veterinarians for their time and interest. 


\section{References}

Courboulay, V., Eugène, A., Delarue, E., 2009. Welfare assessment in 82 pig farms: effect of animal age and floor type on behaviour and injuries in fattening pigs. Animal Welfare 18, 515-521.

EFSA, 2007. Scientific Report on the risks associated with tail biting in pigs and possible means to reduce the need for tail docking considering the different housing and husbandry systems. The EFSA Journal 611, 1-13.

EFSA AHAW Panel, 2014. Scientific Opinion concerning a multifactorial approach on the use of animal and non-animal-based measures to assess the welfare of pigs. EFSA Journal 12, 101.

European Commission, 2011. EU Pilot 1360/10/SNCO Unvollständige Umsetzung der Richtlinie 2008/120/EG, 03 May 2011.

Green, M.J., Leach, K.A., Breen, J.E., Green, L.E., Bradley, A.J., 2007. National intervention study of mastitis control in dairy herds in England and Wales. Veterinary Record 160, 287-293.

Hendriks, H.J., Pedersen, B.K., Vermeer, H.M., Wittmann, M., 1998. Pig housing systems in Europe: current distribution and trends. Pig news and information 19.

Huey, R.J., 1996. Incidence, location and interrelationships between the sites of abscesses recorded in pigs at a bacon factory in Northern Ireland. Veterinary Record 138, 511-514.

Hultgren, J., Manske, T., Bergsten, C., 2004. Associations of sole ulcer at claw trimming with reproductive performance, udder health, milk yield, and culling in Swedish dairy cattle. Preventive Veterinary Medicine 62, 233251.

Hunter, E.J., Jones, T.A., Guise, H.J., Penny, R.H.C., Hoste, S., 1999. Tail biting in pigs 1: The prevalence at six UK abattoirs and the relationship of tail biting with docking, sex and other carcass damage. The Pig Journal 43, 18-32.

Hunter, E.J., Jones, T.A., Guise, H.J., Penny, R.H.C., Hoste, S., 2001. The Relationship Between Tail Biting in Pigs, Docking Procedure and Other Management Practices. The Veterinary Journal 161, 72-79.

Ivemeyer, S., Smolders, G., Brinkmann, J., Gratzer, E., Hansen, B., Henriksen, B.I.F., Huber, J., Leeb, C., March, S., Mejdell, C., Nicholas, P., Roderick, S., Stöger, E., Vaarst, M., Whistance, L.K., Winckler, C., Walkenhorst, M., 2012. Impact of animal health and welfare planning on medicine use, herd health and production in European organic dairy farms. Livestock Science 145, 63-72.

Leeb, C., Bernardi, F., Winckler, C., 2010. Einführung und Monitoring von 'BetriebsEntwicklungsPlänen (BEP) Tiergesundheit und Wohlbefinden' in österreichischen Bioschweinebetrieben. Endbericht zum Forschungsprojekt 100188., Wien, 119.

Madey, D., Vom Brocke, A.L., Wendt, M., Schrader, L., Dippel, S., 2014a. Involving stakeholders in tail biting prevention: Stakeholder opinion on a German tail biting tool. In: Mounier, L., Veissier, I. (Eds.), WAFL-6th International Conference on the Assessment of Animal Welfare at Farm and Group Level, 3-5 September, Clermont-Ferrand, France, 43. 
Madey, D.P., Vom Brocke, A.L., Schrader, L., Wendt, M., Gauly, M., Dippel, S., 2014b. Tail biting risk on German finisher farms: Evaluation of a tail biting intervention tool (in preparation).

Madey, D.P., vom Brocke, A.L., Schrader, L., Wendt, M., Wainwright, N.R., Dippel, S., 2014c. Expert opinion on risk factors for tail biting in conventional German fattening pig housing systems. submitted to Preventive Veterinary Medicine.

Main, D.C.J., Leach, K.A., Barker, Z.E., Sedgwick, A.K., Maggs, C.M., Bell, N.J., Whay, H.R., 2012. Evaluating an intervention to reduce lameness in dairy cattle. Journal of Dairy Science 95, 2946-2954.

Moinard, C., Mendl, M., Nicol, C.J., Green, L.E., 2003. A case control study of on-farm risk factors for tail biting in pigs. Applied Animal Behaviour Science 81, 333-355.

Nicholas, P., Jasinska, A., 2008. Animal Health and Welfare Planning - A Review. Final Report of CORE Organic, ANIPLAN. http://orgprints.org/13409/ (retrieved on 06 July 2014).

Nicholas, P., Roderick, S., Vaarst, M., 2008. Animal Health and Welfare Planning - Identifying key principles and approaches. Report from 1st ANIPLAN project workshop, CORE Organic project nr. 1903 - ANIPLAN. http://orgprints.org/13407/ (retrieved on 29 October 2013). In: Vaarst, M., Roderick, S. (Eds.).

SAS Institute Inc., 2011. SAS 9.3. SAS/STAT® 9.3 User's Guide. Cary, NC: SAS Institute Inc.

Schrøder-Petersen, D.L., Simonsen, H.B., 2001. Tail Biting in Pigs. The Veterinary Journal 162, 196-210.

Sutherland, M.A., Bryer, P.J., Krebs, N., McGlone, J.J., 2008. Tail docking in pigs: acute physiological and behavioural responses. Animal 2, 292-297.

Taylor, N., Edwards, S., Main, D., Mendl, M., Armstrong, D., Parkes, K., Parker, R., 2010. Management tool for predicting tail biting. In, Second Workshop on Pig Welfare Improving implementation of EU legislation, 11 November 2010, Parma.

Taylor, N.R., Parker, R.M.A., Mendl, M., Edwards, S.A., Main, D.C.J., 2012. Prevalence of risk factors for tail biting on commercial farms and intervention strategies. The Veterinary Journal 194, 77-83.

Vaarst, M., Winckler, C., Roderick, S., Smolders, G., Ivemeyer, S., Brinkmann, J., Mejdell, C.M., Whistance, L.K., Nicholas, P., Walkenhorst, M., Leeb, C., March, S., Henriksen, B.I.F., Stöger, E., Gratzer, E., Hansen, B., Huber, J., 2011. Animal Health and Welfare Planning in Organic Dairy Cattle Farms. The Open Veterinary Science Journal 5, 19-25.

Vom Brocke, A.L., Madey, D.P., Gauly, M., Schrader, L., Dippel, S., 2014a. Training veterinarians and agricultural advisers on a novel tool for tail biting prevention. submitted to Veterinary Record Open.

Vom Brocke, A.L., Madey, D.P., Karnholz, C., Gauly, M., Leeb, C., Winckler, C., Schrader, L., Dippel, S., 2014b. Tail lesions in German fattening pigs: relationship with post mortem meat inspection and influence of a tail biting management tool (in preparation).

Wallgren, P., Lindahl, E., 1996. The influence of tail biting on performance of fattening pigs. Acta Veterinaria Scandinavica 37, 453-460.

Whay, H.R., Barker, Z.E., Leach, K.A., Maggs, C.M., Bell, A.K., Main, D.C.J., 2010. Monitoring implementation of cattle health programmes: Levels of 
spontaneous lameness control activities on UK dairy farms. In, 16th World Buiatrics Conference, 14-18th November, Santiago, Chile.

Whay, H.R., Barker, Z.E., Leach, K.A., Main, D.C.J., 2012. Promoting farmer engagement and activity in the control of dairy cattle lameness. The Veterinary Journal 193, 617-621.

Zonderland, J.J., Bosma, B., Hoste, R., 2011. Financiële consequenties van staartbijten bij varkens Rapport 543. Wageningen UR Livestock Research, Lelystad. 


\section{Chapter 6}

Tail lesions in German fattening pigs: relationship with post mortem meat inspection and influence of a tail biting management tool
A. L. vom Brocke, D. P. Madey, C. Karnholz, M. Gauly, C. Leeb, C. Winckler, L. Schrader, S. Dippel 
Chapter 6: Tail lesions in German fattening pigs: relationship with post mortem meat inspection and influence of a tail biting management tool

\begin{abstract}
Tail biting is a major welfare and economic problem in intensive pig production. This paper presents data on tail lesion prevalence in 43,402 pigs from 32 farms where the tail biting management tool 'SchwlP' had been applied, as well as 36,632 pigs from 32 control farms. Tail lesions were scored over the period of one year from automatically recorded pictures. Overall tail lesion prevalence in control farm pigs was $25.4 \%$, with $23.6 \%$ being minor lesions and the remainder being lesions with loss of skin or tail substance. Pneumonia, hind leg inflammation or arthritis and front leg inflammation were the most frequent carcase findings with possible association with tail lesions (prevalences of 7.6, 2.5 and $1.6 \%$, respectively). Hind and front leg findings were significantly more prevalent in pigs with tail lesions of any degree (hind leg inflammation: 2.1 vs. $1.7 \%$, hind leg arthritis: 0.9 vs. $0.6 \%$, front leg inflammation: 1.8 vs. $1.5 \%$, all $p \leq 0.01)$. Tail necrosis scored during meat inspection resulted in lower prevalences than necrosis scored from pictures (0.2\% vs. $0.7 \%)$. During the first season, tail lesion prevalence was significantly higher in pigs from SchwlP farms than in pigs from control farms (32.2 vs. $23.8 \%, p=0.011)$ while it was not significantly higher during the remainder of the year. The application of SchwIP therefore seemed to help in decreasing tail lesion prevalences on problem farms to average farm level. Therefore, tail lesion data from slaughtered pigs provides useful information for fattening pig health and welfare management. Possibilities for automated assessment of lower grade lesions should be examined.
\end{abstract}




\subsection{Introduction}

Tail biting is a behavioural disorder and a major welfare problem in pigs. It is a multifactorial problem, i. e. caused by numerous factors interacting with each other (Schrøder-Petersen and Simonsen, 2001; Moinard et al., 2003). Tail biting is also an economic problem due to reduced weight gain (Wallgren and Lindahl, 1996) or treatment and medication costs (Zonderland et al., 2011). Especially partial or full carcase condemnations due to secondary infections associated with tail biting lesions (Huey, 1996; Harley et al., 2012) can reduce economic gain by up to $€ 1.69$ per pig (Harley et al., 2014).

Most piglets in intensive husbandry systems are tail docked to prevent tail biting which itself is a welfare problem since it causes trauma and pain (Sutherland et al., 2009). Data from farms and abattoirs suggest that 30 to $70 \%$ of farms in various European countries have some degree of tail biting problem despite tail docking, with a tail lesion prevalence at the abattoir of approximately $3 \%$ (EFSA, 2007). This is due to the fact, that docking reduces the symptoms but does not address the main underlying causes (Nannoni et al., 2014).

Since factors that influence tail biting are complex and can vary over time (EFSA, 2007), animal health and welfare planning (AHWP) can be of help, because it includes regular monitoring of the situation and the development of farm specific intervention strategies (Vaarst et al., 2011). We devised a software supported management tool named SchwIP (short for "Schwanzbeiß-InterventionsProgramm" meaning "tail biting intervention programme") that reduces tail biting risk factors through a combination of farm specific risk assessment and AHWP. It was based on the tool developed by Taylor et al. (2012) and adapted through an expert survey to German finisher husbandry conditions (Madey et al., 2014b, submitted). SchwlP was applied on 188 German fattening farms twice within a year, which included scoring pigs for tail lesions (Vom Brocke et al., 2014, in preparation). However, as scoring tails during a farm visit provides only a snapshot of the situation we decided to additionally score tails at the abattoir during the period between the two farm visits. This provided a good opportunity for collecting information on tail lesions in German fattening pigs at slaughter. 
Therefore, the aims of this study were 1) to assess the prevalence of tail lesions in finisher pigs at a German abattoir, 2) to investigate associations between carcase findings and tail lesions, and 3) to test the effect of the SchwIP tool on prevalence of tail lesions in pigs at slaughter.

\subsection{Animals, material and methods}

\subsubsection{Study population}

A total of 188 SchwlP farms were visited twice for one day between June and November 2012 and 2013, respectively. During the visit, data on tail biting risk factors were collected through an interview and qualitative and quantitative assessment of housing parameters, behaviour observations and clinical scoring of pigs. Data were summarised in a farm specific report which was discussed with the farmer, who then determined aims and measures for reducing tail biting risk on his/her farm (detailed description in Madey et al., 2014a, in preparation).

Pigs from SchwlP farms were slaughtered at various abattoirs throughout Germany, but 32 farms regularly delivered pigs to an abattoir with a capacity of 20,000 pigs per day, which we thus chose for data collection. Thirty-two anonymous control farms which matched for postal code and numbers of batches and pigs delivered in the observation period were selected from the abattoir database.

Farms were located in the federal states of Lower Saxony, North RhineWestphalia and Hesse. The mean number of finishing places per SchwIP farm was 1,558 (range 700 to 4,000) but is not known for control farms. The percentage of tail docked pigs could not exactly be determined but was estimated to be approximately $98 \%$. 


\subsubsection{Data collection at the abattoir}

Abattoir data and pictures were recorded from 02.07.2012 to 29.11.2013. Pigs were identified through their nationwide producer unit ID, slap mark, slaughter date and number. ID data were stored in a transponder on the meat hook, which also stored meat inspection results. Meat inspection was performed by veterinarians and veterinary inspectors, who could choose from 96 diagnoses (findings). Based on their potential physiological association with tail lesions, 33 diagnoses were selected for analysing relationships between tail lesions and carcase findings.

\subsubsection{Tail lesion scoring}

Direct scoring of tails was impossible due to the speed of the slaughterline of up to 20 pigs per minute and the large number of batches. Therefore, two colour cameras automatically photographed tails dorsally from two angles after scalding (cameras: IDS Imaging Development Systems UI-5480RE-C-HQ rev.2, lenses: IDS 25 HB Tamron Focal Length 12mm, casing: Videotec Type NXM; Figure 6.1). Pictures were stored in a structured query language (SQL) database together with meat inspection and ID data.

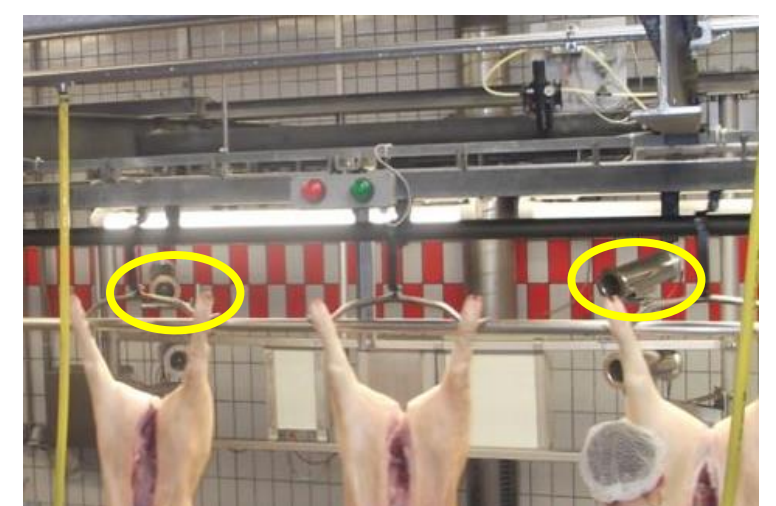

Figure 6.1: Cameras at the slaughterline of the abattoir after scalding. 
Tail lesions were scored on samples drawn from each batch according to the formula for estimating proportions (Dohoo et al., 2012) with a confidence level of $95 \%$ and a precision of $+/-5 \%$ :

$n=\frac{1.96^{2} p q}{0.05^{2}}$

where $\mathrm{n}=$ sample size, $\mathrm{p}=$ expected prevalence, $\mathrm{q}=1-\mathrm{p}$, and $\mathrm{L}=$ precision of the estimate. The expected prevalence was set to $7.2 \%$ based on the review of abattoir data in (EFSA, 2007). Sample sizes were adjusted for batch size (adjusted sample $=1 /(1 / n+1 /$ batch size; (Dohoo et al., 2012) and samples were drawn randomly from each batch using PROC SURVEYSELECT (SAS Institute Inc., 2011).

Tail lesions were scored on a scale from 0 to 3 (Figure 6.2). Discolouring at the tail base was not considered because it seemed to be associated with brushing during scalding. In addition to the lesion score, complete loss of tail (CL) was assessed as present or absent. For analysis, lesion scores were summarised to a combined tail score (CTS) of either 'lesion' (score $>0$ and/or CL present) or 'no lesion' (score 0 and $\mathrm{CL}$ absent). Meat inspection diagnoses with regard to the tail only included tail necrosis which is referred to as TNMI below.

Figure 6.2: Tail lesion scoring key. Complete tail loss was scored independently of lesion score 0 to 3 . CTS = combined tail score. TNP = tail necrosis scored from pictures.

\begin{tabular}{|c|c|c|c|c|}
\hline $\mathbf{0 = \text { no lesion }}$ & $\overline{1} \mathbf{1}=$ minor lesion & $\mathbf{2}=$ severe lesion & $\begin{array}{l}\mathbf{3}=\text { necrosis } \\
\text { (TNP) }\end{array}$ & $\begin{array}{l}\mathbf{C L}=\text { complete } \\
\text { loss }\end{array}$ \\
\hline no visible lesion & $\begin{array}{l}\text { visible skin } \\
\text { perforation with } \\
\text { reddish } \\
\text { discoloration, } \\
\text { skin not dented }\end{array}$ & $\begin{array}{l}\text { visible skin } \\
\text { perforation with } \\
\text { reddish } \\
\text { discolouration } \\
\text { and dented skin } \\
\text { (loss of skin } \\
\text { substance) }\end{array}$ & $\begin{array}{l}\text { skin perforation } \\
\text { with reddish / } \\
\text { brownish / } \\
\text { blackish } \\
\text { discolouration } \\
\text { with uneven } \\
\text { (bumpy and / or } \\
\text { dented) skin }\end{array}$ & $\begin{array}{l}\text { complete loss of } \\
\text { tail up to tail } \\
\text { base with } \\
\text { perforated or } \\
\text { healed skin } \\
\text { surface }\end{array}$ \\
\hline no lesion & \multicolumn{4}{|c|}{ lesion } \\
\hline \multicolumn{5}{|c|}{ CTS } \\
\hline
\end{tabular}


Tail pictures were scored by three trained observers who were blind to treatment. Computer screens were calibrated using the Windows tool dccw.exe and pictures.

Agreement between observers was assessed before and during data collection in a total of nine agreement tests (49 to 120 pictures per test, median lesion prevalence $37 \%$, range 23 to $46 \%$ ). Agreement was evaluated based on exact agreement and prevalence-adjusted bias-adjusted Kappa of observer pairs (PABAK, Gunnarsson, 2000):

$P A B A K=\left(\left(k * p_{0}\right)-1\right) /(k-1)$

where $\mathrm{k}=$ number of categories and $\mathrm{p}_{0}=$ proportion of observed agreement.

Exact agreement $>80 \%$ was regarded as sufficient and PABAK was classified as poor $(\leq 0.40)$, good $(0.40-0.75)$ and very good agreement $(\geq 0.75)$ (Fleiss et al., 2003). Observer agreement for tail lesions was very good in all tests (median exact agreement $87 \%$, range 80 to $94 \%$; median PABAK 0.83 , range 0.73 to 0.92 .

\subsubsection{Data processing}

Meat inspection data were recorded from 409,080 pigs (complete dataset). This included pigs from SchwlP farms and control farms, as well as pigs from farms which were neither and where only the batch ID and meat inspection data were recorded. The latter were only used for calculating the association between TNMI and carcase findings. Due to technical problems with recording pictures, meat inspection data and tail pictures were available from 268,244 pigs from 1,593 batches. The sample dataset included 80,184 pigs, out of which 146 pictures could not be scored (e.g. tail cut in half), and one batch with 4 pigs only was excluded. This left 80,034 pigs from 1,592 batches for analysis (picture dataset). Out of these, 43,402 pigs originated from SchwlP farms ( 860 batches with 5 to 91 pigs (mean $=50$ ) recorded from 02.07.2012 to 29.11 .2013 ) and 36,632 pigs from control farms $(730$ batches with 6 to 85 pigs (mean $=50)$ recorded from 
22.11.2012 to 29.11.2013). For the comparison of SchwlP and control farms data from SchwlP farms were reduced to 730 batches (36,558 pigs, same batch size as above) due to the delayed onset of data collection for control farms.

Data were divided into the seasons winter (Dec 2012 - Feb 2013), spring (Mar May 2013), summer (June - Aug 2013) and autumn (Sep - Nov 2013).

\subsubsection{Statistical analysis}

Prevalences of tail lesions were calculated by batch and prevalences of carcase findings as percentage of animals in the complete dataset or the picture dataset for analysis, respectively. Logistic regression models were calculated (PROC GLIMMIX) to investigate the association between carcase findings and CTS or TNMI, respectively. Only findings with prevalences $>1 \%$ were used for modelling, which were pneumonia $\leq 10 \%, 10 \%$ to $30 \%$, and $\geq 30 \%$, hind leg inflammation, hind leg arthritis, front leg inflammation:

$\operatorname{logit}\left(p_{i}\right)=\mu+\beta X_{i}+u_{f a r m(i)}$

$p=$ probability of carcass finding being present

$\mu=$ intercept

$\beta=$ estimate for CTS or TNMI

$u_{\text {farm }(i)}=$ random farm effect (only used if $X=C T S$ )

When CTS was the independent factor, farm was included as random factor ( $\mathrm{N}=80,034$ pigs from 64 farms). No random effect was included when TNMI was used as independent factor because the calculation included pigs from batches without farm information that were neither from SchwIP nor from control farms ( $N=409,080$ pigs). P-values for single findings were Bonferroni corrected.

In order to test the effect of the SchwIP tool, prevalences of tail lesions in SchwIP pigs and control pigs were compared non-parametrically for each season (Wilcoxon rank sum test, PROC NPAR1WAY, no $p$-value correction) since linear model assumptions were not fulfilled even after data transformation.

All statistical analyses were carried out using SAS 9.3 (SAS Institute Inc., 2011). Differences with (corrected) $p<0.05$ were regarded as significant. 


\subsection{Results}

Tail lesions of any severity were observed in $25.4 \%$ out of 36,632 pigs from control farms, with $23.6 \%$ of pigs being affected by minor lesions (score 1 ) (Table 6.1). Lesions of greater severity were much less prevalent. The mean prevalence of CTS per control farm ranged from $15.4 \%$ to $39.5 \%$ with variable betweenbatch variation ( $\mathrm{N}=2$ to 41 batches per farm; Figure 6.3).

Table 6.1: Prevalence of tail lesions in 36,632 pigs from 32 control farms (730 batches with 6 to 85 pigs recorded from 22.11.2012 to 29.11.2013). Min = minimum, $\max =$ maximum, $\mathrm{SD}=$ standard deviation, $\mathrm{CL}=$ complete tail loss, $\mathrm{CTS}=$ combined tail score "lesion".

\begin{tabular}{llllll}
\hline score & mean & median & min & max & SD \\
\hline 0 & 74.8 & 76.0 & 30.0 & 100 & 11.3 \\
1 & 23.6 & 22.4 & 0 & 58.0 & 10.6 \\
2 & 1.02 & 0 & 0 & 17.1 & 2.08 \\
3 & 0.55 & 0 & 0 & 13.8 & 1.49 \\
\hline CL & 0.43 & 0 & 0 & 16.7 & 1.41 \\
\hline 2,3 and/or CL & 1.90 & 0 & 0 & 22.9 & 3.20 \\
\hline CTS & 25.4 & 24.4 & 0 & 70.0 & 11.4 \\
\hline
\end{tabular}

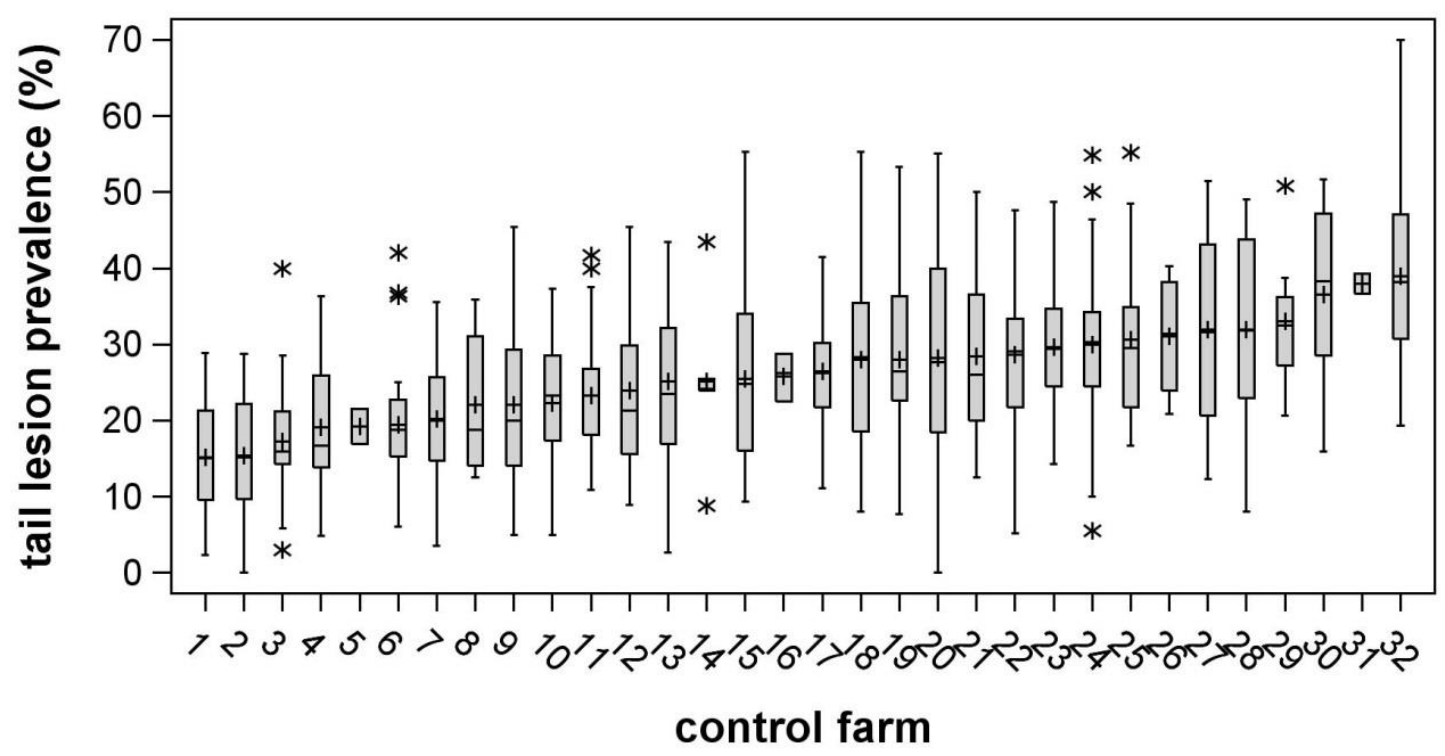

Figure 6.3: Prevalence of tail lesions (\%) on 32 control farms sorted by mean farm prevalence ( $N=2$ to 41 batches per farm; farms $5,14,16,26$ and 31 delivered $\leq 5$ batches). 
Out of the 33 diagnoses selected for potential association with tail lesions, pneumonia was found most often, with $7.63 \%$ of 409,080 pigs being affected by lung findings of any degree (Table 6.2). The second most frequent findings were inflammations in the hind leg which affected $2.49 \%$ of the pigs. TNMI was recorded less frequently than TNP ( $0.22 \%$ vs. $0.55 \%$; Tables 6.1 and 6.2$)$. The following 12 findings had a prevalence of less than $0.22 \%$ both in the complete as well as the picture dataset: rind: necrosis/scar, peritonitis, front leg: arthritis, chop/spine: abscess, belly: abscess, polyarthritis, multiple abscesses, severe peritonitis, severe colour / olfactory deviation, head: abscess, cachexia (emaciation), severe generalised lymphadenitis. Fifteen findings were never chosen: rind bite marks, rind phlegmon, hind leg phlegmon, lung abscess, request for bacteriological culture, hind leg abscess, rib cage abscess, knee arthritis, pelvis abscess, ham abscess, shoulder arthritis, rind abscess, severe purulence, septicaemia / pyaemia / toxaemia / viremia, multiple chop or spine abscesses.

Table 6.2: Frequencies and prevalences of carcase findings with possible relation to tail lesions in the complete and picture dataset (findings with prevalence $\geq 0.22 \%$ only). The picture dataset represents a sample of the complete dataset that includes meat inspection data and tail pictures from SchwIP farms and control farms.

\section{complete dataset}

$\mathrm{N}$ pigs

$\mathrm{N}$ selected carcase findings

pigs with $\geq 1$ finding $(\mathrm{N} ; \%$ of

all pigs)
409,080

51,788

45,$402 ; 11.1 \%$ picture dataset

80,034

10,409

\begin{tabular}{lllllll}
\hline carcase findings & $\mathbf{N}$ & $\%$ of $\mathbf{N}$ pigs & $\mathbf{N}$ & \% of N pigs & \\
\hline pneumonia $(10 \%-30 \%)$ & 12,098 & 2.96 & & 2,623 & 3.28 & \\
pneumonia $(\leq 10 \%)$ & 11,003 & 2.69 & 7.63 & 2,088 & 2.61 & \multirow{2}{*}{8.09} \\
pneumonia $(>30 \%)$ & 8,216 & 2.01 & & 1,778 & 2.22 & \\
\hline hind leg: inflammation & 7,504 & 1.83 & \multirow{2}{*}{2.49} & 1,434 & 1.79 & \multirow{2}{*}{2.39} \\
hind leg: arthritis & 3,107 & 0.76 & & 569 & 0.71 & \\
\hline front leg: inflammation & 6,380 & 1.56 & & 1,264 & 1.58 & \\
\hline tail necrosis (TNMI) & 914 & 0.22 & & 173 & 0.22 & \\
\hline
\end{tabular}

The 33 selected findings were significantly more prevalent in pigs with CTS lesion than in pigs without CTS lesions (12.3\% vs. $11.1 \%$; logistic regression with random farm effect, $\mathrm{N}=80,034$ pigs, $\mathrm{p}<0.001$; Table 6.3 ). The same effect with even greater prevalence difference was found when comparing pigs with and 
without TNMI, (57.9\% vs. $11.0 \%$ with finding; logistic regression without random effects, $\mathrm{N}=409,080$ pigs, $\mathrm{p}<0.001$; Table 6.3).

When testing the six most frequent selected findings separately, hind leg findings and front leg inflammation were significantly more prevalent in pigs with CTS lesion than in pigs without CTS lesion (corrected $p \leq 0.01$, Table 6.3). These differences were even more pronounced in the complete meat inspection dataset, where signs of moderate and severe pneumonia were also more prevalent in pigs with TNMI (Table 6.3). Only signs of mild pneumonia did not differ between pigs with and without CTS lesion or TNMI.

Table 6.3: LSM prevalences (\%) [95\% confidence interval] of selected carcase findings in pigs with or without tail lesions (logistic regression model with random farm effect; $p$ values of individual findings are Bonferroni corrected for 6 tests) and pigs with or without TNMI (logistic regression model without random effects; $p$-values of individual findings are Bonferroni corrected for 6 tests).

\begin{tabular}{|c|c|c|c|c|c|c|}
\hline & \multicolumn{3}{|c|}{$\begin{array}{l}\text { picture dataset: CTS } \\
\text { (80,034 pigs from } 64 \text { farms) }\end{array}$} & \multicolumn{3}{|c|}{$\begin{array}{l}\text { complete dataset } \\
\text { ( } 409,080 \text { pigs, } n \text { farms unknown) }\end{array}$} \\
\hline & no lesion & lesion & $\mathbf{p}$ & no TNMI & TNMI & $\mathbf{p}$ \\
\hline \multirow{2}{*}{$\begin{array}{l}\text { all } 33 \text { selected } \\
\text { findings combined }\end{array}$} & 11.1 & 12.3 & \multirow[b]{2}{*}{$<0.001$} & 11.0 & 57.9 & \multirow[b]{2}{*}{$<0.001$} \\
\hline & {$[10.9-11.4]$} & {$[11.9-12.8]$} & & $\begin{array}{l}{[10.9-} \\
11.1]\end{array}$ & {$[54.7-61.0]$} & \\
\hline pneumonia $\leq 10 \%$ & $\begin{array}{l}2.5 \\
{[2.4-2.7]}\end{array}$ & $\begin{array}{l}2.8 \\
{[2.6-3.0]}\end{array}$ & $>0.05$ & $\begin{array}{l}2.7 \\
{[2.6-2.7]}\end{array}$ & $\begin{array}{l}3.5 \\
{[2.5-4.9]}\end{array}$ & $>0.05$ \\
\hline pneumonia $10 \%$ - & 3.3 & 3.2 & \multirow{2}{*}{$>0.05$} & 3.0 & 4.9 & \multirow{2}{*}{0.003} \\
\hline $30 \%$ & [3.2 - 3.5] & {$[3.0-3.4]$} & & [2.9-3.0] & {$[3.7-6.5]$} & \\
\hline pneumonia $\geq 30 \%$ & $\begin{array}{l}2.2 \\
{[2.1-2.3]}\end{array}$ & $\begin{array}{l}2.3 \\
{[2.1-2.5]}\end{array}$ & $>0.05$ & $\begin{array}{l}2.0 \\
{[2.0-2.0]}\end{array}$ & $\begin{array}{l}4.3 \\
{[3.1-5.8]}\end{array}$ & $<0.001$ \\
\hline $\begin{array}{l}\text { hind leg: } \\
\text { inflammation }\end{array}$ & $\begin{array}{l}1.7 \\
{[1.6-1.8]}\end{array}$ & $\begin{array}{l}2.1 \\
{[1.9-2.3]}\end{array}$ & 0.002 & $\begin{array}{l}1.8 \\
{[1.8-1.8]}\end{array}$ & $\begin{array}{l}21.4 \\
{[18.9-24.2]}\end{array}$ & $<0.001$ \\
\hline hind leg: arthritis & $\begin{array}{l}0.6 \\
{[0.58-0.71]}\end{array}$ & $\begin{array}{l}0.9 \\
{[0.77-1.0]}\end{array}$ & 0.003 & $\begin{array}{l}0.7 \\
{[0.7-0.8]}\end{array}$ & $\begin{array}{l}6.8 \\
{[5.3-8.6]}\end{array}$ & $<0.001$ \\
\hline front leg: & 1.5 & 1.8 & \multirow{2}{*}{0.010} & 1.5 & 18.1 & \multirow{2}{*}{$<0.001$} \\
\hline inflammation & {$[1.4-1.6]$} & {$[1.6-2.0]$} & & {$[1.5-1.6]$} & [15.7 - 20.7] & \\
\hline
\end{tabular}

When comparing the results for tail necrosis based on pictures with those from meat inspection, TNMI were less prevalent than TNP (Table 6.4). Out of the total of 548 TNP, $17 \%$ were also recorded during meat inspection, whereas $53 \%$ of TNMI were also scored from the pictures. 
Table 6.4: Number and proportion of recorded necroses by pictures (score 3) and TNMI detected at the slaughterline. TNMI = tail necrosis recorded during meat inspection, TNP = tail necrosis recorded from pictures.

\begin{tabular}{lllll}
\hline & & TNMI & & \\
& no & yes & $\Sigma$ \\
\hline & no & 79,404 & 82 & 79,486 \\
TNP & & $(99.2 \%)$ & $(0.1 \%)$ & $(99.3 \%)$ \\
& yes & 457 & 91 & 548 \\
& & $(0.6 \%)$ & $(0.1 \%)$ & $(0.7 \%)$ \\
\hline & $\Sigma$ & 79,861 & 173 & 80,034 \\
& & $(99.8 \%)$ & $(0.2 \%)$ & $(100 \%)$ \\
\hline
\end{tabular}

Median tail lesion prevalence was higher in SchwlP farm pigs before data collection started than in control farms (Table 6.5). Moreover, tail lesions were significantly more prevalent in SchwIP pigs during winter (30.3\% vs. $24.5 \%$, $p=0.011$; Wilcoxon rank sum test), but not significantly higher in any of the following seasons (Table 6.5). On SchwIP farms median prevalence was highest during the first two seasons $(>30 \%$ ), while median prevalences on control farms were lower in summer compared to the other three seasons ( $20.6 \%$ vs. $\geq 24.5 \%$; Table 6.5). Tail lesion prevalences varied more on SchwIP farms than on control farms, especially in the first two seasons (interquartile ranges $=20.4 \%$ and $18.9 \%$ for winter and spring, respectively; Figure 6.4).

Table 6.5: Prevalence of tail lesions (\%) in four seasons (S = SchwIP farms, C = Control farms; $N_{\text {winter }} S=30, C=27 ; N_{\text {spring }} S=30, C=32 ; N_{\text {summer }} S=31, C=27 ; N_{\text {autumn }} S=30, C=25$; MIN = minimum; Q25=1st quartile; $Q 75=3$ rd quartile; MAX = maximum; one Wilcoxon test per season). Before = July to November 2012, $\mathrm{N}=29$ farms.

\begin{tabular}{llllllllll}
\hline & \multicolumn{2}{c}{ before } & winter & \multicolumn{2}{c}{ spring } & \multicolumn{2}{c}{ summer } & \multicolumn{2}{c}{ autumn } \\
& S & S & C & S & C & S & C & S & C \\
\hline min & 24.0 & 15.0 & 8.8 & 8.7 & 12.2 & 11.1 & 10.4 & 13.2 & 14.0 \\
Q25 & 38.8 & 24.7 & 18.4 & 17.6 & 20.7 & 20.2 & 16.9 & 19.7 & 21.0 \\
median & 45.5 & 32.2 & 23.8 & 22.6 & 26.9 & 24.2 & 21.4 & 23.9 & 28.0 \\
Q75 & 50.7 & 37.5 & 31.8 & 28.8 & 31.5 & 28.3 & 26.7 & 30.0 & 32.0 \\
max & 62.1 & 59.3 & 49.0 & 44.6 & 44.5 & 36.0 & 43.1 & 47.1 & 45.0 \\
p & n.a. & 0.011 & & 0.215 & & 0.117 & & 0.322 & \\
\hline
\end{tabular}




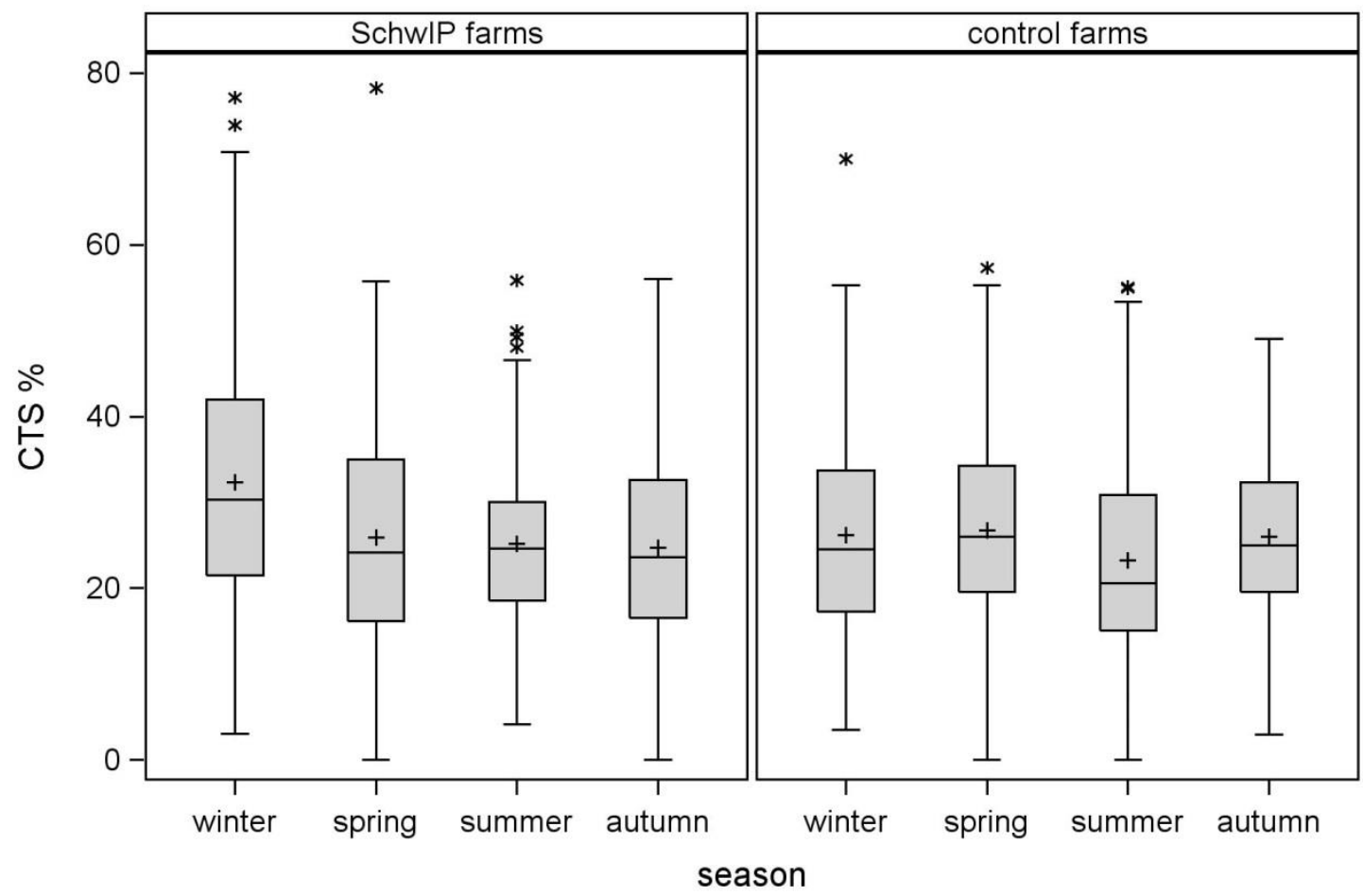

Figure 6.4: Prevalence of tail lesions (CTS \%) of SchwIP and control farms per seasons. Prevalences differed significantly in winter $(p=0.011)$ but not in any other season. Box = 25th -75 th percentile, horizontal line = median, + mean, * outlier $>1.5$ interquartile range.

\subsection{Discussion}

Even though tail biting lesions are a major problem in fattening pigs (EFSA, 2007), lesion prevalences in German fattening pigs at slaughter are not known. This publication presents data on post mortem tail lesion prevalence at a German abattoir, examines their association with carcase findings and tests the effect of the tail biting management tool SchwlP on tail lesion prevalence.

\subsubsection{Prevalence of tail lesions}

Generally a comparison to other studies is relatively difficult since the way of data collection, legislation concerning tail docking and the applied scoring systems may differ (Keeling et al., 2012). In this study the prevalence of tail lesions of control farms was quite high with $25.4 \%$. Two other studies collected their data 
also after scalding (Valros et al., 2004; Harley et al., 2012) and found even higher lesion prevalences of $34.6 \%$ (Valros et al., 2004) and $58.1 \%$ (Harley et al., 2012) with a majority of minor lesions. Since the summarised published data of (EFSA, 2007) addicted a mean prevalence of $7.2 \%$ which was used as the estimate proportion to draw the sample size in this study, our figure is relatively high. It can be assumed that the point of data collection has a major influence on the evaluation of tail biting prevalence. The cameras were positioned after scalding and dehairing. Some researchers stated that if tail lesions are recorded after scalding, marks are left through this process and may mask actual tail lesions (Taylor et al., 2010; Keeling et al., 2012). In this study, the dehairing paddles only caused a discolouration at the basis of the tail which was excluded from the scoring scheme. Based on our observations minor lesions are slightly masked before scalding and dehairing and could have had not be correct classified. Therefore it is also conceivable that the prevalence of tail lesions in studies which inspected tails before scalding is underestimated. The amount of pigs with severe lesions in this study was $1.0 \%$, TNP was found in $0.5 \%$ and a complete loss of the tail in $0.4 \%$ of the pigs. If these lesions were combined as severe lesions we had an amount of $1.9 \%$ which is comparable with the amount of major lesions from other studies. Despite the fact that differences regarding the scoring scheme, point of data collection and status of tails docked vs. un-docked existed. Valros et al. (2004) reported that they found $1.3 \%$ major lesions in un-docked pigs and Keeling et al. (2012) found $1.5 \%$ and $1.9 \%$ major lesions in un-docked pigs in two different slaughterhouses. Harley et al. (2012) detected $1.03 \%$ major lesions in docked pigs but in a more recent study it was slightly higher since they found $2.5 \%$ of docked pigs with major lesions (Harley et al., 2014).

Nevertheless, the results may underestimate the number of pigs with tail lesions since severely bitten pigs had been culled or may have died on-farm (Van Putten, 1969). Furthermore, it has to be considered that healed wounds are not distinguishable from docked tails at the abattoir (Taylor et al., 2010) therefore the true prevalence might be even higher. 


\subsubsection{Relationships between carcase findings and tail lesions}

In comparison of different abattoir studies it should be considered that the recording of findings differs among countries, slaughterhouses and veterinarians (Harley et al., 2012). The result of the slaughterhouse recordings provides an overview of the most common reasons for condemnation associated with tail biting lesions (Table 6.2). On the whole our results are comparable with those of other studies. In our study $11 \%$ of assessed pigs had a finding which was linked with tail lesions. Among the inspected pigs about $8 \%$ had pneumonia. Marques et al. (2012) investigated $10.2 \%$ of respiratory disorders and Wallgren and Lindahl (1996) found that $9.2 \%$ of the pigs were affected by pneumonia. The veterinarians in the abattoir detected arthritis in the front or hind legs in $0.8 \%$ of the pigs. This number is slightly lower than in other studies, even if we consider the finding polyarthritis additionally. Most similar are the results from Wallgren and Lindahl (1996) who found arthritis in 1.7\% of the assessed pigs and Marques et al. (2012) detected arthritis in $2.2 \%$ of the pigs. In the study of Valros et al. (2004) arthritis was the cause for findings in $2.9 \%$ of the animals. Harley et al. (2012) reported that in $26 \%$ arthritis was a reason for a partial condemnation and in $7 \%$ for a total condemnation. It can be assumed that the differences between the studies are due to different definitions for the several findings in the meat inspection data, which are often not specified.

We found significant differences for the presence of inflammation and arthritis of the hind legs and inflammation in the front legs as well as moderate and severe pneumonia in pigs with and without CTS tail lesions or TNMI (Table 6.3). Kritas and Morrison (2007) had a comparable result since they also could not find a significant association between their scored tail lesions and the proportion of lungs with any amount of enzootic pneumonia, neither when they tested only the severe lesions. In a Dutch study the relationship between tail biting as a clinical observation on-farm and the frequency of pneumonia as a pathological finding at the slaughterhouse proved to be significant (Blocks et al., 1994). However, one has to bear in mind that respiratory disease and tail lesion prevalence correlate at farm level indicating that tail biting is more common on disease-prone farms (Moinard et al., 2003). 
The differences between the results from scoring tail lesions from pictures and from veterinarians in the slaughterhouse can be explained by the fact that we used the score 'injury' for the examination of the tail lesions. The majority of lesions in this score were minor lesions. In comparison to the relationship of the TNMI it is therefore explicable that almost all clinical signs proved to be significant. Previous studies showed also that the risk of carcase findings increased with the severity of tail lesions (Kritas and Morrison, 2007; Marques et al., 2012).

\subsubsection{Comparison with meat inspection data}

Additionally we examined the agreement between TNP and TNMI and found that only $0.1 \%$ of necroses had been assigned by both. The low overall prevalence of necrosis (TNMI $0.2 \%$, TNP $0.7 \%$ ) is problematic, since it results in misleading good agreement based on the absence of necrosis (Hoischen-Taubner et al., 2011). Nevertheless, the higher TNP prevalence indicates that considerable numbers of necroses were not recorded during meat inspection. Similar results were found by Keeling et al. (2012) who recorded a tail lesion prevalence of $7.0 \%$ and $7.2 \%$ whilst in the time of data collection the meat inspection data indicated only $1.2 \%$ and $1.6 \%$. Part of this can be explained by the diagnostic key used during meat inspection, which in the current study defined tail necrosis as necrosis in the tail associated with additional carcase abscesses. This would only include severe cases of tail necrosis that would impact product quality and thus explain the lower prevalences.

\subsubsection{Trend of tail lesion prevalence}

In order to evaluate the implementation of the tail biting management tool SchwIP, the level of change in the prevalence of tail lesions at the abattoir was assessed. In winter, the prevalence of tail lesions was significantly higher in SchwlP farm pigs than in control farm pigs but was reduced to a similar extent over the study (Table 6.5). Despite the delayed onset of data collection for control 
farms, this result indicates that mostly farms with tail biting problems volunteered for SchwlP participation, and that the prevalence of tail lesions on those farms could be reduced to an average level.

The highest tail biting prevalence was found in winter and the lowest in summer. Many studies described seasonal effects on the tail biting prevalence but the results are varied (Penny and Hill, 1974; Elbers et al., 1992; Tuovinen et al., 1994; Schrøder-Petersen and Simonsen, 2001) and furthermore, are difficult to compare due to different season categorisation. Time of year influences many factors including temperature, changes in ventilation rates, feed quality and the endocrine state of the pig (EFSA, 2007). Therefore, seasonal effects should be studied over several years to obtain a conclusive statement (Tuovinen et al., 1994).

\subsubsection{Data collection}

Usually, publications regarding the prevalence of carcase tail lesions are based on data collected through direct lesion scoring at the slaughterline during a limited number of days (Valros et al., 2004; Harley et al., 2012; Keeling et al., 2012). This was not possible in the current study due to slaughterline speed and the objective of recording changes in lesion prevalence throughout one year. Therefore, lesions were scored from automatically recorded colour pictures. Pictures were taken after scalding, because tails were clean at that point. Possible implications of skin lesions caused by the scalding brushes were considered preferable to missing data due to tail dirtiness.

The agreement between direct scoring and scoring from pictures could not be tested due to the high speed of the slaughterline. The key used for scoring pictures was comparable to those used for direct scoring in other studies (Hunter et al., 1999; Kritas and Morrison, 2007; Harley et al., 2012). Since it could not be determined whether a tail had been docked or bitten short and healed, tail length was not recorded apart from complete loss of tail. Agreement between observer pairs for scores based on pictures was very good, indicating good repeatability. Scoring from pictures was also a feasible method which avoided observer fatigue 
that would otherwise be caused by the scoring speed determined by the slaughterline.

\subsection{Conclusions}

Scoring tail lesions on pig carcases from automatically recorded pictures proved to be a feasible method for collecting lesion data over one year. Tail necrosis recorded during meat inspection resulted in lower prevalences than necrosis scoring with a research objective. As carcase tail lesions are associated with other carcase findings and can be reduced through improved management, more detailed tail lesion scoring at the abattoir would generate useful information for farm health and welfare management.

\section{Acknowledgement}

This study was financially supported by 'Tönnies Forschung - Gemeinnützige Gesellschaft zur Förderung der Forschung über die Zukunft des Tierschutzes in der Nutztierhaltung $\mathrm{mbH}^{\prime}$. Thoralf Kobert and Hans-Jörg Eynck are gratefully acknowledged for their technical support in the abattoir and Stine Heindorff for her support during data collection and analysis. The authors would like to thank all SchwIP participants for their time and interest. 


\section{References}

Blocks, G.H.M., Vernooy, J.C.M., Verheijden, J.H.M., 1994. Integrated quality control project: Relationships between pathological findings detected at the slaughterhouse and information gathered in a veterinary health scheme at pig farms. Veterinary Quarterly 16, 123-127.

Dohoo, I., Martin, W., Stryhn, H., 2012. 2.11 Sample-size determination. In: Mc Pike, S.M. (Ed.), Methods in Epidemiologic Research. VER Inc., Charlottetown, Prince Edward Island, Canada, 48-55.

EFSA, 2007. Scientific Report on the risks associated with tail biting in pigs and possible means to reduce the need for tail docking considering the different housing and husbandry systems. The EFSA Journal 611, 1-13.

Elbers, A.R.W., Tielen, M.J.M., Snijders, J.M.A., Cromwijk, W.A.J., Hunneman, W.A., 1992. Epidemiological studies on lesions in finishing pigs in the Netherlands. I. Prevalence, seasonality and interrelationship. Preventive Veterinary Medicine 14, $217-231$.

Fleiss, J.L., Levin, B., Paik, M.C., 2003. Chapter 18, The Measurement of Interrater Agreement. Statistical Methods for Rates and Proportions. Wiley Interscience, Hoboken, New Jersey, 598-626.

Gunnarsson, S., 2000. Laying Hens in Loose Housing Systems: Clinical, ethological and epidemiological aspects. Department of Animal Environment and Health Skara. Swedish University of Agricultural Sciences, Uppsala, 70.

Harley, S., Boyle, L.A., O'Connell, N.E., More, S.J., Teixeira, D.L., Hanlon, A., 2014. Docking the value of pigmeat? Prevalence and financial implications of welfare lesions in Irish slaughter pigs. Animal Welfare 23, 275-285.

Harley, S., More, S.J., O'Connell, N.E., Hanlon, A., Teixeira, D., Boyle, L., 2012. Evaluating the prevalence of tail biting and carcase condemnations in slaughter pigs in the Republic and Northern Ireland, and the potential of abattoir meat inspection as a welfare surveillance tool. Veterinary Record 171, 621-627.

Hoischen-Taubner, S., Blaha, T., Werner, C., Sundrum, A., 2011. Repeatability of anatomical-pathological findings at the abattoir for characteristics of animal health. Archiv für Lebensmittelhygiene 62, 82-87.

Huey, R.J., 1996. Incidence, location and interrelationships between the sites of abscesses recorded in pigs at a bacon factory in Northern Ireland. Veterinary Record 138, 511-514.

Hunter, E.J., Jones, T.A., Guise, H.J., Penny, R.H.C., Hoste, S., 1999. Tail biting in pigs 1: The prevalence at six UK abattoirs and the relationship of tail biting with docking, sex and other carcass damage. The Pig Journal 43, 18-32.

Keeling, L.J., Wallenbeck, A., Larsen, A., Holmgren, N., 2012. Scoring tail damage in pigs: an evaluation based on recordings at Swedish slaughterhouses. Acta Veterinaria Scandinavica 54.

Kritas, S.K., Morrison, R.B., 2007. Relationships between tail biting in pigs and disease lesions and condemnations at slaughter. Veterinary Record 160, 149-152.

Madey, D.P., Vom Brocke, A.L., Schrader, L., Wendt, M., Gauly, M., Dippel, S., 2014a. Tail biting risk on German finisher farms: Evaluation of a tail biting intervention tool (in preparation).

Madey, D.P., vom Brocke, A.L., Schrader, L., Wendt, M., Wainwright, N.R., Dippel, S., 2014b. Expert opinion on risk factors for tail biting in conventional German fattening pig housing systems. submitted to Preventive Veterinary Medicine.

Marques, B.M.F.P.P., Bernardi, M.L., Coelho, C.F., Almeida, M., Morales, O.E., Mores, T.J., Borowski, S.M., Barcellos, D.E.S.N., 2012. Influence of tail biting on weight gain, lesions and condemnations at slaughter of finishing pigs. Pesquisa Veterinaria Brasileira 32, 967-974. 
Moinard, C., Mendl, M., Nicol, C.J., Green, L.E., 2003. A case control study of on-farm risk factors for tail biting in pigs. Applied Animal Behaviour Science 81, 333355.

Nannoni, E., Valsami, T., Sardi, L., Martelli, G., 2014. Tail docking in pigs: a review on its short- and long-term consequences and effectiveness in preventing tail biting. Italian Journal of Animal Science 13, 98-106.

Penny, R.H., Hill, F.W., 1974. Observations of some conditions in pigs at the abattoir with particular reference to tail biting. Veterinary Record 94, 174-180.

SAS Institute Inc., 2011. SAS 9.3. SAS/STAT ${ }^{\circledR} 9.3$ User's Guide. Cary, NC: SAS Institute Inc.

Schrøder-Petersen, D.L., Simonsen, H.B., 2001. Tail Biting in Pigs. The Veterinary Journal 162, 196-210.

Sutherland, M.A., Bryer, P.J., Krebs, N., McGlone, J.J., 2009. The effect of method of tail docking on tail-biting behaviour and welfare of pigs. Animal Welfare 18, 561570.

Taylor, N.R., Main, D.C.J., Mendl, M., Edwards, S.A., 2010. Tail-biting: A new perspective. The Veterinary Journal 186, 137-147.

Taylor, N.R., Parker, R.M.A., Mendl, M., Edwards, S.A., Main, D.C.J., 2012. Prevalence of risk factors for tail biting on commercial farms and intervention strategies. The Veterinary Journal 194, 77-83.

Tuovinen, V.K., Grohn, Y.T., Straw, B.E., 1994. Partial condemnations of swine carcasses - a descriptive study of meat inspection findings at Southwestern Finland's Cooperative Slaughterhouse. Preventive Veterinary Medicine 19, 6984.

Vaarst, M., Winckler, C., Roderick, S., Smolders, G., Ivemeyer, S., Brinkmann, J., Mejdell, C.M., Whistance, L.K., Nicholas, P., Walkenhorst, M., Leeb, C., March, S., Henriksen, B.I.F., Stöger, E., Gratzer, E., Hansen, B., Huber, J., 2011. Animal Health and Welfare Planning in Organic Dairy Cattle Farms. The Open Veterinary Science Journal 5, 19-25.

Valros, A., Ahlstrom, S., Rintala, H., Hakkinen, T., Saloniemi, H., 2004. The prevalence of tail damage in slaughter pigs in Finland and associations to carcass condemnations. Acta Agriculturae Scandinavica Section A-Animal Science 54, 213-219.

Van Putten, G., 1969. An investigation into tail-biting among fattening pigs. British Veterinary Journal 125, 511-517.

Vom Brocke, A.L., Madey, D.P., Gauly, M., Schrader, L., Wendt, M., Dippel, S., 2014. Reducing tail biting risk on German fattening pig farms with a management tool for risk planning (in preparation).

Wallgren, P., Lindahl, E., 1996. The influence of tail biting on performance of fattening pigs. Acta Veterinaria Scandinavica 37, 453-460.

Zonderland, J.J., Bosma, B., Hoste, R., 2011. Financiële consequenties van staartbijten bij varkens Rapport 543. Wageningen UR Livestock Research, Lelystad. 
Chapter 7

General Discussion 


\section{Chapter 7: General Discussion}

The tail biting intervention tool SchwlP was developed to support farmers in the challenge of reducing the underlying risk factors for tail biting and to improve the conditions on-farm. The main aim of this thesis was to investigate whether the approach of SchwIP, following the principles of Animal Health and Welfare Planning (AHWP) is appropriate in reducing tail biting risks on-farm and the prevalence of tail lesions at the abattoir. Furthermore, the project investigated the distribution of the tool among farm advisers and veterinarians through training workshops and assessed the knowledge transfer from research into practice.

\subsection{Training of stakeholders and the provision of knowledge transfer}

Taking into consideration that there is an ongoing trend towards the development of novel tools facing problems of animal welfare the question arises how to distribute them in practice. Generally, the implementation and evaluation of new developed tools have only been conducted by trained researchers (Green et al., 2007; Ivemeyer et al., 2012; Main et al., 2012), so it was a completely new concept to train stakeholders such as farm advisers and veterinarians in the implementation of an intervention tool and to involve them in the evaluation on-farm. This approach had two main benefits. Firstly, it was beneficial for the research group to have the tool distributed and in use all over Germany, since a greater number of farms for the evaluation of the tool were received. Moreover, refinements to the tool being further improved by different operators. Secondly, the tool assisted farm advisers and veterinarians in their daily work when facing tail biting problems on-farm.

It turned out that educating the workshop leader in communication and group leadership is a precondition for successful training workshops with stakeholders to minimize the threat that discussions get out of hand. The majority of workshop groups included at least one participant who was strongly or intermediately antagonistic towards the tool or parts of it. In a learning situation adults naturally 
discuss, question and debate a new topic (Bell et al., 2014). The concept of SchwIP was a new advisory approach for most participants of the workshop, which was therefore likely to lead to active questioning and lively debates, but was nevertheless, accepted by stakeholders. No difference was found between the groups in the evaluation grade for knowledge transfer in the feedback forms handed out after the workshop and the ensuing application of SchwIP on-farm. Merely workpace and on-farm usability received a significantly lower assessment from strongly antagonistic groups in the feedback forms.

It is noteworthy that Madey et al. (2014a) reported that $92 \%$ of the respondent farm advisers and veterinarians regarded SchwlP as ready for practical application and $79 \%$ of them stated that they would include the tool in their daily work. Therefore it can be assumed that the strongly antagonistic participants were also convinced of the on-farm practicality after implementing it on their customers' farms. Training workshops for colleagues regarding the uptake and application of similar tools were recommended by $67 \%$ of training participants (Madey et al., 2014a).

The transfer of scientific knowledge about the relationship between enrichment material and pig behaviour is crucial in the process of abstaining from routine tail docking and involves a change in attitudes and awareness (Bracke et al., 2013). A short lecture about pig behaviour and tail biting causation was therefore included in the training workshops; it was much appreciated by the training participants as it is normally not considered in their formal education. Interestingly, a notable change in the provision of enrichment was observed in the second year of study implementation, in that more farms offered enrichment or material instead of objects. It can be assumed that the farm advisers and veterinarians who attended the training courses played a key role in the transfer of knowledge on this topic and the consequent changes on-farm. Madey et al. (2014a) further showed that the SchwIP application itself helped to transfer knowledge about pig behaviour to farms; $71 \%$ of farmers stated that they gained a new overview of tail biting causes. SchwIP helps to raise awareness in farmers and advisers of the issue that provision of enrichment material is essential for the reduction of tail biting risks and therefore bridges a gap between research and practice. 
In contrast to this, a recent study pointed out that farmers who attended a lecture-based symposium or had one-to-one dialogues with scientists were only moderately open to scientific knowledge on the relevance of pigs' social behaviour and tail biting (Bernard et al., 2014). The authors stated that the knowledge transfer from science to practice was hampered in these settings. Participants of this study therefore suggested an integral approach with reliable facts and numbers which are consistent with relevant husbandry practices and which give direction to farmers (Bernard et al., 2014). This proposal is wholly included in the approach of SchwIP and may explain why knowledge transfer from research into practice was achieved in the present study. SchwIP presents scientific knowledge in such a way that farmers become aware of the strengths and weaknesses in the risk profile for tail biting on their own farm. Moreover, farm advisers and veterinarians gave practical advice accompanied by the scientific background of the tool, so that tailor-made solutions could be developed. In addition, the SchwIP approach with its practical relevance is more likely to be accepted by farmers and be more effective in intervening in tail biting issues than lectures on the theory.

It can be concluded that interactive training workshops with stakeholders are an appropriate way to transfer knowledge from research to advisory practice and subsequently to farmers.

\subsection{Effects of implementation of SchwlP on-farm}

SchwlP is a new approach to reducing risk factors for tail biting on German finisher farms. The participating farm advisers or veterinarians from the training workshops stated that they generally addressed tail biting problems by checklists or by improving problems associated with their specific areas of expertise. Advisory tools like SchwIP aim to assess a wide range of risk factors in an objective way without following an unintentional bias or concentrating on areas of initial interest (Taylor et al., 2012). Multifactorial problems like tail biting necessitate an integral approach which considers resource/management-based and animal-based measures to identify and reduce the risk factor pattern specific 
to each farm situation (EFSA AHAW Panel, 2014). SchwIP fulfils these requirements, and its application proved to be successful on farms with existing tail biting problems. The overall aim of reducing tail biting risk factors could be achieved within a span of one year as shown by a significant reduction in the total risk score over all farms (Chapter 5).

The results of the study showed a large variation in the total risk score between the participating farms. Given that even farms with a low risk score suffered from tail biting problems it is all the more important to implement a risk analysis like SchwIP to identify the causal risk factors (Madey et al., 2014b). The effectiveness of SchwIP implementation underlines that due to the complex and multifactorial aspects of tail biting a 'one size fits all' solution is unpromising. These results are in line with the study by Taylor et al. (2012), who also showed that the implementation of a tail biting management tool in the UK caused a reduction in the overall tail biting risk and tail lesion score.

There was a non-significant trend for a decrease in risk score in all categories except health and stress, with a strong trend in the enrichment category. It is feasible that a financial incentive may have helped to reduce the risk score in one of the categories significantly. In the study of Taylor et al. (2012) the group which received a financial incentive reduced their risk scores in the 'health' and 'atmosphere and environment' categories. However, the control group in this study also reduced their risk scores in the 'stocking density' and 'atmosphere and enrichment' categories. The authors stated that changes in the risk categories might depend on several reasons like influences from the pig industry, farmer attitudes or just practical explanations. As suggested by lvemeyer et al. (2012) it is conceivable that the period of one year in the present study might have been too short to record any intervention effects in the single categories.

The majority of farmers $(79 \%)$ in the present study implemented one or more measures fully or partially on their farm. Thus, the knowledge transfer provided by the application of the tool became obvious. More than $90 \%$ of farmers regarded the measures suggested by the tool as realistic, useful and effective (Madey et al., 2014a). General advice does not consider the specific issues and circumstances on a particular farm and is therefore less likely to be implemented than a farm-specific plan (Vaarst et al., 2011). Various intervention studies have 
found a correlation between improvement of the examined risk factors and the implementation level of measures (Green et al., 2007; Leeb et al., 2010). However, in the present study no correlation between the different implementation rates of measures and the change in the total risk score was found. It can be assumed that SchwIP has been influential through increasing farmers' awareness of the tail biting situation on-farm, resulting in subconscious changes which were not measured. Stockpeople might pay more attention to their animals when they have been made more aware of tail biting, so might intervene more quickly. Inclusion in SchwIP nevertheless, encouraged farmers to establish measures to improve the tail biting situation on-farm.

The significant reduction of the tail lesion prevalence between the two on-farm assessments (a year apart) highlights the effectiveness of SchwIP application. Likewise a reduction of ear lesions was achieved, which indicates that the implementation of SchwIP had an additional benefit towards a reduction of other welfare related lesions and was therefore addressing the underlying causes of un-wanted pig-directed behaviours, rather than transferring tail biting behaviour onto other parts of the pig. The reduction of the tail lesion prevalence was further verified through the follow-up data gained at the abattoir of 32 farms assessed with SchwIP (Chapter 6). The initial high level of the tail lesion prevalence decreased and was adapted to the level of the control farms within one year. Therefore, the application of SchwIP not only improved the tail biting situation on-farm and the welfare of the pigs but also showed beneficially at the abattoir. In a recent study Harley et al. (2014) calculated a financial loss of $€ 1.69$ per study pig as a result of carcase condemnations, trimmings and reduced carcase weight associated with tail lesions. Therefore it can be assumed that the effectiveness of SchwIP and the lower tail lesion prevalence also has a beneficial impact on the farm economics on a long-term-view.

In conclusion SchwIP, following the principle of Animal Health and Welfare Planning provide a more meaningful and efficient way of reducing tail biting in finisher pigs rather than the existing resource-based assessments. 


\subsection{The future role of management tools}

Existing problems with the compliance to unitary animal welfare rules raised the question of whether a 'one size fits all' approach could lead to better welfare in the EU, since considerable differences exist among Member States. Therefore, in 2012, the European Commission formulated, the 'Strategy for the Protection and Welfare of Animals 2012-2015', which aims to tackle welfare problems in a more holistic manner with a focus on animal-based indicators instead of measured environmental values (European Commission, 2012).

This approach was likewise incorporated in article 11 (8) (TierSchG, 2006) which since $1^{\text {st }}$ February 2014, has required internal on-farm controls with a record of animal-based parameters to ensure acceptable animal welfare. In a workshop of the German 'Association for Technology and Structures in Agriculture e. V.' (Kuratorium für Technik und Bauwesen in der Landwirtschaft, KTBL) a first draft for recommendations for those parameters were formulated specifically to the requirements of the German legislation (Schrader, L., personal communication). These include for finisher pigs:

- Degree of soiled bodies as an indicator of heat stress

- Health-related parameters (coughing/sneezing, ectoparasites, lameness, condemnations / trimming at slaughter, data on the use of antibiotics)

- Injuries (tail-and ear lesions, other parts of the body)

- Vitality (daily weight gain, growth retarded pigs and runts, mortality)

The majority of these parameters are already integrated in SchwIP and additionally enhanced through resource-based and management-based parameters. The workshop highly recommended the development and implementation of management tools to assess these animal-based indicators and emphasized the distribution among stakeholders through training courses. The results of this thesis confirm that a holistic approach and knowledge transfer among stakeholders is successful in tackling a welfare problem such as tail biting. It is obvious, that management tools, such as SchwlP, motivate farmers much better in the implementation of measures than a legal obligation. The 
implementation of SchwIP is forward-looking in advancing the welfare of finisher pigs since it helps farmers to reduce risk factors for tail biting. Simultaneously, the application enables farmers to increase the welfare of their pigs in general, since underlying causes for tail biting also reduce general pig welfare (EFSA, 2007) even if they do not always trigger tail biting. Therefore a SchwIP application makes sense even if there are no existing tail biting problems on-farm.

The tail lesion prevalence (30.3\%) scored at the abattoir was considerably high for almost exclusively docked pigs (Chapter 6). Similar studies found even higher tail lesion prevalence in docked pigs (Harley et al., 2012; Harley et al., 2014) whilst a Finnish study reported a tail lesion prevalence of $34.6 \%$ in un-docked pigs (Valros et al., 2004). A comparison of the tail lesion prevalence of docked and un-docked pigs at the same abattoir indicated that the tail lesion prevalence was more than three times higher in un-docked pigs (Hunter et al., 1999). Taking these figures into account, it is strongly recommended that risk factors for tail biting should first be reduced before tail docking could be omitted, otherwise farms would experience significant problems and would fail to improve the welfare of their pigs. Therefore changes in husbandry and management are necessary to prevent animal welfare problems due to not tail docking when underlying risks have not been addressed.

SchwIP meet national legal requirements, support farmers in the major task of implementing changes and likewise impair their job satisfaction through visible improvements to their pigs due to lower tail lesion prevalence.

\subsection{Tail lesions as welfare indicator}

Meat inspection data might be valuable for use in herd health management and for monitoring of animal welfare (Alban et al., 2011). Spoolder et al. (2011) highly recommended the monitoring of tail length and injury status at the abattoir as an animal-based indicator for assessing welfare in pigs. Chapter 6 presents results of a tail lesion monitoring in a German abattoir over a period for more than one year. The detailed scoring of tail lesions by the research group was suitable for 
illustrating that the application of SchwIP led to a trend for reduction in tail lesion prevalence over the course of a year compared to control farms.

Tail tip necrosis (a pathological finding of tissue death) was generally identified at this abattoir in $0.2 \%$ of the examined carcases examined in the study and was detected in $0.7 \%$ of the carcases by the research group. Therefore, considerable differences in the recording of a necrosis were found between the research group and the veterinarians at the slaughterline. Tail lesions are often under-recorded in the abattoir especially when the cause of rejection is identified rather than the predisposing factor (Taylor et al., 2010). Additional training courses with veterinarians and meat inspectors should be mandatory to increase the recognition of this pathological finding and awareness of the impact of tail biting in general.

Significant relationships were found by veterinarians at the slaughterline between necrosis and pneumonia (10-30\%, $\geq 30 \%)$, and inflammation in the front leg/hind leg and arthritis in the hind legs. It is particularly interesting, that these findings in the legs were also associated with tail lesions as scored by the research group; however, the majority of tail lesions were scored as mild. In a recent study, carcases with mild lesions were associated with a $1.2 \mathrm{~kg}$ reduction in weight compared with unaffected carcases (Harley et al., 2014). Therefore it can be concluded that it is paramount to pay more regard to mild tail lesions since they also have a huge impact on the susceptibility of the animal to other diseases and might provide information about problems at farm level. Mild lesions arise from manipulation or gentle chewing of the tail (rather than biting) (Schrøder-Petersen and Simonsen, 2001) and producers often remain unaware of these lesions due to the absence of blood and lack of reaction by the recipient (Harley et al., 2014). It therefore seems reasonable to enhance monitoring of tail lesions at the abattoir to give farmers reliable feedback towards the actual level of tail lesions. Additionally it would be preferable to standardise the recording of lesions between the different abattoirs, this would ensure that a farmer who delivers his pigs to different slaughterhouses can use the data for continuously assessing the welfare of his pigs. It seems worthwhile to investigate whether a software could detect lesions automatically from the photos. It might be possible, since the pigs are 
spotlessly clean after scalding and the colourful lesions are silhouetted against the skin.

However, the recording of lesions at the abattoir has limitations in its validity, because severely bitten pigs may die or be culled on-farm. Therefore they should always be combined with on-farm data to identify the factors contributing to tail biting. Nevertheless, abattoir data illustrates one valuable information source from which farmers and advisory services can deduce a need for further, specific, risk assessment and advice e.g. an application of SchwIP.

\subsection{Scope for improvement}

The German pig industry had a high demand for a means to reduce tail biting in finisher pigs before initiating this project. Therefore SchwIP was developed for the risk assessment of finisher farms, however over the study period and trials of other research groups with un-docked pigs, it turned out that it would be reasonable to have a similar tool for the weaning phase since the problem often emerges during this stage. A possible further point of criticism could be that the willingness of advisers / veterinarians and farmers for participation might have been comparably high due to the public and political pressure during the study.

Training stakeholders in the implementation of the tool proved to be an appropriate way to distribute SchwIP. Given that participation of farm advisers and veterinarians was voluntarily the implementation rate of $62 \%$ has room for improvement. In future projects, a stronger, binding, agreement of tool application, as well as a better consideration of the time of implementation (e.g. avoiding the harvest seasons) might increase the implementation rate. Taking into consideration that the time for tool application was limited to 3-4 hours to ensure that farm advisers and veterinarians could include it in their daily work the statistical power was limited due to a small sample size (number of pens) per farm. However, this project was still able to demonstrate the objective of the study, which was a reduction of the tail biting risk on-farm.

National and European legislation now focusses on animal-based parameters in tackling welfare problems. Many of these parameters are already considered in 
SchwIP, but there is still scope to improve their contribution to SchwIP by adding a weighting factor. There is potential to outline the corresponding factors in an extra section with a reference to them being an animal-based parameter. Overall the implementation of SchwIP is beneficial in two different aspects; reducing the on-farm tail biting risk and thereby the tail lesion prevalence, and meeting the legal requirements.

Some batches of farms in the abattoir study were missing due to technical problems with the cameras, which should ideally be eliminated in any further studies. Despite this, scoring tail lesions from photos proved to be a good alternative to direct observations at the slaughterline. This method offered the opportunity to collect data for specific farms over a longer period so that any trends in tail lesion prevalence could be observed. Photos provide a definite link with a farm and the success of implementing changes can be determined. Furthermore, using photos would stop researchers getting in the way of working at slaughterlines.

In conclusion, the results of this thesis indicate that the holistic approach of SchwIP, which considers the multicausal nature of tail biting, is suitable for helping farmers in the challenge of reducing risk factors for tail biting on-farm. Training stakeholders in the application of the tail biting management tool proved to be effective in the distribution of the tool and moreover, in the provision of knowledge transfer about tail biting causation to farmers who are best placed to address these risks. A significant reduction in tail lesion prevalence was recorded between the two on-farm assessments, despite the short time period of the study, and this was confirmed by the monitoring of tail lesions at the abattoir which thereby confirmed the effectiveness of SchwIP. 


\section{References}

Adrian, E.D., 1943. Afferent areas in the brain of ungulates. Brain 66, 89-103.

Alban, L., Steenberg, B., Stephensen, F.T., Olsen, A.M., Petersen, J.V., 2011. Overview on current practices of meat inspection in the EU. Scientific report submitted to EFSA. EFSA, Parma, Italy, 2-12.

Almond, P.K., Bilkei, G., 2006. Effects of oral vaccination against Lawsonia intracellularis on growing-finishing pig's performance in a pig production unit with endemic porcine proliferative enteropathy (PPE). Deutsche Tierarztliche Wochenschrift 113, 232-235.

Amory, J.R., Mackenzie, A.M., Pearce, G.P., 2006. Factors in the housing environment of finisher pigs associated with the development of gastric ulcers. Veterinary Record 158, 260-264.

Arey, D.S., 1991. Tail-biting in pigs. Farm Building progress 105, 20-23.

Baumgarte, J., 2014. Der Tierschutzplan Niedersachsen - Quo Vadis? Züchtungskunde 86, 42-46.

Beattie, V.E., O'Connell, N.E., 2002. Relationship between rooting behaviour and foraging in growing pigs. Animal Welfare 11, 295-303.

Beattie, V.E., O'Connell, N.E., Moss, B.W., 2000. Influence of environmental enrichment on the behaviour, performance and meat quality of domestic pigs. Livestock Production Science 65, 71-79.

Beattie, V.E., Sneddon, I.A., Walker, N., Weatherup, R.N., 2001. Environmental enrichment of intensive pig housing using spent mushroom compost. Animal Science 72, 35-42.

Beattie, V.E., Walker, N., Sneddon, I.A., 1996. An investigation of the effect of environmental enrichment and space allowance on the behaviour and production of growing pigs. Applied Animal Behaviour Science 48, 151158.

Bell, C., Paterson, J., Murison, P., Warman, S., 2014. How do we learn? In Practice 36, 153-154.

Bernard, M., Schuitmaker, T.J., de Cock Buning, T., 2014. Scientists and Dutch Pig Farmers in Dialogue about Tail Biting: Unravelling the Mechanism of Multi-stakeholder Learning. Journal of Agricultural \& Environmental Ethics 27, 431-452.

Blackshaw, J.K., Thomas, F.J., Lee, J.-A., 1997. The effect of a fixed or free toy on the growth rate and aggressive behaviour of weaned pigs and the influence of hierarchy on initial investigation of the toys. Applied Animal Behaviour Science 53, 203-212.

Bracke, M.B.M., De Lauwere, C.C., Wind, S.M.M., Zonerland, J.J., 2013. Attitudes of Dutch Pig Farmers Towards Tail Biting and Tail Docking. Journal of Agricultural \& Environmental Ethics 26, 847-868.

Bracke, M.B.M., Zonderland, J.J., Lenskens, P., Schouten, W.G.P., Vermeer, H., Spoolder, H.A.M., Hendriks, H.J.M., Hopster, H., 2006. Formalised review of environmental enrichment for pigs in relation to political decision making. Applied Animal Behaviour Science 98, 165-182.

Brunberg, E., Wallenbeck, A., Keeling, L.J., 2011. Tail biting in fattening pigs: Associations between frequency of tail biting and other abnormal behaviours. Applied Animal Behaviour Science 133, 18-25. 
Busch, B., 2006. Schweinehaltung. In: Richter, T. (Ed.), Krankheitsursache Haltung Beurteilung von Nutztierställen - Ein tierärztlicher Leitfaden. Enke Verlag, Stuttgart, 112-151.

Busch, M.E., Wachmann, H., Nielsen, O.E., Petersen, H.H., Nielsen, J.P., 2004. Tail biting - can routine meat inspection data be used for classification of herds? In, 18th International Pig Veterinary Society Congress, 27th June1st July, Hamburg, Germany.

Camerlink, I., Bijma, P., Kemp, B., Bolhuis, J.E., 2012. Relationship between growth rate and oral manipulation, social nosing, and aggression in finishing pigs. Applied Animal Behaviour Science 142, 11-17.

CIWF, 2008. Schweinehaltung in Europa: Ein Zustandsbericht. Investigative Recherche von "Compassion in World Farming". http://www.provieh.de/downloads provieh/ciwf zustandsbericht schwein ehaltung eu.pdf (retrieved on 15 September 2014). .

Colyer, R.J., 1970. Tail Biting in Pigs. Agriculture 77, 215-218.

Courboulay, V., Souffran, H., Guingand, N., Massabie, P., Dubois, A., 2008. Intérêt de la brumisation en engraissement pour améliorer le confort des porcs en croissance. Journées Recherche Porcine 40, 243-246.

Day, J.E.L., Burfoot, A., Docking, C.M., Whittaker, X., Spoolder, H.A.M., Edwards, S.A., 2002. The effects of prior experience of straw and the level of straw provision on the behaviour of growing pigs. Applied Animal Behaviour Science 76, 189-202.

Day, J.E.L., de Weerd, H.A.V., Edwards, S.A., 2008. The effect of varying lengths of straw bedding on the behaviour of growing pigs. Applied Animal Behaviour Science 109, 249-260.

Day, J.E.L., Kyriazakis, I., Lawrence, A.B., 1995. The effect of food deprivation on the expression of foraging and exploratory behaviour in the growing pig. Applied Animal Behaviour Science 42, 193-206.

Edwards, S., 2011. What do we know about tail biting today? The Pig Journal 66, 81-86.

Edwards, S.A., 2006. Tail biting in pigs: Understanding the intractible problem. The Veterinary Journal 171, 198-199.

EFSA, 2007. Scientific Report on the risks associated with tail biting in pigs and possible means to reduce the need for tail docking considering the different housing and husbandry systems. The EFSA Journal 611, 1-13.

EFSA AHAW Panel, 2014. Scientific Opinion concerning a multifactorial approach on the use of animal and non-animal-based measures to assess the welfare of pigs. EFSA Journal 12, 101.

Elbers, A.R.W., Tielen, M.J.M., Snijders, J.M.A., Cromwijk, W.A.J., Hunneman, W.A., 1992. Epidemiological Studies on Lesions in finishing Pigs in the Netherlands 1. Prevalence, Seasonality and Interrelationship. Preventive Veterinary Medicine 14, 217-231.

European Commission, 2008. Council Directive 2008/120/EC of 18 December 2008 laying down minimum standards for the protection of pigs. .

European Commission, 2011. EU Pilot 1360/10/SNCO Unvollständige Umsetzung der Richtlinie 2008/120/EG, 03 May 2011.

European Commission, 2012. Communication from the Commission to the European Parliament, the Council and the European Economic and Social Committee on the European Union Strategy for the Protection and Welfare of Animals 2012-2015. 
Feddes, J.J.R., Fraser, D., 1994. Non-nutritive Chewing by Pigs: Implications for Tail-biting and Behavioral Enrichment. Transactions of the ASAE 37, 947950.

Fraser, A.F., Broom, D.M., 1990. 34 Abnormal behaviour 3: Adressed to another animal, Tail-biting. Farm animal behaviour and welfare. Baillière Tindall, London, 327-328.

Fraser, D., 1987a. Attraction to blood as a factor in tail-biting by pigs. Applied Animal Behaviour Science 17, 61-68.

Fraser, D., 1987b. Mineral-deficient diets and the pig's attraction to blood: implications for tail-biting. Canadian Journal of Animal Science 67, 909918.

Fraser, D., Bernon, D.E., Ball, R.O., 1991a. Enhanced attraction to blood by pigs with inadequate dietary-protein supplementation. Canadian Journal of Animal Science 71, 611-619.

Fraser, D., Phillips, P.A., Thompson, B.K., Tennessen, T., 1991b. Effect of straw on the behaviour of growing pigs. Applied Animal Behaviour Science 30, 307-318.

Fritschen, R., Hogg, A., 1983. Preventing Tail Biting in Swine (Anti-Comfort Syndrome). NebGuide, G75-246. University of Nebraska, Lincoln.

Geers, R., Dellaert, B., Goedseels, V., Hoogerbrugge, A., Vranken, E., Maes, F., Berckmans, D., 1989. An assessment of optimal air temperatures in pig houses by the quantification of behavioural and health related problems. Animal Production 48, 571-578.

GfE, 2006. Empfehlungen zur Versorgung mit Mengenelementen Mastschweine. In: Flachowsky, G., Pallauf, J., Pfeffer, E., Rodehutscord, M., Schenkel, H., Staudacher, W., Susenbeth, A. (Eds.), Empfehlungen zur Energie- und Nährstoffversorgung von Schweinen. DLG Verlag, Frankfurt am Main, 122.

Gonyou, H.W.a.L., Z., 2000. Effects of eating space and availability of water in feeders on productivity and eating behavior of grower/finisher pigs. Journal of Animal Science 78, 865-870.

Goossens, X., Sobry, L., dberg, F., Tuyttens, F., Maes, D., De Smet, S., Nevens, F., Opsomer, G., Lommelen, F., Geers, R., 2008. A population-based onfarm evaluation protocol for comparing the welfare of pigs between farms. Animal Welfare 17, 35-41.

Green, M.J., Leach, K.A., Breen, J.E., Green, L.E., Bradley, A.J., 2007. National intervention study of mastitis control in dairy herds in England and Wales. Veterinary Record 160, 287-293.

Grosse Beilage, E., Wendt, M., 2013. 14.5.5.4 Schwanzbeißen. Diagnostik und Gesundheitsmanagement im Schweinebestand. Eugen Ulmer KG, Stuttgart, 457-461.

Hansen, L.L., Hagelsø, A.M., Madsen, A., 1982. Behavioural results and performance of bacon pigs fed "ad libitum" from one or several selffeeders. Applied Animal Ethology 8, 307-333.

Harley, S., Boyle, L.A., O'Connell, N.E., More, S.J., Teixeira, D.L., Hanlon, A., 2014. Docking the value of pigmeat? Prevalence and financial implications of welfare lesions in Irish slaughter pigs. Animal Welfare 23, 275-285.

Harley, S., More, S.J., O'Connell, N.E., Hanlon, A., Teixeira, D., Boyle, L., 2012. Evaluating the prevalence of tail biting and carcase condemnations in slaughter pigs in the Republic and Northern Ireland, and the potential of 
abattoir meat inspection as a welfare surveillance tool. Veterinary Record 171, $621-627$.

Heinonen, M., Orro, T., Kokkonen, T., Munsterhjelm, C., Peltoniemi, O., Valros, A., 2010. Tail biting induces a strong acute phase response and tail-end inflammation in finishing pigs. Veterinary Journal 184, 303-307.

Holmgren, N., Lundeheim, N., 2004. Risk factors for tail biting. In, 18th International Pig Veterinary Society Congress, 27th June-1st July, Hamburg, Germany, 786.

Huey, R.J., 1996. Incidence, location and interrelationships between the sites of abscesses recorded in pigs at a bacon factory in Northern Ireland. Veterinary Record 138, 511-514.

Hughes, B.O., Duncan, I.J.H., 1988. The notion of ethological 'need', models of motivation and animal welfare. Animal Behaviour 36, 1696-1707.

Hunter, E.J., Jones, T.A., Guise, H.J., Penny, R.H.C., Hoste, S., 1999. Tail biting in pigs 1: The prevalence at six UK abattoirs and the relationship of tail biting with docking, sex and other carcass damage. The Pig Journal 43, 18-32.

Hunter, E.J., Jones, T.A., Guise, H.J., Penny, R.H.C., Hoste, S., 2001. The Relationship Between Tail Biting in Pigs, Docking Procedure and Other Management Practices. The Veterinary Journal 161, 72-79.

Ivemeyer, S., Smolders, G., Brinkmann, J., Gratzer, E., Hansen, B., Henriksen, B.I.F., Huber, J., Leeb, C., March, S., Mejdell, C., Nicholas, P., Roderick, S., Stöger, E., Vaarst, M., Whistance, L.K., Winckler, C., Walkenhorst, M., 2012. Impact of animal health and welfare planning on medicine use, herd health and production in European organic dairy farms. Livestock Science 145, 63-72.

Jensen, M.B., Studnitz, M., Pedersen, L.J., 2010. The effect of type of rooting material and space allowance on exploration and abnormal behaviour in growing pigs. Applied Animal Behaviour Science 123, 87-92.

Jensen, P., 2002. Behaviour of Pigs. In: Jensen, P. (Ed.), The Ethology of Domestic Animals, An introductory Text. CAB International, Wallingford, UK, 159-172.

Jericho, K.W.F., Church, T.L., 1972. Cannibalism in pigs. Canadian Veterinary Journal 13, 156-159.

Kamphues, J., 2002. Nutritional disorders and problems in pigs - a challenge for veterinary practitioners. Tierärztliche Praxis 30, 396-403.

Kamphues, J., Schulz, I., 2002. Field relevant aspects of the water supply in food producing/companion animals. Übersichten zur Tierernährung - Survey of Animal Nutrition. DLG Verlag, Frankfurt am Main, 65-107.

Keeling, L.J., Wallenbeck, A., Larsen, A., Holmgren, N., 2012. Scoring tail damage in pigs: an evaluation based on recordings at Swedish slaughterhouses. Acta Veterinaria Scandinavica 54.

Kritas, S.K., Morrison, R.B., 2004. An observational study on tail biting in commercial grower-finisher barns. Journal of Swine Health and Production 12, 17-22.

Kritas, S.K., Morrison, R.B., 2007. Relationships between tail biting in pigs and disease lesions and condemnations at slaughter. Veterinary Record 160, 149-152.

Leeb, C., Bernardi, F., Winckler, C., 2010. Einführung und Monitoring von 'BetriebsEntwicklungsPlänen (BEP) Tiergesundheit und Wohlbefinden' in 
österreichischen Bioschweinebetrieben. Endbericht zum Forschungsprojekt 100188., Wien, 119.

Li, Y.Z., Chenard, L., Lemay, S.P., Gonyou, H.W., 2005. Water intake and wastage at nipple drinkers by growing-finishing pigs. Journal of Animal Science 83, 1413-1422.

Li, Y.Z., Kerr, B.J., Kidd, K.T., Gonyou, H.W., 2006. Use of supplementary tryptophan to modify the behavior of pigs. Journal of Animal Science 84, 212-220.

Lorenzen, S., 2013. Neues Klageschreiben an die Kommssion, reopening of EU Pilot 1360/10/SNCO PROVIEH Verein gegen tierquälerische Massentierhaltung e.V.. http://www.provieh.de/downloads provieh/images/reopening\%20of\%20E U\%20pilot\%201360-10-SNCO.pdf (retrieved on 15 September 2014). .

Madey, D., Vom Brocke, A.L., Wendt, M., Schrader, L., Dippel, S., 2014a. Involving stakeholders in tail biting prevention: Stakeholder opinion on a German tail biting tool. In: Mounier, L., Veissier, I. (Eds.), WAFL-6th International Conference on the Assessment of Animal Welfare at Farm and Group Level, 3-5 September, Clermont-Ferrand, France, 43.

Madey, D.P., Vom Brocke, A.L., Schrader, L., Wendt, M., Gauly, M., Dippel, S., 2014b. Tail biting risk on German finisher farms: Evaluation of a tail biting intervention tool (in preparation).

Madey, D.P., vom Brocke, A.L., Schrader, L., Wendt, M., Wainwright, N.R., Dippel, S., 2014c. Expert opinion on risk factors for tail biting in conventional German fattening pig housing systems. submitted to Preventive Veterinary Medicine.

Main, D.C.J., Leach, K.A., Barker, Z.E., Sedgwick, A.K., Maggs, C.M., Bell, N.J., Whay, H.R., 2012. Evaluating an intervention to reduce lameness in dairy cattle. Journal of Dairy Science 95, 2946-2954.

Marques, B.M.F.P.P., Bernardi, M.L., Coelho, C.F., Almeida, M., Morales, O.E., Mores, T.J., Borowski, S.M., Barcellos, D.E.S.N., 2012. Influence of tail biting on weight gain, lesions and condemnations at slaughter of finishing pigs. Pesquisa Veterinaria Brasileira 32, 967-974.

Martinez-Trejo, G., Ortega-Cerilla, M.E., Rodarte-Covarrubias, L.F., HerreraHaro, J.G., Figueroa-Velasco, J.F., Galindo-Maldonado, F., SanchezMartinez, O., Lara-Bueno, A., 2009. Aggresiveness and Productive Performance of Piglets Supplemented with Tryptophan. Journal of Animal and Veterinary Advances 8, 608-611.

Martinez, J., Jaro, P.J., Aduriz, G., Gomez, E.A., Peris, B., Corpa, J.M., 2007. Carcass condemnation causes of growth retarded pigs at slaughter. Veterinary Journal 174, 160-164.

McGlone, J.J., Sells, J., Harris, S., Hurst, R.J., 1990. Cannibalism in Growing Pigs: Effects of Tail Docking and Housing System on Behaviour, Performance and Immune Function. Texas Technical University Agricultural Science Technical Report No. T-5-283, 69-71.

McIntyre, J., Edwards, S.A., 2002a. An investigation into the effect of different protein and energy intakes on model tail chewing behaviour of growing pigs. Applied Animal Behaviour Science 77, 93-104.

McIntyre, J., Edwards, S.A., 2002b. An investigation into the effect of tryptophan on tail chewing behaviour. In: Proceedings of the British Society of Animal Science. 34. 
MKULNV, WLV, RLV, 2014. Gemeinsame NRW-Erklärung zum Verzicht auf das "routinemäßige" Kürzen des Schwanzes bei Schweinen vom 18 Februar 2014. Düsseldorf.

MKULNV Nordrhein-Westfalen, 2011. Erlass zum Tierschutz / CrossCompliance-Recht: Amputation von Schwänzen neugeborener Ferkel. Ministerium für Klimaschutz, Umwelt, Landwirtschaft, Natur- und Verbraucherschutz des Landes Nordrhein-Westfalen, Düsseldorf.

Moinard, C., Mendl, M., Nicol, C.J., Green, L.E., 2003. A case control study of on-farm risk factors for tail biting in pigs. Applied Animal Behaviour Science 81, 333-355.

Munsterhjelm, C., Brunberg, E., Heinonen, M., Keeling, L., Valros, A., 2013a. Stress measures in tail biters and bitten pigs in a matched case-control study. Animal Welfare 22, 331-338.

Munsterhjelm, C., Simola, O., Keeling, L., Valros, A., Heinonen, M., 2013b. Health parameters in tail biters and bitten pigs in a case-control study. Animal 7, 814-821.

Nannoni, E., Valsami, T., Sardi, L., Martelli, G., 2014. Tail docking in pigs: a review on its short- and long-term consequences and effectiveness in preventing tail biting. Italian Journal of Animal Science 13, 98-106.

Nicholas, P., Jasinska, A., 2008. Animal Health and Welfare Planning - A Review. Final Report of CORE Organic, ANIPLAN. http://orgprints.org/13409/ (retrieved on 06 July 2014).

Nicholas, P., Roderick, S., Vaarst, M., 2008. Animal Health and Welfare Planning - Identifying key principles and approaches. Report from 1st ANIPLAN project workshop, CORE Organic project nr. 1903 - ANIPLAN. http://orgprints.org/13407/ (retrieved on 29 October 2013). In: Vaarst, M., Roderick, S. (Eds.).

Nielsen, B.L., Lawrence, A.B., Whittemore, C.T., 1996. Feeding behaviour of growing pigs using single or multi-space feeders. Applied Animal Behaviour Science 47, 235-246.

Niemi, J.K., Sinisalo, A., Valros, A., Heinonen, M., 2011. The timing and treatment of tail biting in fattening pigs. In, 24th NJF Congress and 2nd NFS Conference, 14-16 June, Uppsala, Sweden, 50-55.

Noonan, G.J., Rand, J.S., Priest, J., Ainscow, J., Blackshaw, J.K., 1994. Behavioural observations of piglets undergoing tail docking, teeth clipping and ear notching. Applied Animal Behaviour Science 39, 203-213.

Ohm, S., Johningk, S., 2011. Verstümmelungen ade. PROVIEH Magazin 38, 2427.

Palander, P.A., Heinonen, M., Simpura, I., Edwards, S.A., Valros, A.E., 2013. Jejunal morphology and blood metabolites in tail biting, victim and control pigs. Animal 7, 1523-1531.

Paul, E.S., Moinard, C., Green, L.E., Mendl, M., 2007. Farmers' attitudes to methods for controlling tail biting in pigs. Veterinary Record 160, 803-805.

Peet, B., 2003. Using pig behaviour to optimize pen design. The Pig Site. http://www.thepigsite.com/articles/928/using-pig-behaviour-to-optimizepen-design (retrieved on 15 September 2014).

Penny, R.H.C., Walters, J.R., Tredget, S.J., 1981. Tail-biting in pigs: A sex frequency between boars and gilts. Veterinary Record 108, 35. 
Petersen, H.H., Nielsen, O.E., Hassing, A.-G., Ersbøll, A.K., Nielsen, J.P., 2008. Prevalence of clinical signs of disease in Danish finisher pigs. Veterinary Record 162, 377-382.

Randolph, J.H., Cromwell, G.L., Stahly, T.S., Kratzer, D.D., 1981. Effects of group-size and space allowance on performance and behavior of swine. Journal of Animal Science 53, 922-927.

Sambraus, H.H., 1985. Mouth-Based Anomalous Syndromes. In: Fraser, A.F. (Ed.), Ethology of Farm Animals A Comprehensive Study of the Behavioural Features of Common Farm Animals. Elsevier Science Publishers, Amsterdam, 391-472.

Schroder-Petersen, D.L., Ersboll, A.K., Busch, M.E., Nielsen, J.P., 2004. Tail biting in pigs - how it relates to other behavioural disorders and diseases. In, 18th International Pig Veterinary Society Congress, 27th June-1st July Hamburg, Germany, 787.

Schrøder-Petersen, D.L., Simonsen, H.B., 2001. Tail Biting in Pigs. The Veterinary Journal 162, 196-210.

Schrøder-Petersen, D.L., Simonsen, H.B., Lawson, L.G., 2003. Tail-in-mouth behaviour among weaner pigs in relation to age, gender and group composition regarding gender. Acta Agriculturae Scandinavica Section aAnimal Science 53, 29-34.

Schulze-Horsel, T., Engeland, N., 2013. Blutbilduntersuchungen im Rahmen des Schwanzbeißerprojektes. In, Abschlussveranstaltung des Projektes: Gesunde Tiere - gesunde Lebensmittel, 10 July 2013, Münster, Germany. http://www.projekt-

gesundetiere.de/downloads/docs/Vortraege Abschluss Clusterprojekt (retrieved on 15 September 2014).

Scott, K., Chennels, D.J., Campbell, F.M., Hunt, B., Armstrong, D., Taylor, L., Gill, B.P., Edwards, S.A., 2006a. The welfare of finshing pigs in two contrasting housing systems: Fully-slatted versus straw-bedded accomodation. Livestock Science 103, 104-115.

Scott, K., Taylor, L., Gill, B.P., Edwards, S.A., 2006b. Influence of different types of environmental enrichment on the behaviour of finishing pigs in two different housing systems 1. Hanging toy versus rootable substrate. Applied Animal Behaviour Science 99, 222-229.

Scott, K., Taylor, L., Gill, B.P., Edwards, S.A., 2007. Influence of different types of environmental enrichment on the behaviour of finishing pigs in two different housing systems: 2. Ratio of pigs to enrichment. Applied Animal Behaviour Science 105, 51-58.

Sibley, R., 2000. Planning health care on dairy farms. In Practice 22, 405-407.

Sibley, R., 2006. Developing health plans for the dairy herd. In Practice 28, 114121.

Simonsen, H.B., Klinken, L., Bindseil, E., 1991. Histopathology of intact and docked pigtails. British Veterinary Journal 147, 407-412.

Sinisalo, A., Niemi, J.K., Heinonen, M., Valros, A., 2012. Tail biting and production performance in fattening pigs. Livestock Science 143, 220-225.

Smolders, G., 2009. Improving animal welfare by assessing college's farms. In: Vaarst, M., Roderick, S. (Eds.), CORE Organic project nr: 1903 - Aniplan. Workshop report - The process of researching animal health and welfare planning. http://orgprints.org/15918/1/15918.pdf (retrieved on 15 September 2014). 28-30. 
Smulders, D., Hautekiet, V., Verbeke, G., Geers, R., 2008. Tail and ear biting lesions in pigs: an epidemiological study. Animal Welfare 17, 61-69.

Smulders, D., Verbeke, G., Mormède, P., Geers, R., 2006. Validation of a behavioral observation tool to assess pig welfare. Physiology \& Behavior 89, 438-447.

Spoolder, H., Bracke, M., Mueller-Graf, C., Edwards, S., 2011. Technical report submitted to EFSA, Report 2: Preparatory work for the future development of animal based measures for assessing the welfare of weaned, growing and fattening pigs including aspects related to space allowance, floor types, tail biting and need for tail docking. 1-106.

Spoolder, H.A.M., Aarnink, A.A.J., Vermeer, H.M., van Riel, J., Edwards, S.A., 2012. Effect of increasing temperature on space requirements of group housed finishing pigs. Applied Animal Behaviour Science 138, 229-239.

Stolba, A., Wood-Gush, D.G.M., 1989. The behaviour of pigs in a semi-natural environment. Animal Science 48, 419-425.

Studnitz, M., Jensen, M.B., Pedersen, L.J., 2007. Why do pigs root and in what will they root? A review on the exploratory behaviour of pigs in relation to environmental enrichment. Applied Animal Behaviour Science 107, 183197.

Sutherland, M.A., Bryer, P.J., Krebs, N., McGlone, J.J., 2008. Tail docking in pigs: acute physiological and behavioural responses. Animal 2, 292-297.

Taylor, N.R., Main, D.C.J., Mendl, M., Edwards, S.A., 2010. Tail-biting: A new perspective. The Veterinary Journal 186, 137-147.

Taylor, N.R., Parker, R.M.A., Mendl, M., Edwards, S.A., Main, D.C.J., 2012. Prevalence of risk factors for tail biting on commercial farms and intervention strategies. The Veterinary Journal 194, 77-83.

Terlouw, E.M.C., Lawrence, A.B., Koolhaas, J.M., Cockram, M., 1993. Relationship between feeding, stereotypies, and plasma-glucose concentrations in food-restricted and restrained sows. Physiology \& Behavior 54, 189-193.

TierSchG, 2006. Tierschutzgesetz in der Fassung der Bekanntmachung vom 18. Mai 2006 (BGBI. I S. 1206, 1313), das durch Artikel 3 des Gesetzes vom 28. Juli 2014 (BGBI. I S. 1308) geändert worden ist.

TierSchNutztV, 2006. Tierschutz-Nutztierhaltungsverordnung in der Fassung der Bekanntmachung vom 22. August 2006 (BGBI. I S. 2043), die zuletzt durch Artikel 1 der Verordnung vom 5. Februar 2014 (BGBI. I S. 94) geändert worden ist.

Tsourgiannis, C.A., Robertson, J.F., Fowler, V.R., 2002. Influence of salt application on biting by growing-finishing pigs. In, Proceedings of the British Society of Animal Science, 223.

Tuovinen, V.K., Grohn, Y.T., Straw, B.E., 1994. Partial condemnations of swine carcasses - a descriptive study of meat inspection findings at Southwestern Finland's Cooperative Slaughterhouse. Preventive Veterinary Medicine 19, 69-84.

Tuyttens, F.A.M., 2005. The importance of straw for pig and cattle welfare: A review. Applied Animal Behaviour Science 92, 261-282.

Vaarst, M., Winckler, C., Roderick, S., Smolders, G., Ivemeyer, S., Brinkmann, J., Mejdell, C.M., Whistance, L.K., Nicholas, P., Walkenhorst, M., Leeb, C., March, S., Henriksen, B.I.F., Stöger, E., Gratzer, E., Hansen, B., 
Huber, J., 2011. Animal Health and Welfare Planning in Organic Dairy Cattle Farms. The Open Veterinary Science Journal 5, 19-25.

Valros, A., Ahlstrom, S., Rintala, H., Hakkinen, T., Saloniemi, H., 2004. The prevalence of tail damage in slaughter pigs in Finland and associations to carcass condemnations. Acta Agriculturae Scandinavica Section AAnimal Science 54, 213-219.

Van de Weerd, H.A., Day, J.E.L., 2009. A review of environmental enrichment for pigs housed in intensive housing systems. Applied Animal Behaviour Science 116, 1-20.

Van de Weerd, H.A., Docking, C.M., Day, J.E.L., Breuer, K., Edwards, S.A., 2006. Effects of species-relevant environmental enrichment on the behaviour and productivity of finishing pigs. Applied Animal Behaviour Science 99, 230-247.

Van de Weerd, H.A., Docking, C.M., Day, J.E.L., Edwards, S.A., 2005. The development of harmful social behaviour in pigs with intact tails and different enrichment backgrounds in two housing systems. Animal Science 80, 289-298.

Van Putten, G., 1969. An investigation into tail-biting among fattening pigs. British Veterinary Journal 125, 511-517.

Van Putten, G., 1979. Ever been close to a nosey pig? Applied Animal Ethology $5,298$.

Van Putten, G., 1980. Objective observations on the behaviour of fattening pigs. Animal regulation studies 3, 105-118.

Walker, P.K., Bilkei, G., 2006. Tail-biting in outdoor pig production. The Veterinary Journal 171, 367-369.

Wallgren, P., Lindahl, E., 1996. The influence of tail biting on performance of fattening pigs. Acta Veterinaria Scandinavica 37, 453-460.

Whay, H.R., Barker, Z.E., Leach, K.A., Main, D.C.J., 2012. Promoting farmer engagement and activity in the control of dairy cattle lameness. The Veterinary Journal 193, 617-621.

Widowski, T., 2002. Causes and prevention of tail biting in growing pigs: a review of recent research. London Swine Conference - Conquering the Challenges, 11-12 April. London, Ontario, 47-56.

Winckler, C., 2008. The use of animal-based health and welfare parameters what is it all about? Report from 1st ANIPLAN project workshop, CORE Organic project nr. 1903 - ANIPLAN. http://orgprints.org/13405/1/13405.pdf (retrieved on 15 September 2014). In: Vaarst, M., Roderick, S. (Eds.), Core Organic project nr. 1903.

Wondra, K.J., Hancock, J.D., Behnke, K.C., Hines, R.H., Stark, C.R., 1995. Effects of particle size and pelleting on growth performance, nutrient digestibility, and stomach morphology in finishing pigs. Journal of Animal Science 73, 757-763.

Wood-Gush, D.G.M., Vestergaard, K., 1993. Inquisitive exploration in pigs. Animal Behaviour 45, 185-187.

Wood-Gush, D.G.M., Vestergaard, K., Petersen, H.V., 1990. The significance of motivation and environment in the development of exploration in pigs. Biology of Behaviour 15, 39-52.

Zonderland, J.J., Bosma, B., Hoste, R., 2011. Financiële consequenties van staartbijten bij varkens Rapport 543. Wageningen UR Livestock Research, Lelystad. 
Zonderland, J.J., Bracke, M.B.M., Den Hartog, L.A., Kemp, B., Spoolder, H.A.M., 2010. Gender effects on tail damage development in single- or mixed-sex groups of weaned piglets. Livestock Science 129, 151-158.

Zonderland, J.J., Wolthuis-Fillerup, M., van Reenen, C.G., Bracke, M.B.M., Kemp, B., Hartog, L.A.d., Spoolder, H.A.M., 2008. Prevention and treatment of tail biting in weaned piglets. Applied Animal Behaviour Science 110, 269-281. 


\section{Danksagung}

Viele Menschen haben entscheidend zur Fertigstellung dieser Dissertation beigetragen, für Ihre Hilfe möchte ich mich an dieser Stelle ganz herzlich bedanken!

Mein offizieller Dank gilt der „Tönnies Forschung - Gemeinnützige Gesellschaft zur Förderung der Forschung über die Zukunft des Tierschutzes in der Nutztierhaltung $\mathrm{mbH}^{\prime}$ und dem Land Niedersachsen für die finanzielle Unterstützung des Projektes und der damit verbundenen Möglichkeit zur Promotion.

Prof. Dr. Dr. Matthias Gauly möchte ich für seine Unterstützung und Betreuung sowie die thematischen und fachlichen Hinweise während der Anfertigung meiner Arbeit danken; Prof. Dr. Eberhard von Borell für die Bereitschaft, meine Disputation zu prüfen.

Mein besonderer Dank gilt Herrn Dr. Lars Schrader und Frau Dr. Sabine Dippel für die Bereitstellung des interessanten Themas, für das entgegengebrachte Vertrauen und für die Erfahrungen, die ich während meiner Promotionszeit sammeln durfte. Insbesondere Sabine und auch Herrn Dr. Schrader möchte ich ganz herzlich für die ausgezeichnete Betreuung danken, der Möglichkeit eigene Ideen und Vorstellungen in das Projekt einfließen zu lassen sowie das stets gewährte offene Ohr.

Einen großen Anteil daran, dass meine Promotion zu einem unvergesslichen Lebensabschnitt geworden ist hat meine Mitdoktorandin Dana Madey. Bei ihr möchte ich mich ganz besonders dafür bedanken, dass wir in den zurückliegenden drei Jahren jede Talfahrt zusammen durchgestanden haben, wir umso mehr viele tolle gemeinsame Momente erlebt haben, stets zusammen lachen und weinen konnten und wir zwei das SchwIP zu „unserem" Projekt gemacht haben. You are „Always on my mind“! Stine Heindorff danke ich ganz herzlich für Ihren Einsatz im gesamten Projekt, für die Suche nach Lösungen diverser SAS Probleme, für Ihre ausdauernde Bonitur der Fotos und für Ihre Frohnatur, die stets zu neuer Motivation beigetragen hat. 
Außerdem gilt ein großer Dank Hans-Jörg Eynck, der mir in fachlichen Fragen stets weitergeholfen hat und sich immer enorm für das Projekt eingesetzt hat. Herzlichen Dank Thoralf Kobert für die unermüdliche Hilfe bei der Datenerfassung der Fotos.

Besonders hervorheben möchte ich auch alle Landwirte, Betriebsberater und Tierärzte, die ihr Interesse, ihre Zeit und fachliches Knowhow in dieses Projekt eingebracht haben. Vielen Dank Ihnen Allen!

Für die Unterstützung bei der sprachlichen Korrektur der Dissertation möchte ich dem Ehepaar Beile, sowie Dr. Nina Wainwright danken; ihre kritischen Anregungen und Kommentare haben wesentlich zum letzten Schliff der Arbeit beigetragen.

Für meine guten Erinnerungen an die Zeit im FLI möchte ich mich persönlich bei allen Kolleginnen und Kollegen bedanken, insbesondere bei der "9.30 Frühstücksrunde" bei der ich immer auf aufbauende Worte und erheiternde Momente vertrauen konnte.

All meinen Freundinnen und Freunden, insbesondere Jan, Thomas, Luise, Kathrin, Jenny und Inga möchte ich für den moralischen Zuspruch während der Arbeit danken, besonders allerdings bei Nadine, die mir immer unterstützend zur Seite stand, viele Karten und Pakete an mich verschickt hat und die Tag und Nacht ein offenes Ohr für Freude und Sorgen hatte.

Mein größter Dank gebührt meiner Familie, die mir immer bedingungslosen Rückhalt gab, mich in schwierigen Zeiten motivierte, stets an mich glaubte und ohne deren Unterstützung und Vertrauen ich nie so weit gekommen wäre. Meinen Eltern widme ich diese Arbeit, da Sie mich immer in all meinem Tuen unterstützten, in meinen Entscheidungen beraten und gestärkt haben und mir vor allem den nötigen Freiraum gaben, meine Ziele zu verfolgen. 


\section{Curriculum Vitae}

Name: Astrid Luise Lydia Elfi vom Brocke

Geburtsdatum: 17.04.1983

Geburtsort: Hagen (Westfalen)

Staatsangehörigkeit: deutsch

\section{Schulausbildung}

1989 - 1993 Bartholomäus Grundschule, Iserlohn-Oestrich

1993 - 1999 Gymnasium Letmathe der Stadt Iserlohn

1999 - 2002 Märkisches Gymnasium Iserlohn

21.Juni 2002 Erreichen der Allgemeine Hochschulreife

\section{Ausbildung}

2002 - 2004 Ausbildung zur Pferdewirtin (FN) im

Dressur-Ausbildungsstall Finken $\mathrm{GmbH}$, Kirchwalsede

\section{Studium}

2005 - 2008 Studium der Agrarwissenschaften mit dem Studienschwerpunkt Agribusiness an der Georg-August-Universität Göttingen Abschluss: Bachelor of Science

2008 - 2011 Studium der Agrarwissenschaften mit dem Studienschwerpunkt Nutztierwissenschaften an der Georg-August-Universität Göttingen Abschluss: Master of Science

\section{Promotionsstudium}

2011 - 2014 Dissertation im Institut für Tierschutz und Tierhaltung im

Friedrich-Loeffler-Institut unter der Betreuung von Dr. Lars Schrader, Dr. Sabine Dippel

\section{Berufstätigkeit}

2004 - 2005 Pferdewirtin im| Dressurausbildungsstall Finken GmbH, Kirchwalsede seit $2014 \quad$ Beratungs- und Koordinierungsstelle Caudophagie in der Landwirtschaftskammer Nordrhein-Westfalen

Celle, den 26. September 2014 


\section{Publications}

Results of this thesis were submitted or prepared for submission to journals with a peer review system:

Training veterinarians and agricultural advisers on a novel tool for tail biting prevention

A. L. vom Brocke, D. P. Madey, M. Gauly, L. Schrader, S. Dippel Veterinary Record Open

Submitted August 18, 2014

Reducing tail biting risk on German fattening pig farm with a management tool for risk planning

A. L. vom Brocke, D. P. Madey, M. Gauly, L. Schrader, M. Wendt, S. Dippel Ready for submission

Tail lesions in German fattening pigs: relationship with post mortem meat inspection and influence of a tail biting management tool

A. L. vom Brocke, D. P. Madey, C. Karnholz, M. Gauly, C. Leeb, C. Winckler, L. Schrader, S. Dippel

Ready for submission 


\section{Conference Proceedings:}

Tail lesions in conventional German pigs at the abattoir: seasonality and relation to herd size

vom Brocke, A. L.*a; Madey, D.a; Karnholz, C. ${ }^{\text {b; }}$ Gauly, M.c; Schrader, L. ${ }^{\text {a. }}$; Dippel, $S$ a

In: Proc. of the 6th International Conference on the Assessment of Animal Welfare at Farm and Group Level (WAFL), Clermont-Ferrand, France, September 3-5, 2014. $2^{\text {nd }}$ poster prize, p.169.

Oral behaviour of pigs as an indicator for tail biting risk on farm

vom Brocke, A., Madey, D., Gauly, M., Schrader, L., Dippel, S., 2013.

In: Joint East and West Central Europe ISAE Regional Meeting 8.-10.10.13, Skopje, Macedonia, p.27.

Link: http://www.applied-

ethology.org/hres/13Dec13\%20PROCEEDINGS reg ISAE 2013 in Skopje[1].pdf

\section{Managementhilfe gegen Schwanzbeißen}

vom Brocke, A., Madey, D., Dippel, S., Schrader, L., 2013 In: DGFZ-Schriftenreihe Heft 62, p. 166-172.

Link: http://www.dgfz-bonn.de/list schriftenreihe.html

Articles in trade journals:

\section{Nicht zum Anbeißen}

vom Brocke, A., Madey, D., Dippel, S., 2014

Top Agrar 1, p. 16-19.

Link: http://www.topagrar.com/archiv/Nicht-zum-Anbeissen-1315737.html

\section{Schwanzbeißen und Schwanzkupieren beim Schwein}

vom Brocke, A., Madey, D., Dippel, S., Schrader, L., 2012.

Amtstierärztlicher Dienst 1.Quartal/2012, p. 31-32.

Link: http://www.amtstieraerzte.de/zeitschrift-amtstieraerztlicher-dienst/adt-abstracts/605schwanzbeissen-und-schwanzkuoieren-beim-schwein 


\section{Declaration}

1. I, hereby, declare that this Ph.D. dissertation has not been presented to any other examining body either in its present or a similar form. Furthermore, I also affirm that I have not applied for a Ph.D. at any other higher school of education.

Göttingen, den 26. September 2014

(Signature)

Astrid Luise Lydia Elfi vom Brocke

(Name in block capitals)

2. I, hereby, solemnly declare that this dissertation was undertaken independently and without any unauthorised aid.

Göttingen, 26 September 2014

(Signature)

Astrịd Luise Lydia Elfi vom Brocke

(Name in block capitals) 